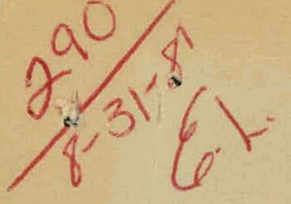

SAND81-1187

Unlimited Release

UC-37

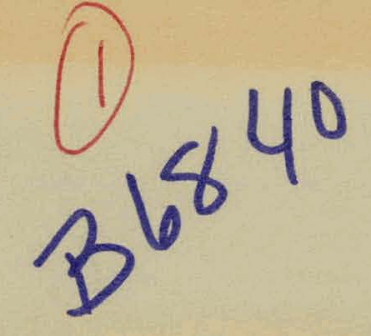

\title{
An Automated Fresnel Lens Tester System
}

Gary S. Phipps

Prepared by Sandia National Laboratories, Albuquerque, New Mexico 87185

and Livermore, California 94550 for the United States Department

of Energy under Contract DE-ACO4-76DPO0789

Printed July 1981

\section{Sandia National Laboratories}




\section{DISCLAIMER}

This report was prepared as an account of work sponsored by an agency of the United States Government. Neither the United States Government nor any agency Thereof, nor any of their employees, makes any warranty, express or implied, or assumes any legal liability or responsibility for the accuracy, completeness, or usefulness of any information, apparatus, product, or process disclosed, or represents that its use would not infringe privately owned rights. Reference herein to any specific commercial product, process, or service by trade name, trademark, manufacturer, or otherwise does not necessarily constitute or imply its endorsement, recommendation, or favoring by the United States Government or any agency thereof. The views and opinions of authors expressed herein do not necessarily state or reflect those of the United States Government or any agency thereof. 


\section{DISCLAIMER}

Portions of this document may be illegible in electronic image products. Images are produced from the best available original document. 

Issued by Sandia National Laboratories, operated for the United States Department of
Energy by Sandia Corporation.

NOTICE : This report was prepared as an account of work sponsored by an agency of the United States Government. Neither the United States Government nor any agency thereof, nor any of their employees, nor any of their contractors, subcontractors, or their employees, makes any warranty, express or implied, or assumes any legal liability or responsibility for the accuracy, completeness, or usefulness of any information, apparatus,
product, or process disclosed, or represents that its use would not infringe privately owned rights. Reference herein to any specific commercial product, process, or service by trade name, trademark, manufacturer, or otherwise, does not necessarily constitute or imply its endorsement, recommendation, or favoring by the United States Government, any agency thereof or any of their contractors or subcontractors. The views and opinions expressed herein do not necessarily state or reflect those of the United States

Printed in the United States of America Available from

National Technical Information Service U. S. Department of Commerce

5285 Port Royal Road

Springfiold, VA 22161

NTIS price codes

Printed copy: $\$ 7.00$

Microfiche copy: A01 


\title{
An Automated Fresnel Lens Tester System
}

Gary S. Phipps

Photometrics and Optical Development Division 1556

Sandia National Laboratories, Albuquerque, NM 87185

\begin{abstract}
An automated data collection system rontrolled by a desktup computer has been developed for testing Fresnel concentrators (lenses) intended for solar energy applications. The system maps the two-dimensional irradiance pattern (image) formed in a plane parallel to the lens, whereas the lens and detector assembly track the sun. A point detector silicon diode $(0.5-\mathrm{mm}$-dia active area) measures the irradiance at each point of an operator-defined rectilinear grid of data positions. Comparison with a second detector measuring solar insolation levels results in solar concentration ratios over the image plane. Summation of image plane energies allows calculation of lens efficiencies for various solar cell sizes. Various graphical plots of concentration ratio data help to

visualize energy distribution patterns.
\end{abstract}




\section{Contents}

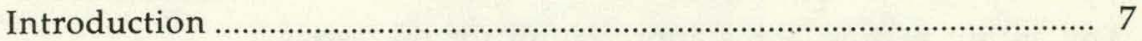

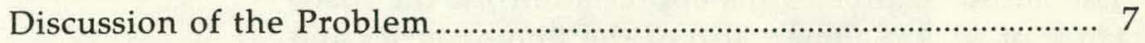

Detailed System Description …………………….............................. 8

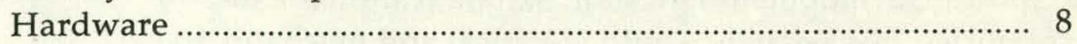

Theory of Operation ………………………………...................... 9

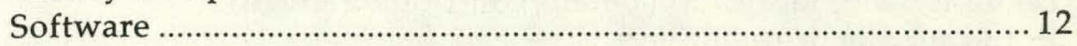

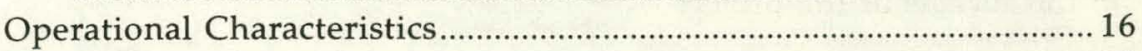

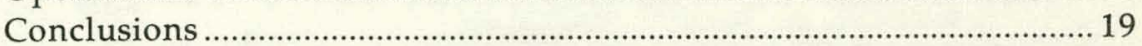

APPENDIX A - System Characteristics and Schematics......................... 21

APPENDIX B - Listing of 9845B Program ………………................... 27

\section{Illustrations}

\section{Figure}

1 Definition of Lens Tester Components …………........................ 8

2 Fresnel Lens Tester System …………………................................ 8

3 Hardware Timing Diagram for Output 2 WHS .......................... 10

4 Hardware Timing Diagram for Enter 2 WFHS ............................. 10

5 Sample 3-D Plot ......................................................................... 14

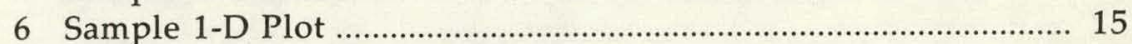

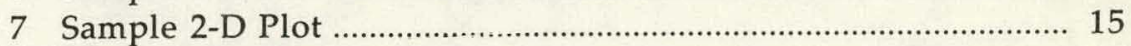

8 Sample Histogram Plot .............................................................. 15

9 Diode Off-Axis Response for Both System Diodes …….............. 17

10 Typical Stray Skylight Admitted to Open Filter Holder with Lens Carriage Blocked .............................................................. 17

11 Ratio vs Reference Measurement ................................................ 17

A-1 Filter Thickness Correction …….............................................. 23

A-2 Physical Layout of Digital Control Chassis for

Fresnel Lens Tester System (Bottom View) ……………………... 23

A-3 Wire Wrap Locations (View from socket side) ............................. 23

A-4 Component Carrier Details (Top View) ........................................ 24

A-5 Schematic of Digital Control Chassis, Fresnel Lens

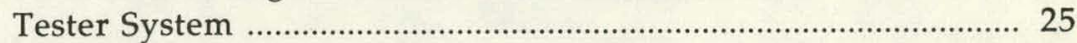

A-6 Schematic of Fresnel Lens Tester System ………........................ 26 


\section{Acknowledgment}

The author expresses his appreciation for the assistance of A. A. Sehmer, also of the Photometrics and Optical Development Division, Sandia National Laboratories. His assistance with electrical and mechanical design and fabrication details contributed greatly to the success of the project. 


\section{An Automated Fresnel Lens Tester System}

\section{Introduction}

The energy contained in sunlight is relatively diffuse, occasionally approaching $1000 \mathrm{~W} / \mathrm{m}^{2}$ measured normal to the incident rays. Conversion of this diffuse energy directly to electricity by photovoltaic solar cells is possible, but relatively expensive. A concentrator system greatly reduces the area and cost of the needed cells, but a tracking system is required. The cost of a concentrator system must be low to offset the added expense of the tracking system. Fresnel lens-like concentrators may be suitable for such a system because they are lightweight, and mass production may make them relatively inexpensive.

An ideal lens forms an irradiance pattern in its image plane that has a one-to-one spatial correspondence to the radiance of the object being imaged. An ideal image of the sun's disc will be a circular pattern of nearly uniform irradiance. Solar Fresnel concentrators rarely produce such a uniform circular pattern on their cells. The typical Fresnel concentrator will be designed to produce a desired pattern on a particular size and shape of cell. That cell may well be square. The diameter of the sun's image formed by a lens is roughly $9 \mathrm{~mm}$ for each meter of focal length. To minimize the physical size of concentrator systems, the cell is normally much larger than an imaging system would allow, and it is placed not at an image plane but somewhat closer to the concentrator. In addition, different areas of the concentrator may have different "focal lengths" to produce the desired encrgy distribution on the cell plane. For these reasons, the typical solar Fresnel concentrator is not really a "lens," but in common usage it is referred to as a "Fresnel lens." The distance between the solar Fresnel lens and the cell, or measurement plane, will be called lens-to-cell distance.

\section{Discussion of the Problem}

Lens efficiency of a solar concentrator is defined as the amount of light energy concentrated on a test cell area compared with the amount of light energy incident on the total lens surface. Absorption in the lens material and light falling outside the designated cell areas are the two main loss mechanisms. Different sized test cell areas normally will give different efficiency numbers. A common method of measuring lens efficiency assumes linearity of test cell shortcircuit current. The short-circuit current of a large area test cell irradiated by the lens under test, while tracking the sun, is compared to the test cell shortcircuit current from one sun irradiance. If the test cell is larger than desired, an aperture is inserted to physically restrict the active area of the cell. This method of testing, although useful for comparing lenses, provides no means to separate any effects of spatial nonuniformaties of the lens image and/or test cell uniformity. The Fresnel lens tester system was developed to measure the lens effects independently. At the request of Sandia's Photovoltaic Projects Division, a Fresnel Lens Tester System (Figures 1 and 2) was designed and built. To be compatible with other Sandia photovoltaic data collection systems, the controlling element of the system is a Hewlett-Packard 9845 Desktop Computer. A point detector PIN silicon photodiode detector mounted on a two-axis $(X-Y)$ motorized positioning table allows raster scans of a selected cell plane parallel to the lens. This table diode signal is compared to an identical PIN reference photodiode baffled by a $32-\mathrm{mm}(1.25$-in.)-dia flat black tube. The reference diode tube is normal to the cell plane with a length-to-diameter ratio of 20:1. Test lenses are held to an aluminum carriage mounted on three $19-\mathrm{mm}(0.75$-in.)-dia, casc-harlened steel rods. The rods move in linear ball-bushing pillow blocks for lens-to-cell distance adjustments. The $X-Y$ table and lens carriage assembly is suspended in a Celetron-14 telescope equatorial fork and mount drive, allowing the table and lens to track the sun accurately with the Celestron clock drive. The mount and all system electronics are bolted to a wheeled base for portability. The base has attached locking feet that hold the system stationary during operation.

By sampling the cell plane irradiance with a point detector while tracking the sun, the system of Figure 2 characterizes the performance of lenses as they would actually be used. Because of variable weather conditions it would be desirable to test lenses with an artificial source. Development of the present system using a tracking mount does not compromise the 
possible future use of a solar simulator. A suitable simulator could be used by turning off the lens tester clock drive. By taking advantage of system portability, laboratory tests and outdoor tests could be intermixed with ease. This intermixture of tests would be useful in determining the magnitude of the problems, if any, introduced by a particular simulator.

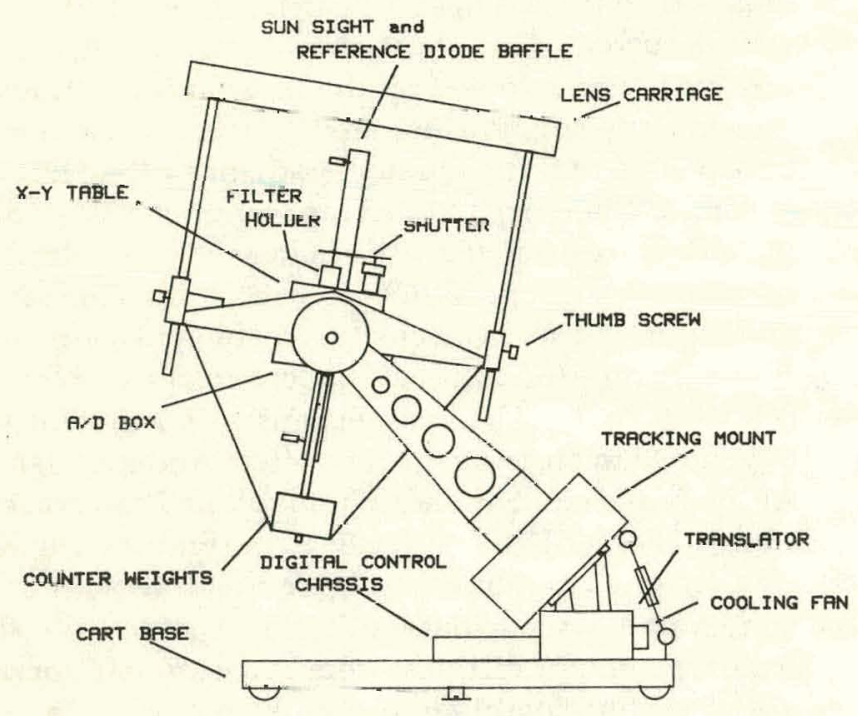

Figure 1. Definition of Lens Tester Components

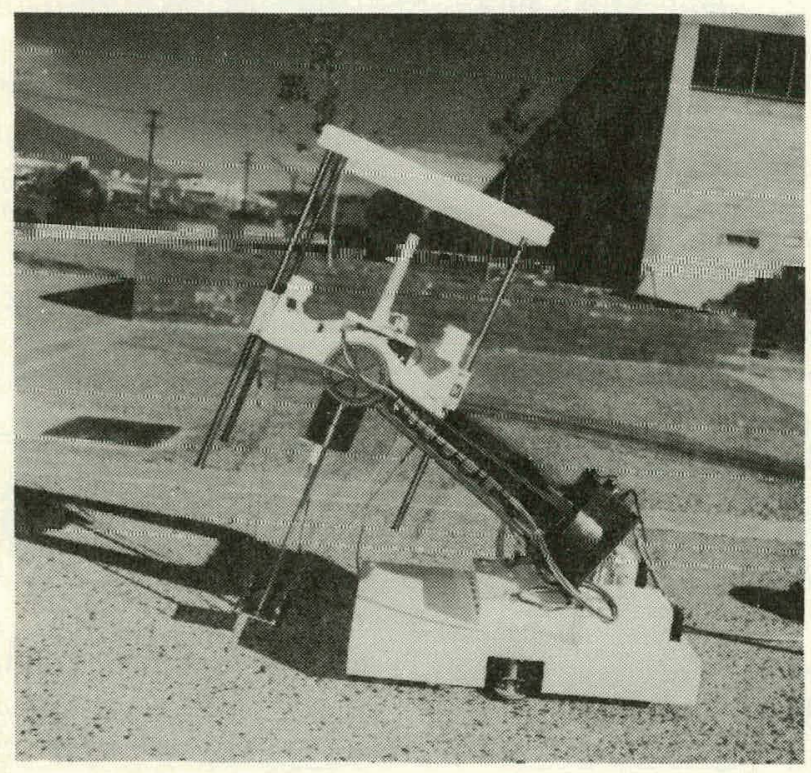

Figure 2. Fresnel Lens Tester System

\section{Detailed System Description}

\section{Hardware}

Both photodiodes are UDT PIN-020A silicon detectors which have an active diameter of 0.5$\mathrm{mm}(0.020 \mathrm{in}$.). Each diode is mounted directly to a preamplifier which produces approximately $8 \mathrm{~V}$ for one sun insolation. The high-level preamplifier signals are fed to identical Analog Devices ADC 1130 14bit high-speed analog-to-digital converters (ADCs). The ADCs are mounted in an aluminum chassis attached to the underside of the $X-Y$ table to minimize the length of analog signal lines. Simultaneous conversions by the ADCs give a pair of 14-bil binary datwords for cach sampling location. The reference diode 20:1 battle tube is attached to the tracking muunl declination axis and is shimmed to be normal to the $X-Y$ table top. A pinhole sun sight attached to the reference tube is adjusted to be collinear with the reference tube axis. When the sun's disc is centered on the sighting circle, the tracking yoke is aligned with the sun. An additional pinhole in the lens cartiage has its nwn crosshair on the table carriage as a check for proper alignment of the reference lube.

The $\mathrm{X}-\mathrm{Y}$ motorized table is a Summit Engineering Model 21610404 with double-ended motor shafts and dampers. Each axis has a $100 \mathrm{~mm}$ (4-in.) travel and is positioned hy a stepper motor coupled to a 5 thread$\mathrm{s} / \mathrm{in}$. lcad Ecrew Step size for each motor is $1.8^{\circ}(200$ stcps/rev), resulting in a table step size of 0.025 $\mathrm{mm}(0.001$ in.). Each motor has its own Sumunit Model 21808300 Translator mounted on the wlieeled cart baseplate. A small fan on each translator enclosure provides the needed cooling. Limit switches prevent the translators from attempting to step the table into the stops at the end of travel in either direction. A Summit Model 6-05 Return-to-Zero Encoder on each motor allows accurate centering of the table for initial setup. The table motors are capable of a maximum stepping rate near 10000 steps per second $(10000 / \mathrm{sec})$, but must be slarted and stulped below $500 / \mathrm{sec}$. Attempting to start above $500 / \mathrm{sec}$ will produce either no movement or the loss of several steps while the motor accelerates to the pulse rate. Stopping at high pulse rates causes the motor to overrun. Since the absolute table position is determined by counting steps, either case is undesirable. Highspeed movements are controlled by the charging and discharging of a capacitor. Starting is at $400 / \mathrm{sec}$ with a nearly linear ramp-up to $4000 / \mathrm{sec}$. An exponential ramp-down to $400 / \mathrm{sec}$ is necessary before stopping. Short movements at low speed are controlled directly from a $500-\mathrm{Hz}$ clock. The mass moved by the $\mathrm{Y}$-motor 
is roughly twice the mass moved by the $X$-motor. When the $Y$-motor is used in the fast mode, its power is marginal to move the table vertically. A helper spring has been installed around the $Y$-axis lead screw to assist the $Y$-motor in its fast uphill movement.

Signals from the two photodiodes are of similar magnitude because of a set of $25-\mathrm{mm}(1-\mathrm{in}$.)-dia Inconel neutral density filters used over the table diode. With only one sun irradiance on the table diode, its temperature never rises appreciably above ambient even with no cooling. Because of this slight temperature rise, there should be no detector temperature effects to consider. Filters are available for measuring concentration ratios in the range of 10 to 2000. Each glass laminated filter is glued in a 6.3$\mathrm{mm}(0.25$-in.)-thick aluminum filter carrier. Each carrier is held in the filter holder by the pressure exerted from a 6-32 ball plunger in the side of each filter slot. Two slots allow the use of two neutral density filters with a loss of total accepted angle. The calibration will be invalid for two filters because of multiple reflections between the mirror-like surfaces. A single filter should be used in the bottom slot to allow the widest angular light acceptance. A set of narrow bandpass interference filters at $50 \mathrm{~nm}$ intervals from 400 to $1100 \mathrm{~nm}$ has also been mounted in filter carriers for measurement of relative pattern shapes. A table of characteristics for all filters is in Appendix A. The bandpass filters are not suitable for calibrated measurements because their bandpass is dependent upon the angle of incidence. If used with a neutral density filter, they may physically restrict the angular acceptance because both filter slots are used. They can, however, give an idea of the energy distribution at different wavelengths. For calibration purposes, empty filter carriers and $10: 1$ and 20:1 baffles in filter carriers are available. The baffles restrict the field of view of the table diode to approximate that of the reference diode. To minimize the decrease in off-axis diode sensitivity the glass lens assembly has been removed from the table diode. The diode is recessed $9.5-\mathrm{mm}(0.375 \mathrm{in}$.) in the bottom of the filter holder to protect the exposed diode chip. The inside of the filter holder is flat black to reduce stray light reflections. The filter holder is attached to the $X-Y$ table so it will be directly under the lens carriage center when the $X-Y$ table is also centered. The use of any filter in the system effectively increases the lens-to-cell distance because of the lower speed of light in the filter material. The amount of increase depends on the refractive index of the filter glass, $n$. $\Lambda$ graph indicating the amount of change for $n=1.5$ is in Appendix A.
The maximum clear aperture of the lens carriage is $0.47 \mathrm{~m}$ (18.5 in.) square. Lenses are attached to the carriage by $3-\mathrm{mm}(0.125 \mathrm{in}$.)-thick lens boards specially made for each lens. During initial assembly, the lens carriage was shimmed to assure that the lens surface was parallel to the $X-Y$ table top. Lens-to-cell distance is adjusted manually by moving the carriage while measuring the lens-to-filter holder distance. Thumbscrews on the linear ball-bushing pillow blocks lock the carriage in position. As the carriage is moved out, two $6.8 \mathrm{-kg}$ (15-lb) steel counterweights are moved rearward to preserve the balance of the tracking system. The range of available lens-to-cell distances is 0.10 to $0.76 \mathrm{~m}$ ( 4 to $30 \mathrm{in}$.). Lenses to be tested can gather more than 200 watts of solar energy, creating a thermal problem for both the filters and the detector. All components (except filters) exposed to the concentrated beam are painted with Nextel diffuse white paint which can withstand $149^{\circ} \mathrm{C}\left(300^{\circ}\right.$ F). In addition, a shutter on a rotary solenoid keeps the filter holder covered when measurements are not being taken. Exposure to concentration ratios in excess of 1000 can destroy stationary, uncooled Inconel filters in short order. No stationary filter should be exposed to a concentrated beam. The filter is exposed to the high energy flux for the shortest possible time by taking measurements only while moving at high speed $(100 \mathrm{~mm} / \mathrm{sec})$.

Table movements, shutter control, A/D conversions, and data communications with the computer interface are handled by the Digital Control Chassis found below the base of the Celestron mount. The translator mounted cooling fans also supply cooling air to the Digital Control Chassis. An HP-98032A (Option 445) 16-bit parallel interface is used with a $15-\mathrm{m}(50-\mathrm{ft})$ extension cable to allow a $20-\mathrm{m}(60-\mathrm{ft})$ separation between the HP-9845 computer and the tester. The physical layout of the control chassis and wire wrap cards and complete system schematics are contained in Appendix A. No routine electrical adjustments should have to be made.

\section{Theory of Operation}

An HP-98032A interface using Select Code 2 is used with either an HP-9845A or HP-9845B computer to control the system. The signal nomenclature and terminology used here to describe this interface is that used by HP in their Hewlett-Packard 98032A 16bit Interface Installation and Service Manual, HP part 98032-90000, May 4, 1979. Seven jumpers must be installed on the Configuration Board located Inside the rear housing of the interface card. Access to these 
jumper locations is by removing the screws and disassembling the housing. Jumper 2 causes output data to be in positive true logic. Jumpers 3 and 5 complement the logic sense of the signal PCTL and PSTS, respectively. Jumpers 8 and $E$ allow data transfers on the transistion of PFLG from ready to busy, while jumpers $B$ and $F$ make all data transfers in words of 16-bits. The interface connects to the Digital Control Chassis with a 53-pin LJT00 23-53S connector. There are 16 data output lines, 16 data input lines, 10 control lines, and various ground and shield lines. The discussion below makes reference to the schematics of Appendix A.

Data sent from the ADCs to the computer are placed on the data input lines (DIs); values nutput to the testes are found on the data output lined (DOs). The control lines consist of 5 sending information to the tester (PCTL, I/O, CTL1, CTLO, and RESET) and 5 returning to the computer (PFLG, PSTS, STI0, STI1, and EIR). Any data transfer is controlled by a "handshake". This handshake is a means to insure that both computer and interface are ready to transfer the data. A handshake is initiated by PCTL and completed by PFLG. I/O indicates the direction of data transfer. All handshakes of the Fresnel lens tester are full handshakes. The detailed timing diagrams for OUTPUT... and ENTER... are shown in Figures 3 and 4. PFLG is multiplexed by CTLO: CTLO low allows OUTPUT handshakes; CTLO high allows ENTER handshakes. Attempting to perform an $1 / O$ with CTLO in the wrong state will tie up the calculator waiting for a handshake that will not happen. CTL1 controls the shutter opening and closing. If the romputer is not plugged into the tester, CTL1 is pulled high, closing the shutter. RESET stops any table motion and resets the ADC multiplexer circuitry. PSTS is connected to an inverter output, U11 (8), whose input. U11 (9), is tied to $+5 \mathrm{~V}$ to provide an indication if the tester power is tuned on. STIO is an indicator that all table movements have been completed; STI1 is a monitor of the various table limit switches and encoder signals. EIR is used only during DMAs; since no DMAs are used, EIR is grounded.

The Digital Control Chassis uses mostly standard TTL integrated circuits of the 54/74 family installed in DIP wire wrap sockets. There are three binary counters in the control chassis: 12-bit X (U12, U13, U14) and $Y$ (U17, U18, U19) muvement counters and an 8-bit interval counter (U15, U16). Each time a stepper motor is stepped, its corresponding counter is decremented. When a movement counter reaches zero no more movement is allowed in that axis until a nonzero value is loaded to that counter. Each step of either motor also decrements the interval counter.

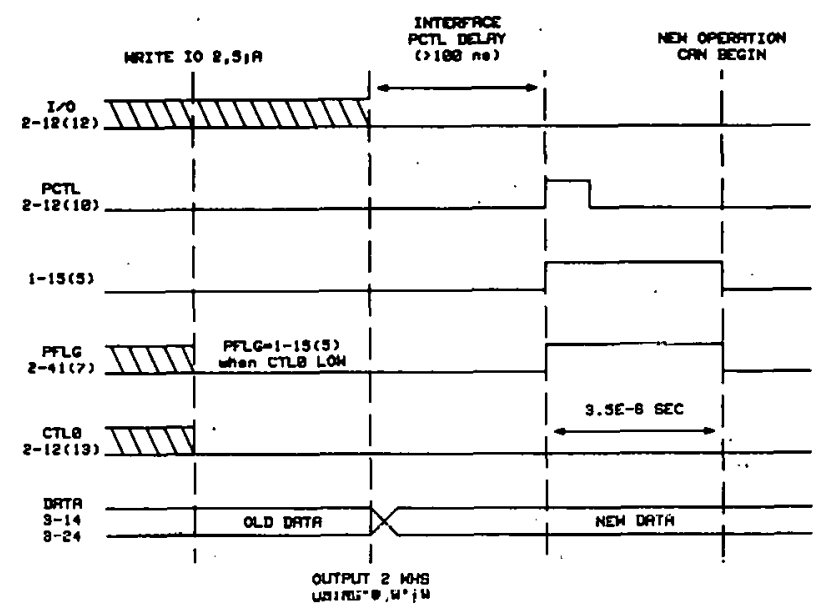

Flgure 3. Hardware Timing Diagram for Output 2 WHS...

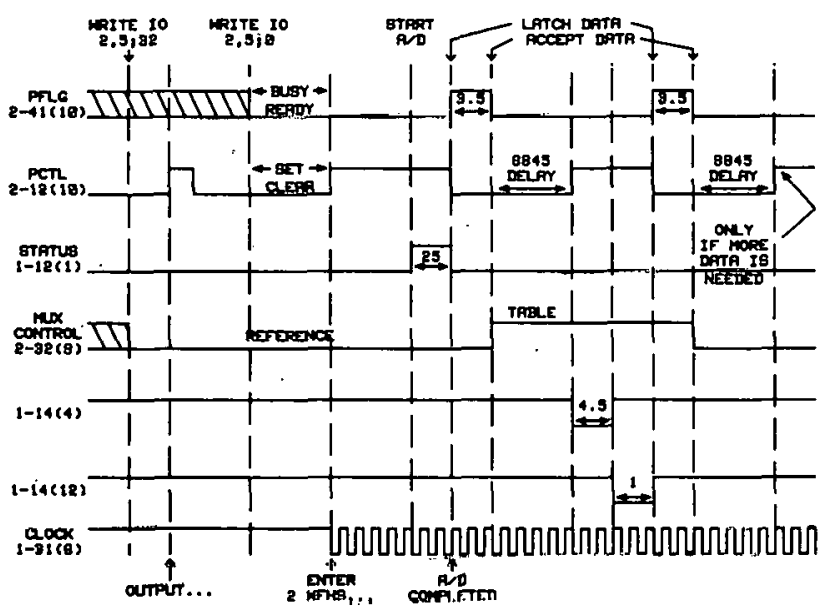

Figure 4. Hardware Timing Diagram for Enter 2 WFHS... (Pulse Widths are Labelled in Microseconds.)

When the interval count reaches zero, a Convert pulse, U44 (13), is sent to each ADC. The lower 8 bits of the data output lines are also loaded to the interval counter after each convert pulse. Six one-bit control registers contained in $U 28$ and $U 29$ are used to enable the $X, Y$, and interval counters, select $X$ and $Y$ dircrtions of movement, and determine the speed of table motion (fast or slow). Data output to the tester is in 16-bit positive true binary words. The lower 12 bits are used as a data bus to the 3 counters and 6 control registers. The upper 4 bits control the destination of the other 12 by use of a 7442 4-line-to-10-line decoder, U36. Three combinations of the upper 4 bits (D012 to D015) have special meanings other than controlling data destinations. D08 is also used as a multiplex control signal for table encoder signals. Diode data are sent to the computer in pairs of 16-bit words, one from each ADC, alternately. Four $74157 \mathrm{~s}$ 
in the $\mathrm{A} / \mathrm{D}$ box do this digital multiplexing, but they are controlled by a 745112 , U45, in the control chassis. Timing details of this flip-flop are included in the ENTER timing diagram of Figure 4.

The $X$ and $Y$ motor encoders consist of a slotted disc attached to each motor shaft. The slotted disc is used as the light interruptor for an optical sourcesensor assembly. Besides the + and - limit switches for each motor there is a third switch for each axis that indicates the table is within one revolution ( 200 steps) of its centered position. After this switch has been located, the encoder TTL signal can be used to locate the centered position within one step. The procedure is done separately for each axis after locating the $-X,-Y$ corner by using the limit switches. The translator limit switch inputs use pull-up resistors to their CMOS $+12 \mathrm{~V}$ supply. Likewise, the control chassis uses pull-ups to $+15 \mathrm{~V}$ on the zero switches. All four switch signals are filtered and converted to 5V signals by a CMOS 4009 hex inverter, U46. The two minus direction limit switch signals are NANDed to form $X_{H} \cdot Y_{H}, U 7$ (3). The $X$ and $Y$ encoder and zero switch signals are multiplexed to a single line $X 0$ $+Y 0, U 2(1)$, by D08 and their respective counter enable signals. The $X 0+Y 0$ and $X_{H} \cdot Y_{H}$ signals are multiplexd to STI1, U33 (9), by D08, U36 (5), and CTLO. STI1 is described by Table 1. :

\section{Table 1. Determination of STI1 $(X=$ Don't Care)}

\begin{tabular}{|c|c|c|c|c|c|}
\hline CTLO & U36 (5) & $\begin{array}{c}\text { D08 } \\
\text { (256-bit) }\end{array}$ & $\underset{\text { Enable }}{\mathrm{X}}$ & $\underset{\text { Enable }}{\mathbf{Y}}$ & STI1 \\
\hline$x$ & Lo & $x$ & $\mathrm{X}$ & $x$ & $X_{H} \cdot Y_{H}$ \\
\hline$x$ & $\mathrm{Hi}$ & $x$ & Lo & Lo & $?$ \\
\hline$x$ & $\mathrm{Hi}$ & Lo & Lo & $\mathrm{Hi}$ & X Zero Switch \\
\hline$x$ & $\mathrm{Hi}$ & Lo & $\mathrm{Hi}$ & Lo & Y Zero Switch \\
\hline$x$ & $\mathrm{Hi}$ & $x$ & $\mathrm{Hi}$ & $\mathrm{Hi}$ & $\mathrm{Hi}$ \\
\hline$x^{\prime}$ & $\mathrm{Hi}$ & $\mathrm{IIi}$ & Lu & I-Ii & $X$ Encoder Signal \\
\hline$x$ & $\mathrm{Hi}$ & $\mathrm{Hi}$ & $\mathrm{Hi}$ & Lo & Y Encoder Signal \\
\hline
\end{tabular}

The stepping signal applied to the motor and counter circuits, U8 (6), is gated on and off by U34 (10). The minimum stepping pulse width acceptable to the translators is $30 \mu \mathrm{sec}$. Computer commands and the control chassis clock must be synchronized to avoid a first pulse shorter than $30 \mu \mathrm{sec}$. The computer controls flip-flop U35, which in turn allows U34 to be set only by an oscillator positive-going transition. This assures that no short pulses are passed by U8 $(4,5,6)$. Which of two clocks is used as the oscillator for the stepping signal is determined by the speed control register U29 (15). The low-speed clock, $\mathrm{U} 34(6)$, is a $500-\mathrm{Hz}$ square wave obtained by dividing by two a $1 \mathrm{kHz}$ oscillator, U38 with U34. The highspeed clock is generated by a voltage-to-frequency converter (V-F), U42, whose pulse rate is ramped between $400 \mathrm{~Hz}$ and $4000 \mathrm{~Hz}$ by charging and discharging an RC network. A 4053 analog multiplexer, U37, controls the frequency by connecting a charging resistor to $+15 \mathrm{~V}, \mathrm{U} 37$ (2), or a discharge resistor to ground, U37 (1). A buffer amplifer, U41, between the capacitor and V-F input provides gain and offset control of the ramping voltage. The signal which initiates the stepping signal, U3 (1), also causes the V$F$ to ramp-up, even if the low speed is selected. In order for the motor not to lose its position, the stepping rate must be ramped below $500 \mathrm{~Hz}$ by the time the counter reaches zero. $X=352$, U5 (13), and $Y$ $=352$. U4 (10), are NORed to produce a ramp-down signal, U5 (1), for the V-F. If both motors are moving simultaneously, they move at the same speed. The motor that reaches 352 first causes both to rampdown. Movements at slow speed that exceed 352 steps cause the V-F to ramp-down, even though the $\mathrm{V}-\mathrm{F}$ signal was not being used. If slow movements shorter than 352 steps are executed, a ramp-down signal will not occur, leaving the V-F at $4000 / \mathrm{sec}$. Before any fast movement, the V-F must be at $400 / \mathrm{sec}$. If a short, slow movement has left the V-F at $4000 / \mathrm{sec}$ it must first be ramped-down by loading a 352 in one of the counters, enabling that counter, and waiting $300 \mathrm{msec}$ to allow the capacitor to discharge. In the software section that follows, this resetting of the V-F is called Screwy Fast Reset.

The step and direction inputs to the translator are CMOS inputs with pull-up resistors to $+12 \mathrm{~V}$. Interfacing between the TTL logic and the translator CMOS is by open collector 7426 NAND gates, U31. The upper four bits of the data output word, D012D015, control a 7442 decoder, U36. Three of the 7442 outputs denote special control functions which send stepping signals directly to the translators, by passing all other registers and counters. U36 (5) is the Go-ToHard-Stops signal that, in addition to multiplexing STI1, forces both the $X$ and $Y$ motors to step in the minus direction at $500 / \mathrm{sec}$. U36 (6) is the Step-X signal which, when taken low for $30 \mu \mathrm{sec}$ and high again, causes the $X$ motor to take one step in the direction specified by the normal $X$ direction register, U28 (16). U36 (7) is the corresponding Step-Y. For single steps it is much easier to use Step- $X$ or Step- $Y$ than to load, enable, and start the counters in the normal manner.

To take a line of data points, the movement and interval counters are loaded and enabled as necessary. The movement must be at least one step longer than needed to reach the last data point or handshake failure will occur; this means a minimum 2-step movement. By proper programming, the points can be on a line in the $X$ or $Y$ direction, or on a $45^{\circ}$ 
diagonal. Before the ENTER, it is necessary to set CTL0 high. When the ENTER is executed, PCTL goes to a Control Set and requests the first data word. A Control Set on PCTL while CTLO is high sets U35 (10), enabling U34 to gate on the stepping signal, U8 (6), in sync with the selected clock, as well as starting the V-F ramp-up. When the interval counter reaches zero a convert pulse is generated, U44 (13), and two digital diode readings are taken as the table moves. Total convert time is $25 \mu \mathrm{sec}$ or less, and maximum table speed is $100 \mathrm{~mm} / \mathrm{sec}$. The maximum movement of the table during the convert time is $25 \mu$. The STATUS signal of the table ADC, U49 (4), together with I'CI'L complete the handshake for the pair of data words (Figure 4). The computer Data Output lines remain latched with the last data word that was OUTPUT. The data on DO0-DO7 are Inaded to the interval counter during the convert cycle. For multiple data readings, the last OUTPUT before the ENTER must have been the interval count in order to reload the proper interval. (If only a single pair of data values is desired, this is not required.) The computer is forced to wait one stepping interval before another CONVERT/STATUS cycle handshakes a pair of data words through the interface. Once all data have been taken, the computer can go on to other operations. If the movement counters reach zero before all requested data have been collected, the computer will be tied up waiting for data that never arrives. If data taking is completed before the programmed table movement is finished, it is advisable to wait until the motion has ceased before attempting to communicate with the lens tester to avoid interrupting the table movement.

Since an ENTER initiates movement as well as data taking, it is necessary to perform an ENTER to make any table movements. If no data are wanted, a dummy variable is used to start the table in motion. Once started, the motion will continue until the movement counters reach zero unless a computer $\mathrm{I} / \mathrm{O}$ interrupts. As with data taking, although it is possible to do so, no I/O should be attempted with the lens tester until the programmed movement has ceased.

\section{Software}

All lens tester functions are controlled by an HP Enhanced BASIC program written for the HP 9845A/ $B$ desktop computer system. The program is written in a conversational style with prompts to the operator indicating the proper inputs needed at any time. In this respect the normal system operating instructions are contained in the program itself. The program consists of roughly 1600 lines and when STOREd on either tape or flexible disc occupies 285 records of $\mathbf{2 5 6}$ bytes. The size of the complete program prohibits loading it into a $9845 \mathrm{~A}$ as a single unit. A version of the program for a $9845 \mathrm{~A}$ with $64 \mathrm{~K}$ of memory, two tape drives, graphics, and $\mathrm{I} / \mathrm{O}$ capability (actually a 9845S) is available which LINKs various parts of the program to core only as they are needed. The $9845 \mathrm{~A}$ program is similar in execution to the $9845 \mathrm{~B}$ program except that 3-D plots are done with a maximum dimension of $50 \times 50$ because of memory limitations. (If the data array is larger than $50 \times 50$, a subset of alternate lines of the array is used for plotting.) If the 9845A program segments are stored on flexible disç, little difference from the $9845 \mathrm{~B}$ program will be noticed. If the $9845 \mathrm{~A}$ segments are stored on tape, the LINKing process sometimes will cause noticeable delays. A listing of the $9845 \mathrm{~B}$ program is contained in $A$ ppendix $B$. References to ine numbers below are to the 9845B program of Appendix B although variations of the program exist. Also in Appendix B is a table of variable names used in the program. Variable names used in the text will be in italics to avoid confusion. The program is in OPTION BASE 1 and has five parts:

1. Parameter initialization and task definition, lines $10 \cdot 400$

2. All subroulinites, GO SUBs, lines 510 - 1530

3. ACQSTN for collection of raw data, linés $1650-66 \%$

4. ANALYS for analysis and display of reduced data, lines 6790 - 11820

5. All subroutine subprograms, CALLed SUBs, lines 11940 - 16100

Program line number 30, (30), dimensions certain variables as SHORT to conserve memory space. $Z$ $(102,102)$ is the reduced data array which has no more than 5-decimal-digit accuracy. The limitation of 102 lines of 102 points each comes from this DIM statement. All raw diode data are integer data, two values per location. (40) defines the raw data array as integer $A$ (204). Reference and diode data are stored in alternate locations of $A\left({ }^{*}\right)$. The filter factors that are used for conversion of raw data to solar concentration ratios are contained in the DATA statement of (90). They are read into the SHORT array $F(20)$ at $(100)$. The medium used for data storage or retrieval is defined by a MASS STORAGE IS statement in lines 250-300. Control is transferred to the desired program section in lines $310-400$. Before program execution is terminated, the standard mass storage is returned to T15 as it would be at power on. 
The subroutine Mass (510) handles errors encountered while writing to or reading from mass storage units. Most common errors are handled in a way that minimizes operator action. Any error not specifically anticipated results in the message ERROR NOT RECOGNIZED...(650). These errors require more operator knowledge and interaction. Subroutine Ioerr (1170) is used for I/O failures. It anticipates mostly TIMEOUT errors caused by a loss of handshake between the computer and lens tester. TIMEOUT interrupts are not allowed during an ENTER WFHS, however. Any handshake failures during a WFHS data entry will cause the computer to lock up. Subroutine check (1460) makes sure any computed table movements will not exceed the $(100-x 100-\mathrm{mm})(4-x$ 4 -in.) table travel. If the proposed movement would place the table more than 2000 steps from the centered position, a warning message is printed on the CRT and return parameter $S$ is left $=0$. Check is mostly used in the routine to center the lens pattern on the data-taking array. The limit switches are actually more than 2000 steps from the center position. Maximum table movement is more nearly 4100 steps. A small increase in utilized area could result if limit switch locations were measured more accurately and their true position entered into Check.

When data acquisition is desired, control is transferred to line 1650 . The STATUS of \#2 interface card is checked by line 1670 to be sure $\# 2$ is a 16-bit parallel interface. If no \#2 card is present, or if it is not a $98032 \mathrm{~A}$, the program cannot proceed. Once the proper interface has been verified, the PSTS line is checked to see if the lens tester is connected and turned on (1720). The SET TIMEOUT statement of line 1770 allows a 0.5 -sec wait for completion of a handshake before the I/O error causes a GO SUB Ioerr (1790). The first I/O attempted to the lens tester that requires a handshake is in line 1800 . If 1800 is successfully completed, there should be no problems with further $I / O$. The table-centering routine is entered at Zero (1840). Table movements with no data gathering are done by a call to subroutine subprogram Move (15600). Movements must be at least two steps in length $(0.002 \mathrm{in} .=0.051 \mathrm{~mm})$ or the ENTER statement never receives its handshake. By line 2060, the $X$ centering is completed. The centered position of 0,0 is reached at Yzero (2220). If the centering routine was performed because of invalid data, the original $X$ and $Y$ offset distances are reentered in lines 2240-2310. Various operator inputs between lines 2320 and 3430 specify a rectilinear raster scan of data locations as well as other information about the test. The scan lines in either the $X$ or $Y$ direction are done at high speed, with the stepping between lines done at $500 / \mathrm{sec}$. Between scan lines, the raw data array, $A\left({ }^{*}\right)$, is written to MASS STORAGE by a random PRINT. If this print is to tape, a momentary delay will be evident. Disc storage is faster and may not produce noticeable delays. The scan lines are longer than the required data area to always park the filter outside the concentrated beam during this mass storage wait time. The amount of overscan, $A$, at each side of the data area is calculated in lines 3200-3310. Smaller scan areas should produce more highly concentrated beams than larger scan areas. For this rea-1 son, $A$ gets larger as the maximum scan dimension decreases. At the $4000 / \mathrm{sec}$ rate the inertia of the stepper motor causes the rotor to lag 2 steps behind the expected position. Line 3240 makes a software correction for this motor lag to avoid any misalignment of data-taking locations. The linear spacing between data points in the $X$ and $Y$ directions, Int, is always the same. A rectangular grid of points is always taken even if the scan area is circular.

A unique file base name for the test data is requested at line 3430 . Three files of the proper size and names are CREATEd on the standard mass storage device starting at Create (3490). The request for timeof-day input (3600) is after the file creation to place it closer to the actual data taking. Instructions for aligning the mount are contained in 3690-3800 but are displayed on the CRT only on request. Measurement of diode dark current and gain ratio is accomplished between 3810 and 4180 . Instructions for lens installation are contained in $4250-4420$ and as before are displayed only if requested. Between 4460 and 5720 , raw data are taken in two prependicular scans through the $X$ and $Y$ centers of the scan area. These raw data are plotted on the CRT for operator observation within axes drawn and labelled by subroutine subprogram Scale (15890). This process can be repeated indefinitely to determine the needed filter and centering offsets. Once the operator is satisfied, preparations for the raster scan are begun at 5730. A graphical display of the raster scan is presented on the CRT in scale during the data scan. As each line of data is taken a new line is added to the CRT. This informs the operator that handshake failures have not occurred and also indicates the portion of data still to be taken. The graphics statements of 5820-5890 prepare for this plot.

All raster scans start at the $-X,-Y$ corner of the scan area; movement of the table toward a motor is in the negative direction. Scan lines are oriented in the direction that will maximize their length. The data area scanned has dimensions of Xscan by Yscan. If $Y$ scan $>X$ scan, the long scan lines are in the $Y$ direction. If $X s c a n \geq Y s c a n$, the long lines are in the $X$ 
direction. A square pattern will produce $X$ direction lines, but by adding 0.001 -in. to the $Y$ scan dimension the array of data locations will probably be unchanged but scan lines will be in the $Y$ direction. If $X-$ direction scan lines are used, Lns scans with two data words from each of Pts locations are taken starting at Xscan (5960). Otherwise, Pts Y-direction scans with two data words from $L n s$ locations are started at $Y$ scan (6190). After the raster scan is completed the table is returned to its centered position at $\mathrm{Xzyz}$ (6410). The operator is asked to check that the table is indeed centered (6570). If it is not, a new scan using all old scan parameters will be repeated. If the operator's answer indicates the table is centered, the test directory file is written to mass storage (6650) and the acquisition phase ends.

The analysis section begins by requesting a file base name (6790). The proper three files are ASSIGNed (6820-6900) and the directory file (\#1) is read (6910). General information about the file is displayed on the CRT (7030-7080). If the raw data have already been reduced, the resulting information is also displayed (7130-7190). If the raw data have not been reduced, various operator inputs are needed before reduction can begin (7210-7490). The raw data (file \#2) consist of pairs of integer variables in the range of $0-16383.16383$ indicates no light, while 0 is a maximum irradiance. Conversion to single, floating point, SHORT variable, concentration ratios is done in the 7510-7650 loop. The raw data are taken with adjacent lines from scans done in opposite directions. The conversion loop reverses alternate lines to make all reduced data appear to have been from scans done in the positive direction. Once reduced, the concentration ratio data are written to mass storage file \#3 (7670). Lens efficiencies and average concentration ratios for the previously defined cell areas are calculated in 7710-7980. If the cell area is defined to be circular, data points from the corners of the square scan area are ignored $(7780,7810)$. After reduction is completed, line 8000 allows the entire process to be repeated with different parameters if desired. When no more reduction is desired, the most recent calculated values are stored to file \#1 (8020). If plots of the reduced data are desired, control is transferred to line 8250; otherwise, the analysis phase ends (8110).

For plotting purposes the concentration ratio data file \#3 is READ from mass storage at 8270 . Four types of plots are available to be performed in any order or combination: a one-dimensional slice through the data along either $X$ or $Y$ directions (1-D), a two dimensional contour plot of iso-concentration values (2-D), a three-dimensional representation of energy distribution (3-D), and a histogram of concentration ratio distributions (HIST). Once NONE is given in answer to a plot request (8290), the analysis of the current test files ends (8380). A sample 3-D plot is shown in Figure 5. The 3-D plot routine (8440-9040) calls subroutine subprogram Tdplt (12690) to do the actual plotting. Operator in puts concerning the viewing position, lines to be drawn, and where to make the plot are requested at Param3 (8560). Plotting is done at 8760 with labels being added after the plot is finished. Tdplt reserves an area for labels on either the right side or below the plot, whichever would make more efficient use of available space. Labels are added to the right margins at Ylbl (8820) while labels below the plot are added at $\mathrm{Xlbl}$ (8870). If the plot was done on the CRT, a paper printer copy of the display can be generated using GO SUB 'Therml at 8950-8990. Additional 3-D plots using different parameters can be generated ad infinitum. When no further 3-D plots are wanted, selection of other plot types is allowed (9030). The perspective plot with hidden line removal was written using the algorithm described by N.Y. Graham in Perspective Drawing of Surfaces With Hidden Line Elimination, The Bell System Technical Journal, April 1972, pp 843-861. The technique orders the surface patches between data points in such a way "that no part of any patch occurring earlier in the ordering is obscured from the vantage point by any part of a patch occurring later". The patches are then plotted in that order. "The delineation of the hidden region of the projection plane, after each patch is drawn, by means of two piecewise linear continuous functions" accomplishes the hidden line identification. Subroutine subprograms Ptloc (15350) and Infill (15440) are used by Tdplt.

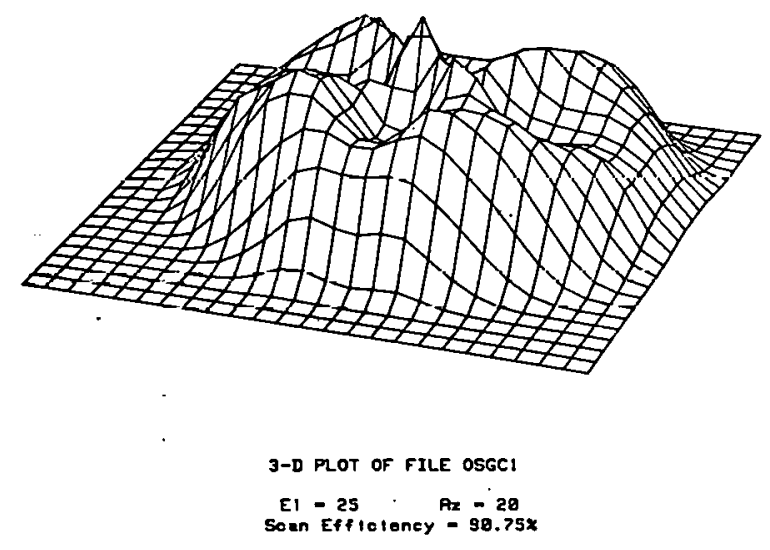

Figure 5. Sample 3-D Plot 
The 1-D plot (9100-10100) draws the reduced concentration ratio data for up to five lines (Figure 6.) The lines to be plotted are operator-specified before each plot (9130-9190). Axes are drawn (9280-9530) and the lines are plotted on the same axes (95609670). Labels are added between 9740 and 9930 . A paper plot (10030) or a 9872A plotter copy (10060) can be generated. The 2-D plot (10160-10990) produces up to 10 two-dimensional iso-irradiance contour plots. A sample 2-D plot is shown in Figure 7. The number of contours (10210) and their values (10240) are operator specified. The plot is produced on either the CRT (10340) or an HP 9872.A plotter (10360). Labels are added on the axes (10530) and the right margin (10830). The data plotting (10770) is performed by subroutine subprogram Contour (11940) within the area reserved by the SHOW statement of line 10410. Paper plots of the CRT are produced if requested (10980). Plotting starts at the left edge of the area and draws all contour lines between the first and second columns before moving one column to the right and repeating the process. Histogram plots such as Figure 8 are done between lines 11050 and 11820 . Points within the specified cell area are counted $(11070-11140)$ to generate the integer histogram values, $A(50)$. Axes (11240) and labels (11490) are drawn much as before. The histogram bars are drawn by repeated CLIP and FRAME operations (11320$11350)$. Either printer (11750) or 9872A (11780) paper copies are available.

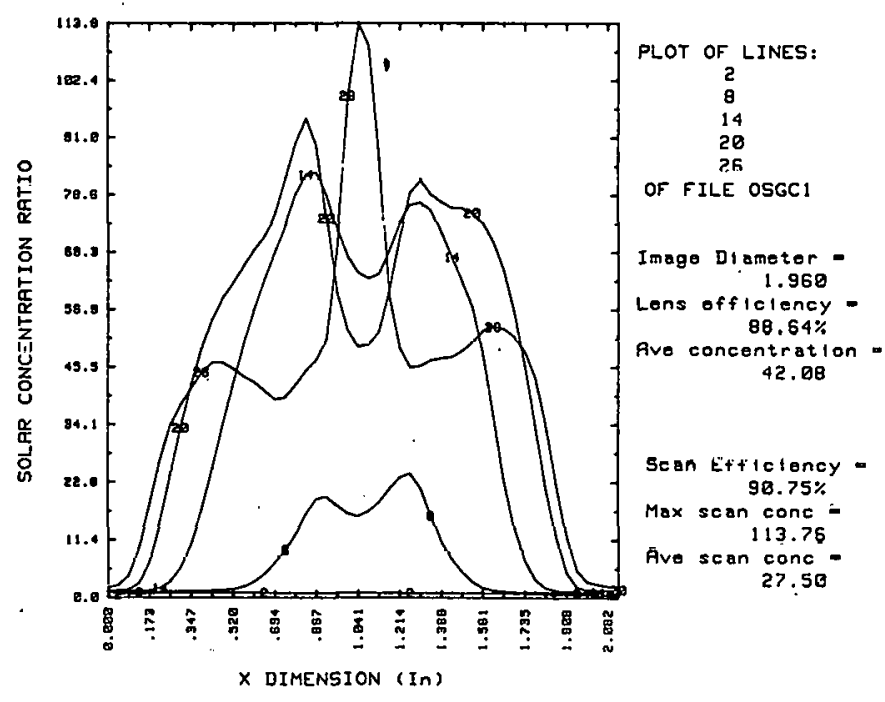

Figure 6. Sample 1-D Plot

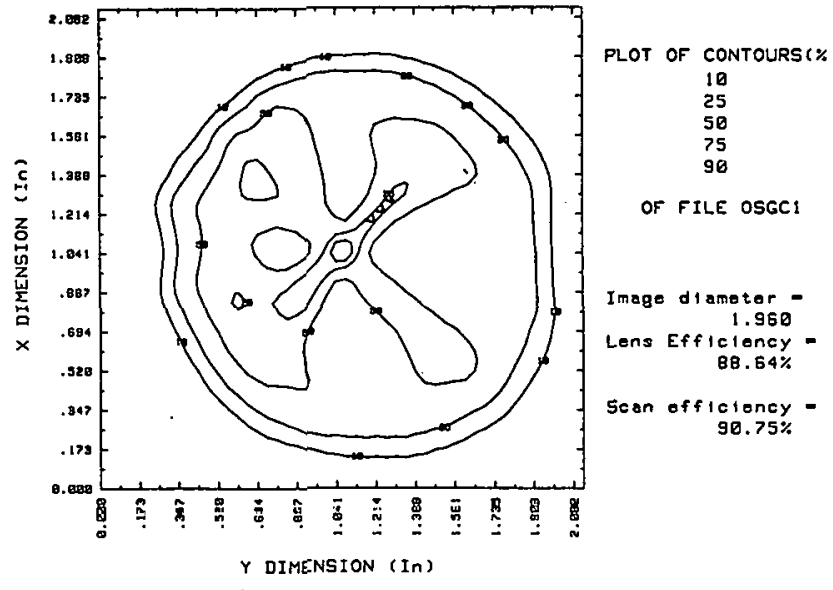

Figure 7. Sample 2-D Plot

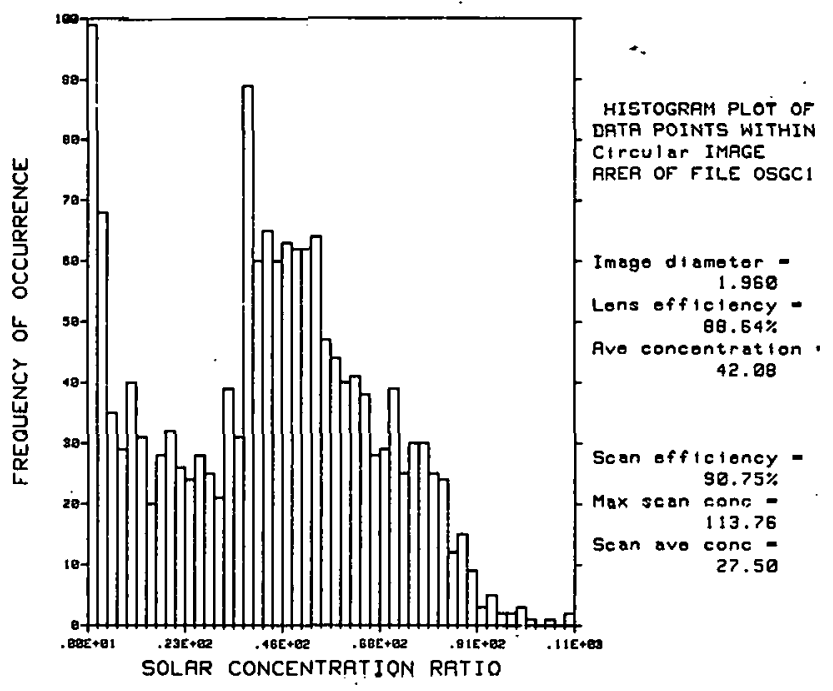

Figure 8. Sample Histogram Plot

Two files of documentary information are stored as programs but are entirely comment statements intended to be read as text when LISTed. One 21 records long (DCMSPC) produces a $1-1 / 2$ page brief description of lens tester specifications. The other (DCMOPB) is 135 records long and is an $8+$ page monograph of operating and programming instructions pertaining to the $9845 \mathrm{~B}$ program. Copies of both these LISTings are contained in Appendix B. 


\section{Operational Characteristics}

Calibration of the Fresnel lens tester relies on the linearity of the short circuit current of a silicon PIN photodiode with incident energy. However, because of its small physical size, uniformity of response over its area is not a factor. (The resulting silicon cell measurements may, or may not, be appropriate for other detectors of different spectral response, such as gallium arsenide, etc.) One sun irradiance on the 0.5 mm-dia active area produces approximately $40 \mu \mathrm{A}$ of photocurrent. Maximum specified dark current for the diodes is $150 \mathrm{pA}$, a factor of $250000 \mathrm{x}$ lower. The photocurrent for each diode is amplified by a linear $\mathrm{np}$ amp with an electrical bandpass of $5 \mathrm{kHz}$. At maximum table speed, $5 \mathrm{msec}$ is required for the table diode to move one active area diameter. The $5 \mathrm{kHz}$ bandpass should have no effect on measured spatial resolution, but it reduces high frequency noise produced by the motor translators, etc. Spatial resolution is limited only by the diode diameter. Likewise, the 14-bit A/D conversion process limits the analog dynamic range of each diode to a theoretical 16383:1. At times there is a slight interaction between the two signals. The average digitized dark current for either diode may change \pm 2 LSBs depending on the signal level from the other diode. The cause of this change is unknown; it does not always occur. It is on the order of $0.01 \%$ of full scale, giving a more realistic dynamic range of 10000:1. After being digitized, only data transmission errors can occur. Detection of bit errors in the LSBs might be difficult; errors in the MSBs would be obvious. Bit errors should occur equally often in MSBs and LSBs making random bit error detection simpler. HP would not recommend a cable length of more than $15 \mathrm{~m} \mathrm{(50} \mathrm{ft)} \mathrm{for} \mathrm{their} \mathrm{98032A}$ interface. Several tests conducted using the $5-\mathrm{m}$ standard cable length with and without the $15-\mathrm{m}$ extension cable indicated no problems with the $20-\mathrm{m}(60 \mathrm{ft}$ ) cable.

In an attempt to improve the angular off-axis response of the table diode, its metal can and lens assembly was removed, leaving the bare die on a ' $\mathrm{TU}$ 18 header. Even then a falloff in response approximating $\operatorname{Cos} \theta$ is to be expected. The measured angular response using the sun $\left(1 / 2^{\circ} \mathrm{dia}\right)$ as a source is shown in Figure 9. The mount was allowed to track the sun in hour angle while the declination axis was raised in steps of $5^{\circ}$. The response falls only slightly below Cos $\theta$ up to $45^{\circ}$. The edge of the filter holder physically blocks the incoming light at $50^{\circ}$. Light coming in at the corners of the rectangular holder will be admitted to nearly $60^{\circ}$ but the largest unobstructed cone will be $45^{\circ}$. Included in Figure 9 with a different scale is the reference diode response. The full angle viewed by the reference diode in its $20: 1$ tube is roughly $3^{\circ}$. Because of the restricted field of view, the metal can and lens assembly is left on the reference diode. The data of Figure 9 are the scattered skylight for Albuquerque, NM, 1400 MST, 23 December 1980. Skylight varies greatly with atmospheric conditions, with Figure 9 being typical for a "clear" Albuquerque day. Besides admitting a $45^{\circ}$ cone the filter holder has one open side. The stray light thus admitted to the filter is also dependent on atmospheric conditions. The data of Figure 10 were collected with an npaque lens board blocking the lens carriage aperture. This is a measurymunt of and wirly the nopen side atray light but aisoo that parr of the $45^{n}$ acceplance cune that falls outside the lens carriage. Larger lens-to-cell distances admit more stray skylight because more of the $45^{\circ}$ cone is outside the carriage. Even then only large measurement areas or low concentration ratios will have a significant percentage of stray light contributions.

In order to characterize the linear response of each photodiode detector it is necessary to locate two points on the response curve of each. These points are measured with no light (dark current) and one sun irradiance (light current) on each diode. Since only relative measurements are attempted, these four readings are condensed to only three stored variables:

$$
\begin{aligned}
& T z=\text { Table diode dark current } \\
& R z=\text { Reference diode dark current } \\
& \text { Ratio = Relative gain ratio between diodes }
\end{aligned}
$$

Ratio includes contributions due to preamplifier gain differences, photodiode sensitivity differences, and the absorption of the glass lens uver the reference diode. Standard industry practice for measuring direct solar insolation (light current) physically restricts the field of view of the detector with a baffle tube painted flat black whose length is 10 times its diameter, i.e., a 10:1 baffle. For calibratiun purposes, a baffle is required for each system diode. The reference diode is permanently mounted in a 20:1 tube painted flat black on the inside which acts as its baffle. The table diode must be easily inserted and removed. A modified filter holder with a solid disc containing a small circular hole is used in the top filter slot. Because the concentration ratio is unity, a blank filter holder is used in the botton filter slot to exclude stray skylight during the light current readings. This creates a flat black cavity over the table diode with an opening to the sun. 


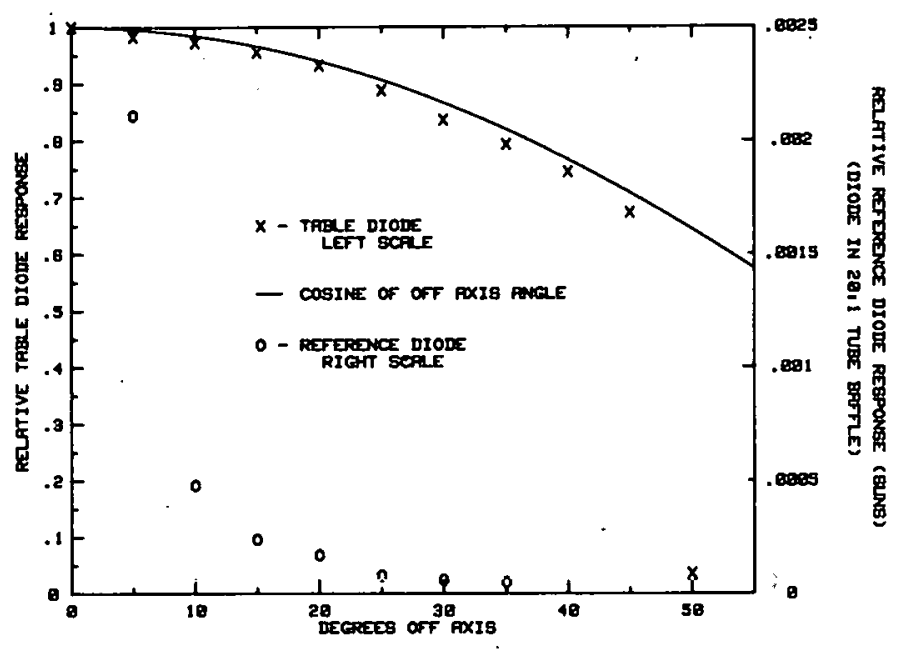

Figure 9. Diode Off-Axis Response for Both System Diodes. (The sun's disc was used as a source.)

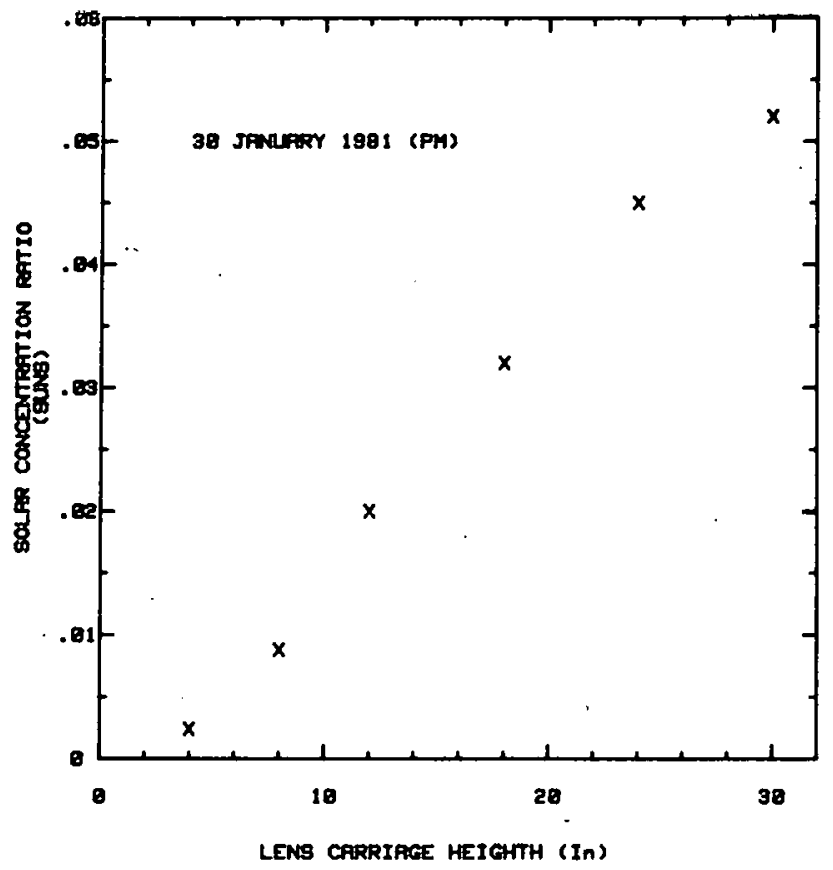

Figure 10. Typical Stray Skylight Admitted to Open Filter Holder with Lens Carriage Blocked

Ratio not only reflects differences in the electrical hardware for each diode, but differences in the baffle structure as well. By restricting the field of view of each diode to a 20:1 cone it would seem reasonable to assume that Ratio would remain the same unless preamplifier gains rhange. Such is not the case. A
20:1 cavity baffle on the table diode when compared to a 20:1 tube baffle on the reference diode will produce a Ratio that may vary by $5 \%$ depending upon atmospheric conditions. This can be explained by the difference in spectral absorption and reflections of the two filter holders. The spectrum of light reaching each diode will be different. This may cause a Ratio change as the input insolation spectrum changes. Since the spectral response to silicon is nonuniform, the cell output current will change. If not corrected, the Ratio change will cause concentration ratio and efficiency errors of an equal percentage. Figure 11 indicates the typical magnitude of this error caused by approaching clouds. As the insolation decreases not only do the absolute numbers decline but so does Ratio. The purpose of the reference diode is to correct for changes in insolation as a test is being made. Referring to Figure 11, a $60 \%$ decrease in insolation, when corrected by the reference diode reading, will give concentration ratios that are still $5 \%$ low. This is better than no correction, but points to the need to measure lens efficiencies only when the atmospheric conditions are fairly stable.

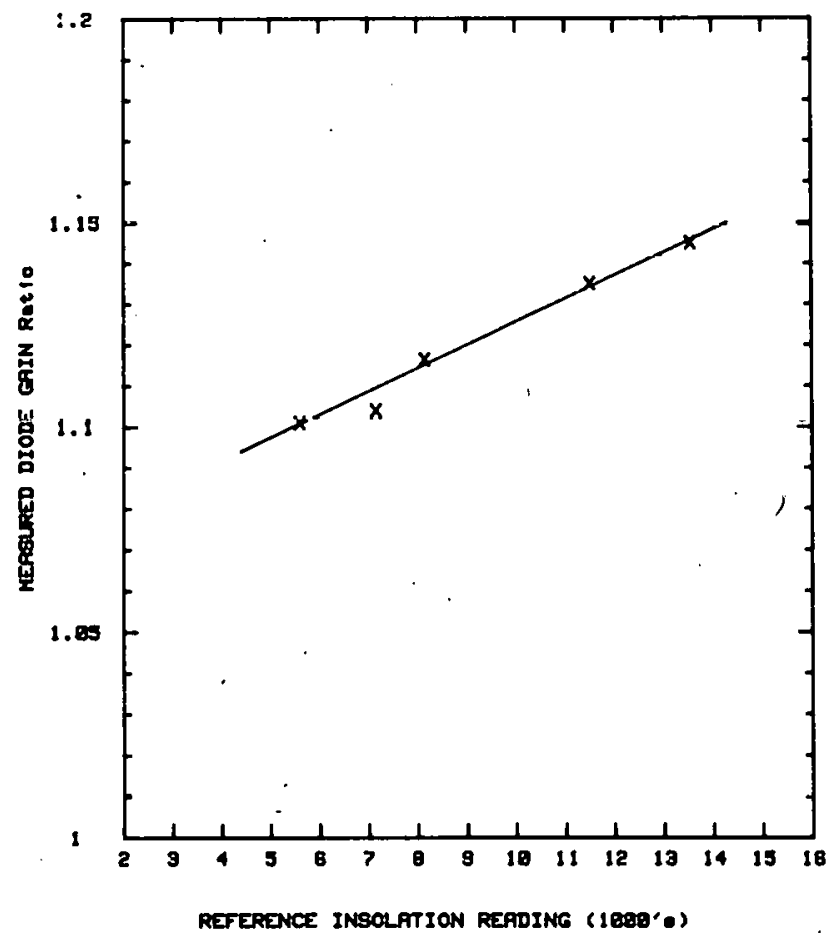

Figure 11. Ratio vs Reference Measurement. (Reference varied by approaching clouds.) 
A filter holder identical to the table holder was built and used as a reference diode holder. With these identical holders, Ratio did not show the variation present with the different holders. Retaining the 20:1 tube baffle for the reference diode is operationally easier. Regardless of what reference baffle is used, the concentrated beam measured by the table diode is unaffected. It was experimentally varified that if the Ratio for current conditions is measured before every test, the absolute numbers may be different for different reference diode holders, but the measured efficiencies will be similar provided the insolation changes during the test are small.

If spectral shifts during testing are neglected, the type of baffle used on the reference diode is immaterial since it is left in place during the entire test and is taken into account by Ratio. The type of baffle used on the table diode is significant for accurate measurements. Tests with identical cavity holders indicate that a tube baffle may deliver $5 \%$ to $10 \%$ more light to the diode than will a comparable cavity type. The exact amount would depend upon the reflecting properties of its inner surface. A one-sun table calibration measured with a tube-type baffle would have more energy/area than a similar cavity calibration. This measurement defines one-sun insolation. A cavity measurement will define fewer watts $/ \mathrm{m}^{2}$ as one sun than would a flat black tube because of the absence of reflections. Identical table readings of the concentrated beam would give different efficiency values, depending upon which type of baffle was used for calibration. A similar but less important factor is the baffle size; i.e., 10:1, 20:1, etc. The reference diode baffle size is not as critical for the same reasons as above. Measurements on "clear" days indicate as much as $0.5 \%$ less light is admitted by a $20: 1$ as compared to a $10: 1$ cavity baffle. This $0.5 \%$ is highly dependent on the scattering conditions on test day. A 20:1 baffle will define a one-sun reference of $\sim 0.5 \%$ less energy density with corresponding higher concentration ratio and efficiency numbers than would a 10:1. To more closely approximate industry standard, the table diode baffle is $10: 1$, but it is a cavity, not a tube baffle.

The effect upon the cell plane pattern caused by varying atmospheric conditions is difficult for a human observer to estimate. Conditions that appear "clear" can cause subtle changes to the measured pattern. These subtle changes can take place from day to day or in a matter of minutes with no obviously apparent atmospheric changes. 1-D plots through the center of each of the patterns may seem similar at first glance, but closer observation will indicate that one is spread over a slightly larger area than the other. If there is light spillage outside the measured areas, it is easy to explain why slight shape changes can affect efficiency by a percent or two for seemingly identical scans. An appreciable change in Ratio from one scan to another is a good indication that conditions have changed, and different shapes and efficiencies may result. If the shapes for two identical scans of the same lens are the same, the efficiencies will normally agree quite well. More pronounced but still small shape changes were observed when a pair of large polarizing sheets were placed in front of a lens and used to adjust cell plane energy densities. Nonuniformities in the polarizing sheets tended to randomize the rays, creating a consistently larger pattern. It is not recommended that polarizers be used in this manner because of the relatively large shape changes. Very obvious shape changes can occur for short lens-to-cell distances if the lens carriage, table top, and reference tube are not well aligned. If they are not aligned to 20 arc minutes (or better), very noticeable skewed patterns can result.

The concentration ratio is calculated on a pointby-point basis by using Ratio, $R z, T z$, and filter factors predetermined and stored in the BASIC program. If the lens and cell plane areas are equal, an efficiency of $100 \%$ is achieved when the average cell area concentration ratio is unity. A cell only $1 / 100$ the size of the lens would require an average concentration ratio of 100 for the same efficiency. We do not have complete information about the cell plane patterns, but rather a two-dimensional sampling of the pattern. An average concentration ratio, Avcon, is calculated for the $N$ points that fall within or on the boundary of the area of interest. Each point represents a square of dimension Int. Method 1 for calculating efficiency, Eff, would be:

$$
E f f_{1}=(\ln t)^{2}(N)(\text { Avcon }) /(\text { Lens Area) }
$$

This assigns Avcon to a square of area $\operatorname{Int}^{2}$ for each of $N$ points. Unfortunately, a point on the boundary is assigned a full-size square even if some of its area lies outside the desired area. Method 2 would assign Avcon to the designated area only. This might be larger or smaller than the calculated $(I n t)^{2}(N)$ depending on the particular dimensions:

$$
E f f_{2}=A v c o n *(\text { Cell Area }) /(\text { Lens Area })
$$

Arguments could be made for either method. An ideal lens design would have zero spillage of light, i.e., its concentration ratio outside the boundary would be zero. With no energy, the Eff contribution from outside the boundary should be zero also. The 
average concentration ratio would be the same for this ideal lens using either Method 1 or 2. (The boundary points can not be left out of Avcon, especially for cases with nonzero boundary values, or $A v c o n$ would be too high.) If this cell area were $1 \times 1$ in. with Int $=0.020 \mathrm{in}$. an array of $51 \times 51$ points would result $\left(N=51 * 51=2601,(\operatorname{In} t)^{2}=4 \times 10^{-4}\right)$. Method 1 would overstate the efficiency by a factor of $N * I n t^{2}$ compared to Method 2. For our hypothetical example:

$$
E f f_{1}=1.0404 * E f f_{2} \text {. }
$$

Neither method is perfect for efficiency calculation, but the limitations of both arise from the sampling process. The lens tester uses Method 2 for all efficiency calculations.

Any change in the filter factors of the neutral density filters directly affects the efficency values calculated. The filter factors are the attenuation factors of each filter used with the table diode to measure a concentrated solar spectrum. Different spectral sensitivities and attenuations can give different filter factors when the same filter is used with a different detector or source. For high density filters, it is difficult to measure the attenuation accurately by using the lens tester itself because of limited dynamic range. The method employed for relative calibration of higher density filters is to scan a concentrated pattern with both a known and an unknown filter. If, in both cases, the scans are the same size and large enough to include the entire pattern (no spillage), the efficiency for both scans must be the same. The filter factor of the unknown filter will be correct when the calculated efficiencies are equal.

\section{Conclusions}

An automated Fresnel lens tester system was designed, built, and is in use which can quickly characterize the silicon cell plane irradiance pattern and efficiency of various Fresnel concentrator elements as they track the sun. The precision of such measurements approaches $0.01 \%$, but the calculated lens efficiency accuracy depends upon several operational and philosophical decisions. The spatial distribution information as presented in four graphical outputs is highly useful both for concentrator design and evaluation purposes. 


\section{APPENDIX A \\ System Characteristics and Schematics}


Table A-1. Fresnel Lens Tester Filter Characteristics NEUTRAL DENGITIEB;

\begin{tabular}{|c|c|c|}
\hline FILTER & |THICANESB (In) & FILTER FACTOR \\
\hline 1 & .084 & 11.7 \\
\hline 2 & .185 & 25.8 \\
\hline s. & .082 & 35.5 \\
\hline 4 & .884 & 54.8 \\
\hline $\mathbf{s}$ & .1 & $77.0^{\prime}$ \\
\hline 6 & .685 & 114 \\
\hline 7 & .21 & 314 \\
\hline$\theta$ & .289 & 990 \\
\hline 9 & .200 & 843 \\
\hline 10 & .200 & 1515 \\
\hline 11 & .127 & 2780. \\
\hline
\end{tabular}

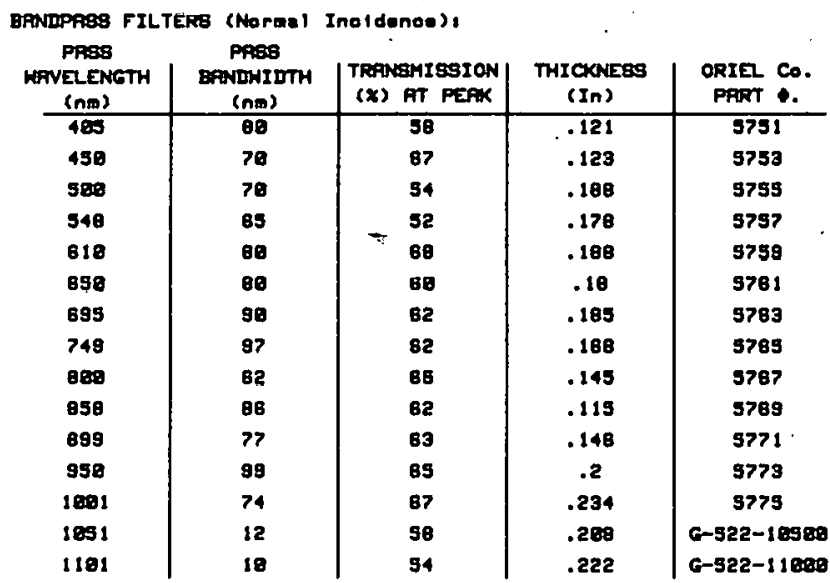

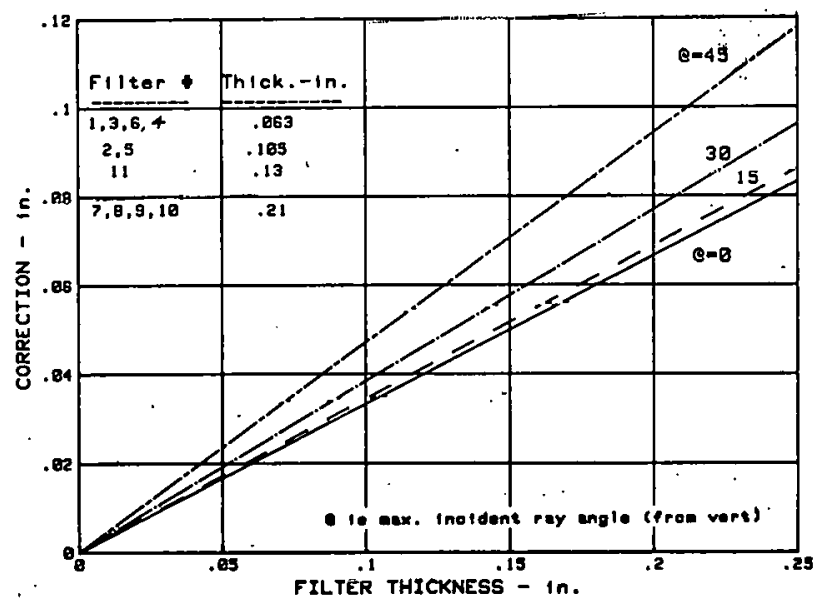

Figure A-1. Filter Thickness Correction. (Add to Lens-to-cell distance.)

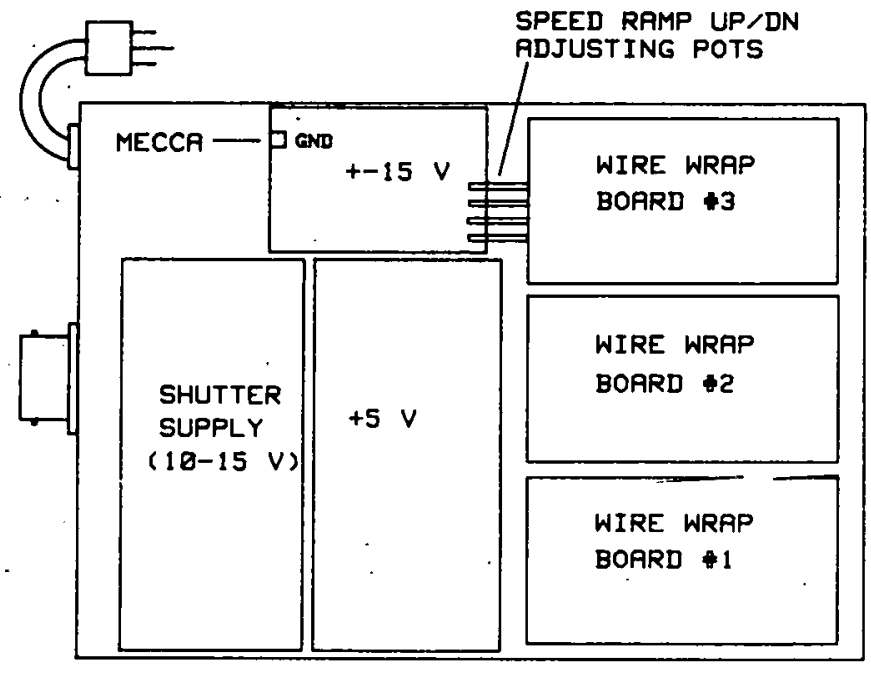

Figure A-2. Physcial Layout of Digital Control Chassis for Fresnel Lens Tester System (Bottom View)

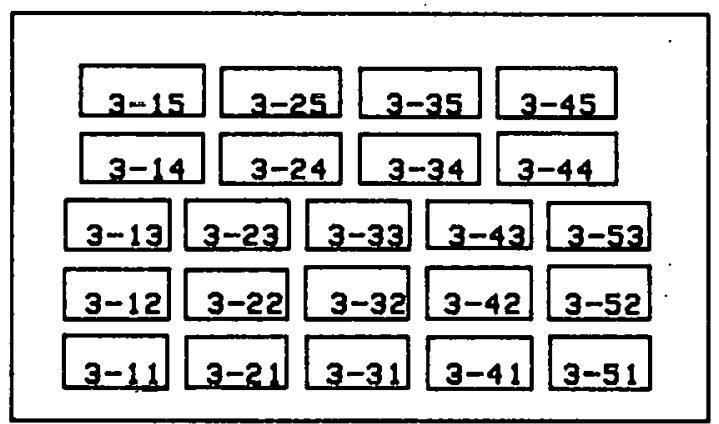

BORRD

$\$ 3$.
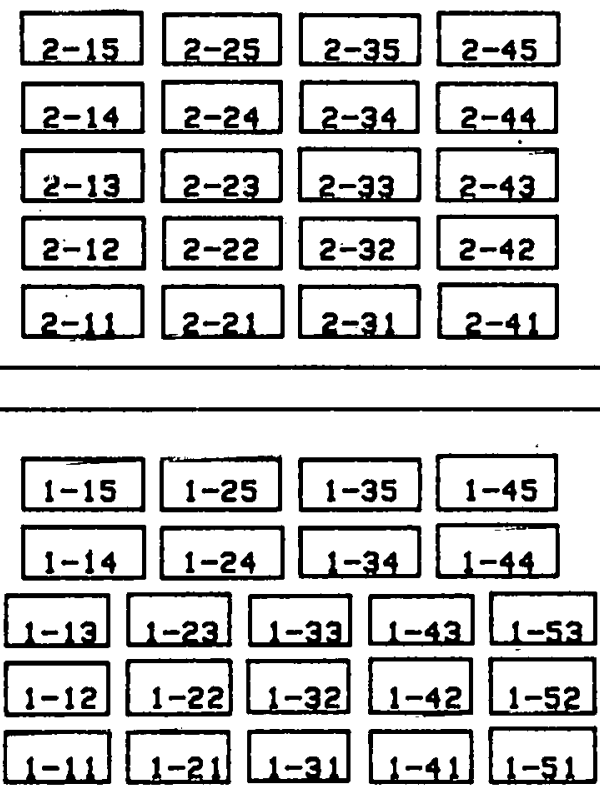

BORRD 

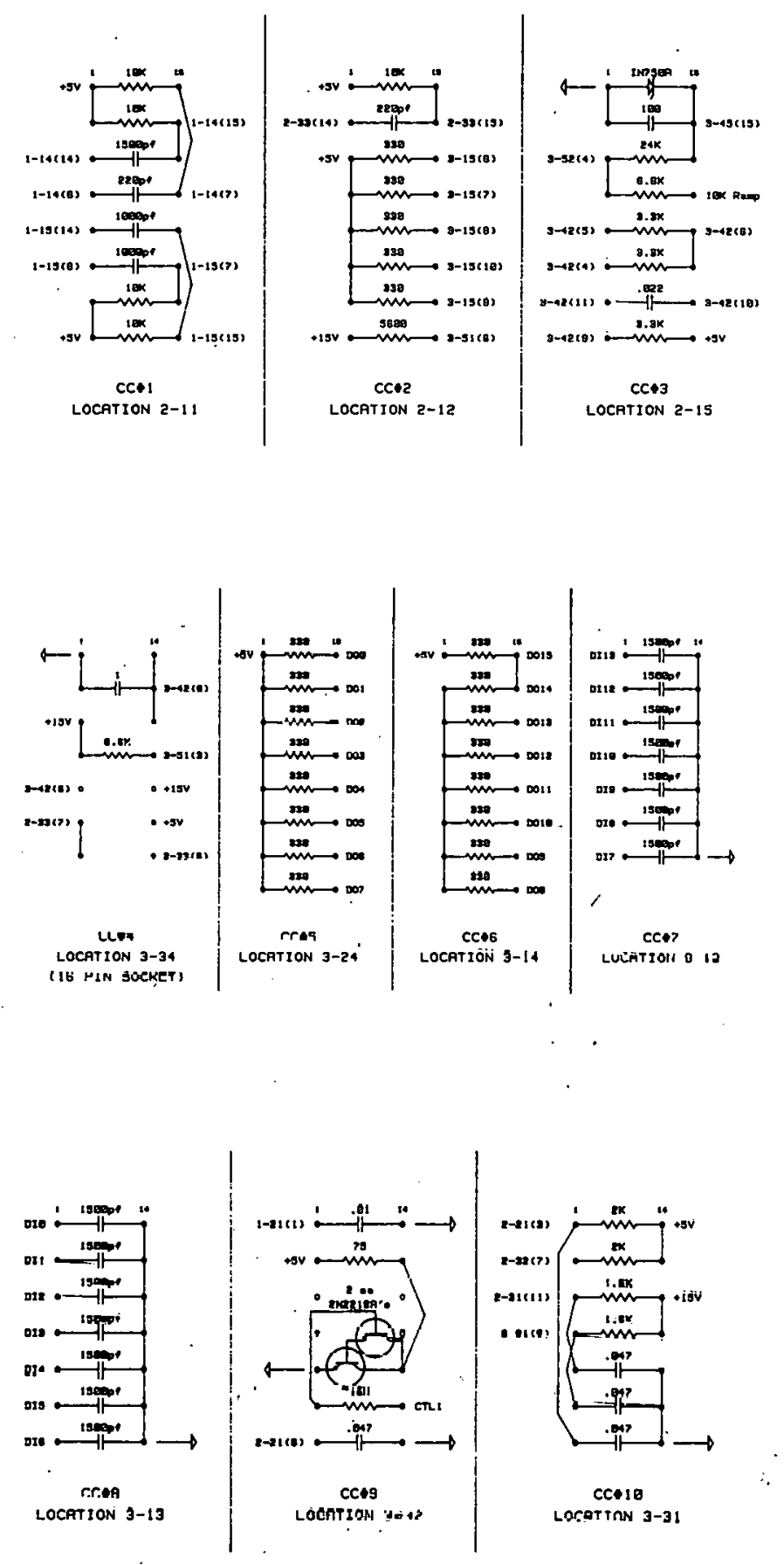

Figure A-4. Component Carrier Details (Top View). (Rs in ohms, Cs in microfarrads.) 


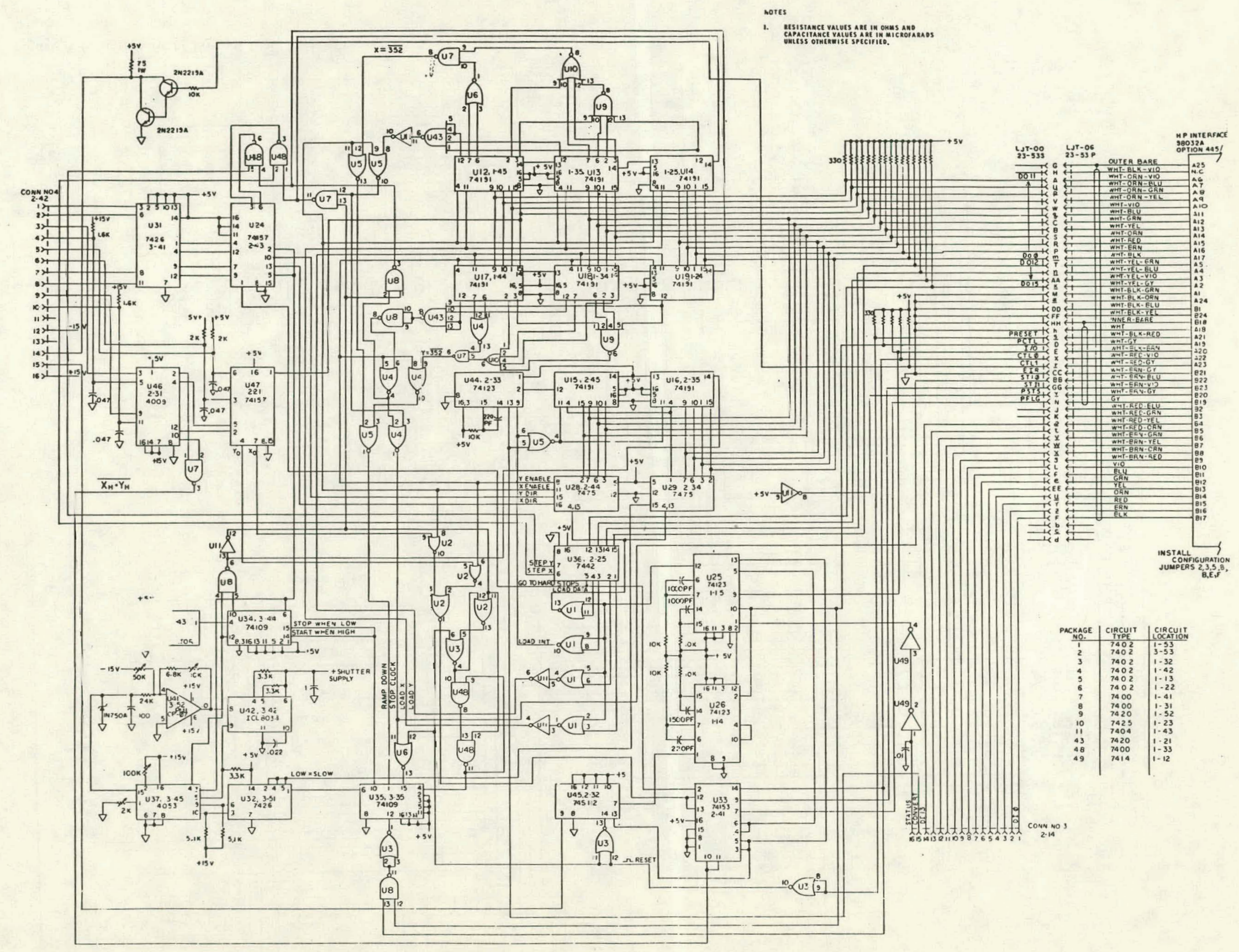




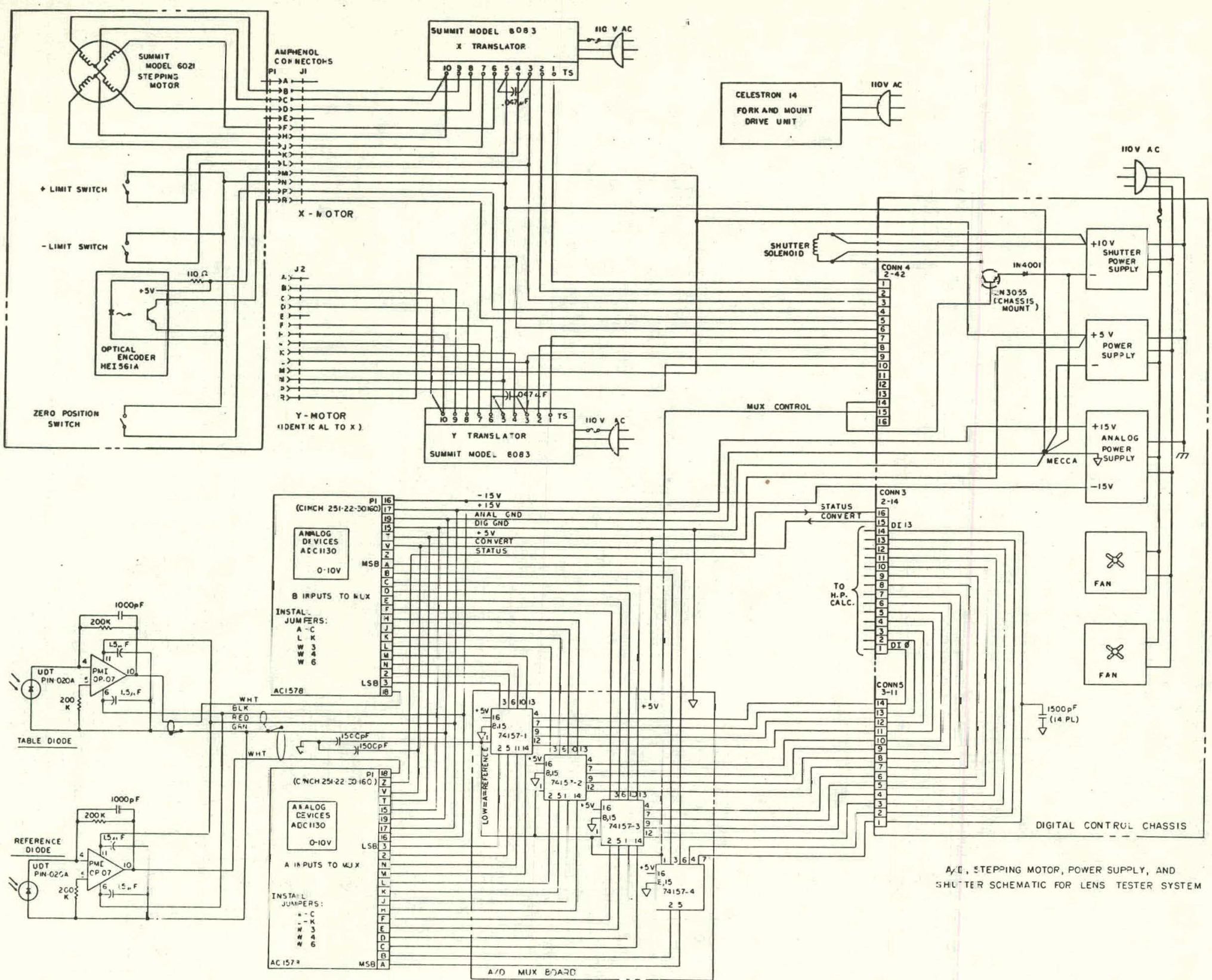

Figure A-6. Schemalic of Fresnel Lens Tester $\subseteq$ ystem 


\section{APPENDIX B}

\section{Listing of 9845B Program}




\section{Lens Tester Program}

20 IIM C\$[ $[Q], W \$[8 \theta], F 1 \operatorname{tr} \$(2)[3]$

30 SHORT $F(2 \theta), P(10), Z(102,102)$

40 INTEGER $A(204), D a(409)$

50 PRINTER IS 16

G0 WRITE IO 2,$5 ; 32$

30 V.alid $=$ "NONE"

80 Zerloc $=0$

90 DАTA $11.7,25.9,35.5,54.8,77.6,114,314,550,643,1515,2790,0,0,0,0,0,0,0,0,0$

100 MAT REAII $F$

110

ps",

y".

170 PRINT "disk (:F8,0), or the left tape cartridge (:T14)of the 9845 for each

t.est. "

180 PRINT "These files contain:",LIN(3), TAB(18), "1. Test directory, assorted t est info"

190 PRINT TAB (18), "2. Raw data from test", LIN(1), TAB(18), "3. Reduced data in solar ioncentration ratios", LIN(2)

200 FRINT "Fl disk can have 352 data files (117 tests) while a tape can have anl $y "$

210 PRINT 42 files (14 tests). Storage capacity will probably lim! the rumbe $r "$, LN(1), "of tests to less than these numbers for normal size data artays."

220 PRINT "No data file can have more than 102 lines, or 192 data locations per line."

230 DISF "Press 'CONT' to proceed."

240 FALISE

250 FRINT PAGE," Do you wish your mass storage to be floppy disk (Fe) or tape C

$\mathrm{T} 14$

26日 LINFUT "F8 OR T14?",M\$

279 IF NOT ( $M \$=" F 8 "$ ) OR $(M \$=" T 14 ")$ ) THEN GOTO 250

280 FPINT TAB $(20), M \$$

20日 IF M\$="F8" THEN MASS STORAGE IS ": F8, Q"

5010 IF M="T14" THEN MASS STORAGE IS ":T14"

i10 What:PRINT PAGE, "Do you wish to acquire a rew data file, analyze alraady rec grded" LIN(1), "data, or end prograli execution?"

325 FIRINT LIN(4)," Please answer with HLW, HNL, or EHI fulluwed by 'CDHT':

330 INPUT Aะ:

340 PRINT TAB (43), RE

350 IF $A=$ "END" THEN PRINT FAGE, "H-F RECOMMENDS TO RE-WIND YOUR THPES BEFDRE ST ORALE.", LIM〈Z〉, "PLERSE STORE RLL EQUIPMENT IN ITS FROPER PLACE. ", LIN(2), "BYE."

350 IF $A=" E N D "$ THEN MRSS STDRAGE IS ":T15"

3. IF $A \$=$ "END" THEN STOP

$3 B$ IF $A \$=" A C Q "$ THEN GOTO RCQ

390 IF $A=$ "FIHL" THEH GOTO An

403 GDTO What

410 !

$420 !$

4301

440 !

$450 !$

$460 !$

$470 !$

$480 !$

$490 !$

$500 !$

510 M.3.s: $F \mid:=1$

ร20

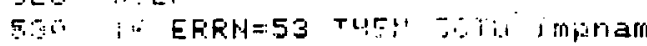

\begin{tabular}{|c|c|c|c|}
\hline sssssss & UU & ULI & B B BEBEE \\
\hline ss & UU & UU & \\
\hline sssssss & UU & UU & 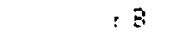 \\
\hline$\$ s$ & UU & UU & 2 \\
\hline SSSSSSS & \multicolumn{2}{|c|}{ บ1อบบบบ } & SEEL: . E \\
\hline
\end{tabular}

5 


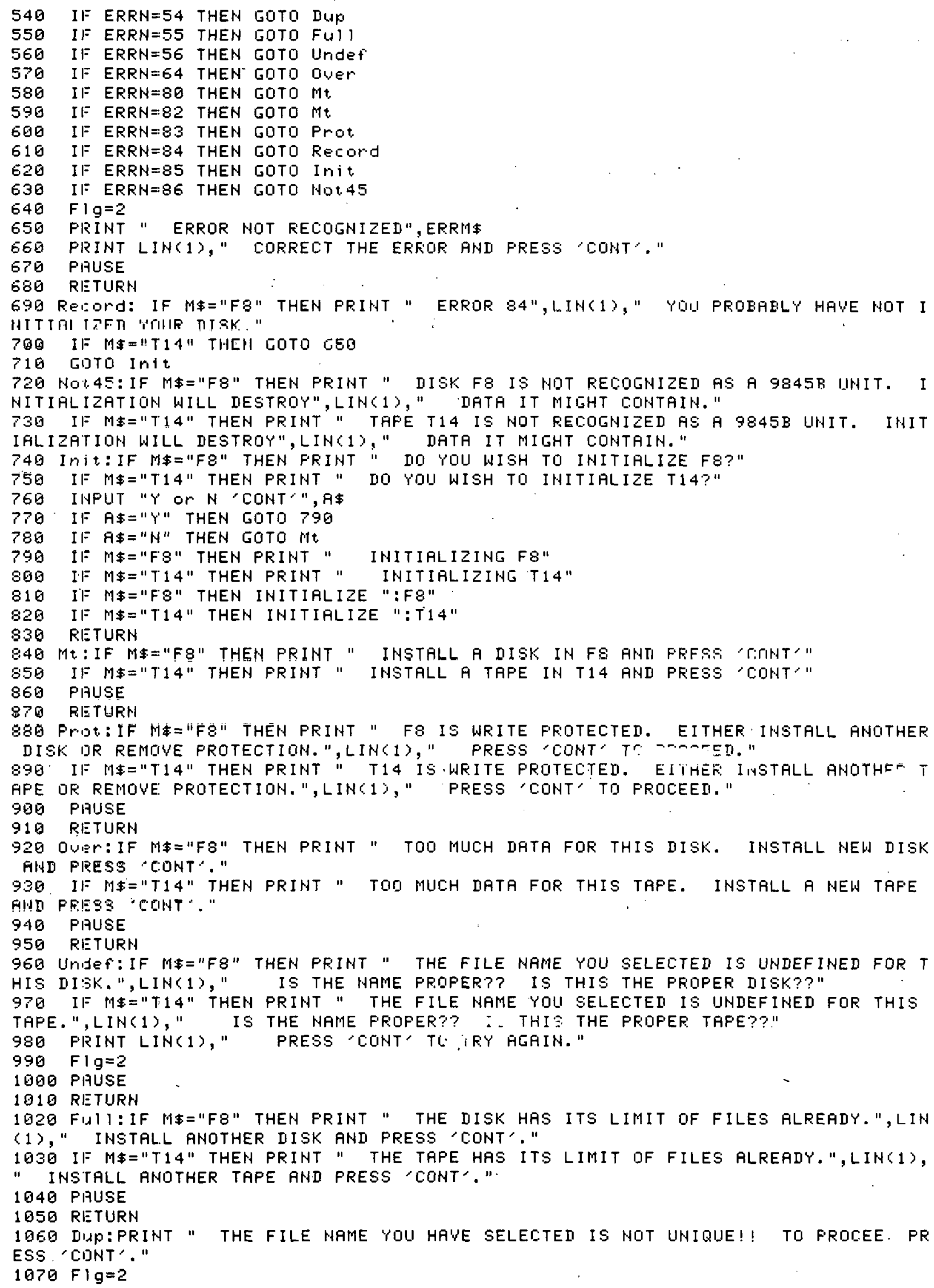




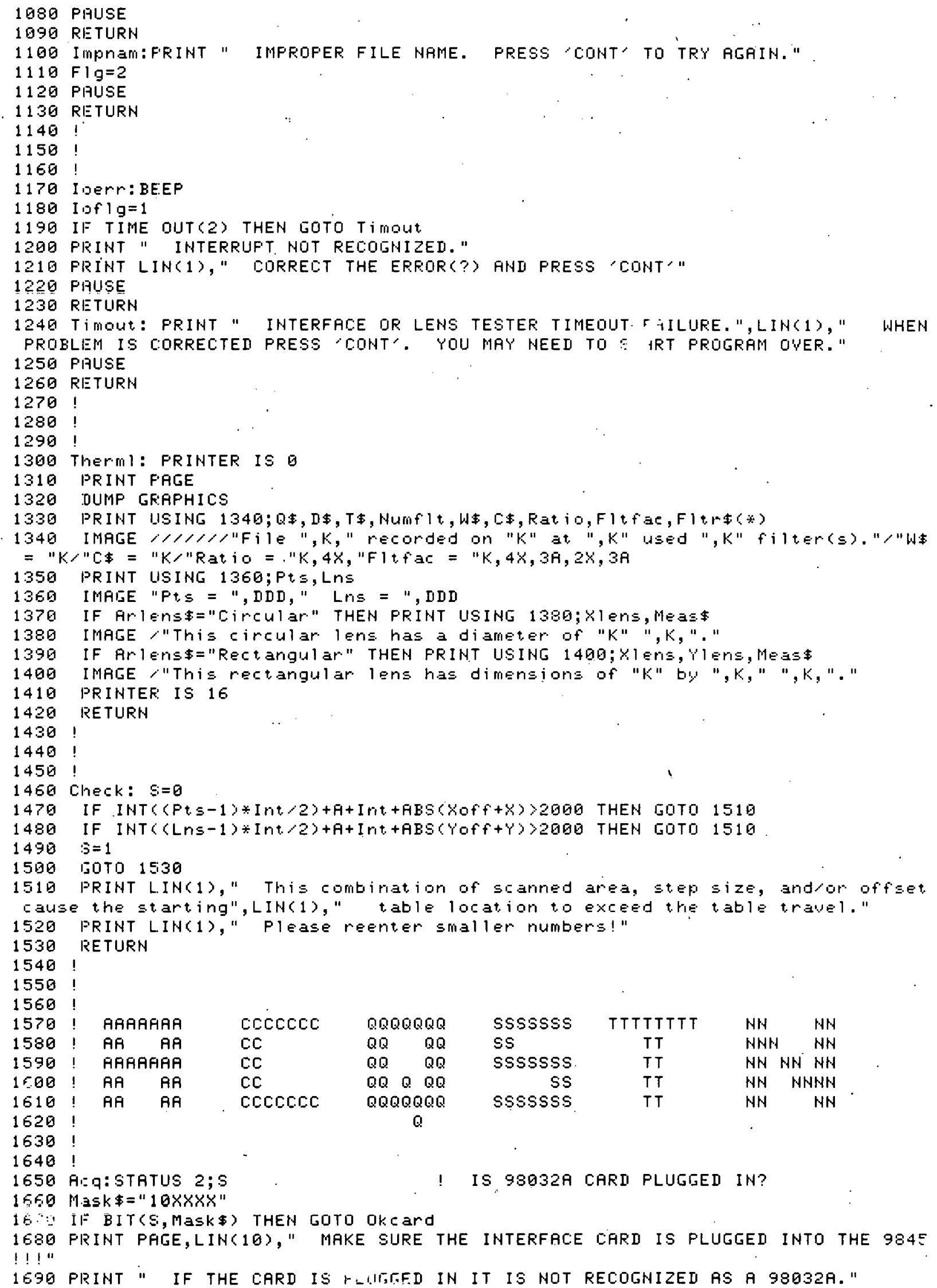


1709 PRINT LIH(2)," TURH OFF THE 9845 AND INSTALL THE LENS TESTER 98932A CARI W ITH A SELECT",LIN(1)," CODE 2, THEN START THIS PROGRAM AGAIN FROM FOHER DH." 1710 GITO 1710

1720 OKCard: IF BIT(S,8) THEN GOTO OKbOX IS THE TESTER OPERATIOHAL?

1730 PIRINT PFGE, LIN(10)," EITHER THE INTERFACE CABLE IS NOT PLUGGED INTO THE LE NS", LIN(1)," TESTER, OR THE AC PONER HAS HOT BEEN APPLIED TO THE LENS TESTER." 1749 PRINT " WHEN EITHER OR BOTH OF THESE DEFECTS RRE CORRECTED PRESS 'CONT'."

, LIN (1)

1750 PIAUSE

1760 GIJTO ACQ

1770 OKBOX:SET TIMEOUT 2;500

1780 SER I RL

1790 OH INT \#2 GOSUB IOERr

1800 WRITE IOI 2,$5 ; 33$

1810 I I $19=0$

1820 OIJTPUT 2 WHS USING "\#,W"; 12288

1830 IF I Of Iq=1 THEN GOTO 1810

1846 zero: $L=6$

1850 IF (Zerloc=1) AND (Valid\$="Y") THEN GOTO Yzero

1860 WRITE IO 2,5;33 ! RLLOW OUTFUT, RESET

1870 PRINT PHGE," We are now searching for table position (0,0)."

1880 OUTPUT 2 WHS USING "\#,W";16384 ! GO TO Hd Stps, MUX Lim SWS.

1890 STATUS $2 ; S$

1909 IF NOT EIT(S, 1$)$ THEN GOTO 1890

1910 PRINT LIN(2)," That, was the extreme upper left hand corner of table travel ."

1920 WIA I SBL

1930 CALL Move $(1,1,2500,0)$

1940 OITPUT 2 WHS USING "\#,W";8193

! XV, YG SEARCH

! MOVE $+X 2.5$ "

1950 STATUS $2 ; 5$

1960 IF NOT EIT $(S, 1)$ THEN GOTO 1950

1970 OITPUT 2 WHS USING "\#,W"; 12288

1200 WHIT 500

1990 X:step:OUTPUT 2 WHS USING "\#,W"; 12368

2000 OUTPUT 2 WHS USING "\#,W";20480

2010 OITPUT 2 . WHS USING " $" W " ; \theta$

2020 OUTPUT 2 WHS USING "\#,W";8449

! Int $=1$, MUX Xo SWITCH

2030 WIIT 20

2040 STATUS $2 ; 5$

2050 IF NOT EIT(S,1) THEN GOTO 2000

2060 Xzero:PRIHT LIH(2), "The table is now positioned with $x=0 . "$

2070 WAIT 500

2080 CHLL MOWE $(0,1,2500,0)$

2090 OUTPUT 2 WHS USING "\#, W"; 8193

! STOP TAELE, DISAELE COUNTERS

2100 STATUS $2 ; S$

2110 IF NOT EIT(S,1) THEH GOTO 2100

2120 OITPUT 2 WHS USING "\#, W"; 12288

2130 WIIT 590

2149 Y:StEP:OUTPUT 2 HHS USING "\#,W"; 12448

2150 OIJTPUT 2 WHS USING "\#,W";24576

2160 OIJTFUT 2 WHS. USIHG "H,W"; 4096

2170 OUTPUT 2 WHS USING "\#,W";8448

$X$ ENABLE $(-)$

STEP

$-X$

MUX XO ENCODER

2180 WAIT 20

2190 STATUS $2 ; 5$

2200 IF NOT EITSS, 1) THEN GOTO 2150

2210 Zer 1 oc $=1$

2220 Y:zero:PRiNT LIN(2)," The table is now at its center position, (G, g)."

2230 HAIT 1800

2240 IF (Valid\$="Y") OR (Walid\$="HONE") THEN GOTO MSYS

2250 IF XOff $=0$ THEN GOTO 2280

2260 CALL MONe( $1, \operatorname{SGH}(X$ of $f), \operatorname{RBS}(X \circ f), 0)$

2270 WHIT $2 * A B S(X O F f$ )

2280 IF Yoff $=0$ THEN GOTO 4560

2290 CALL MOVE (, SGN (Yoff), ABS(Yoff), D)

2300 WIAIT 2*FBS (Yoff)

1 MUVE +Y $2.5 "$

! Int $=1$, MUX Yo SHITCH

2310 GIJTO 4560

IF DATA WRS INVALID THEN: MOVE TO Xoff arid,

MOVE TO Yof 
2320 M:SYS:PRINT LIN(3), "Which measurement system would you prefer to use for y our input: "L.IN(1), TAB(25), "1. Inehes", LIN(1), TAB(25), "2. Mil1imeters"

$2339 \quad A: 5=" 1$

2340 INPUT " 1 or 2 'CONT"

2350 Mizas $\$=" I n "$

2360 IF $A \$=" 2 "$ TH!EN Meas $\$=" M m "$

2370 IF NOT $(A \$=" 1 ")$ OR $(A \$=" 2 ")\rangle$ THEN GOTO 2320

2380 PRINT USING 2390;MEas\$

2390 IMAGE " YOU SELECTED "2A"."

2400 PRINT LIN(3), "The aperature of the fresnel lens that transmits 1 ight. is:" , LIN(1), TAB (25), "1. Cireular", LIN(1), THB(25), "2. Rectangular"

$2410 \mathrm{~A}: \mathrm{D}=" 11$

2420 INPUT " 1 or 2 COHT,",AF

2430 IF $A \$=" 1 "$ THEN GOTO Round

2440 IF NOT (A\$="2") THEN GOTO 2400

2450 Siguare: Arlens $\$=" R e c t a n g u l a r "$

2460 PRINT LIN $(1)$, "What are the $x$ and $Y$ dimensions of the lens?", Meast

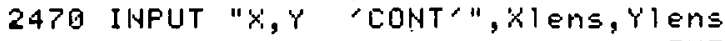

2480 IF (Xleris<=0) 0R (Ylens<=0) THEH G0T0 2520

2490 PRINT THB(30), "X= ", $X 1$ Ens

2500 PRINT THB (30), "Y = "Ylens

2510 GITO 2630

2520 PRINT " POSITIVE NUNZERO NUMEERS PLEASE!"

2530 GITO 246.9

2540 Riound: Frlens\$="Cireular"

2550 FRINT LIN(1), " What is the diameter of the lens area?", THB(E1),Meast

2569 INPUT " Diameter' CONT'", Xlens

2570 IF $\times 1$ IES $<=0$ THEN G0T0 2610

2580 PRINT TAB(25), "Diameter = ", $\times 1$ ens

2590 Ylens $=X 1$ ens

2600 GITO 2630

2619 PRINT " POSITIVE NONZERO NUMBERS FLEASE!"

2620 GITO 2550

2630 PRINT LIH(2), " The table will always perform a rectangular scarin the ina ge plane but",LIN(1), " efficiency data can be calculated from either;"

2640 PRINT TFB(25), "1. A circular image area", TAB(25), "2. A rect.angular. image area", IN IN (1)," Which do you prefer?", LIN(1)

2656 A:t $=" \|$

2660 INPUT " 1 or 2 followed by 'CONT'", A\$

2670 Area $\$=" F e c t$ angular"

2680. IF $A \$=" 1 "$ THEH Areat="Circular"

2690 IF NOT $(\langle A \$=" 2 ")$ OR $(A \$=" 1 ")\rangle$ THEN GOTO 2630

2700 PRINT " YOU SELECTED", RrEat

2710 IF Areat="Circular" THEH GOTO Circ

2720 RECt: PFINT LIN(2), " WHAT ARE THE X RHD Y IIIHENSIOHS OF THE SCANHEI AFEA?" Meass

2730 INPUT "Xsean, Yscan' CONT'", Xscan, Yscan

2740 IF (XSGan>4) AND (MEas\$="In") OR (XSCan>1016) RHD (MEaSF="Mm") THEN GOTO La

rge

2750 IF (Yscan>4) RND (Meas\$="In") OR (Ysean>1016) FND (MEast="Mm") THEN GOTO La

rge

2760 PIRINT THB(30)," Xscan=", Xscan

2770 PRINT TAB (30)," Yscan=", $Y \leq c a n$

2780 IF (Xscan>g) RHD (Yscan>0) THEN GOTO Step

2790 PRINT " POSITIVE NONZERO NUMBERS PLERSE!"

2800 G13T0 2730

2810 LARgo: FRIHT" Xsgan or Yscan TDD LARGE, TRY AGRIN."

2820 GITO 2730

2830 Circ: PFINT LIN(2)," WHAT IS THE DIAMETER OF THE CIRCULAR SCAHHED RREA?", IA

eas\$

2840 INPUT "Iliameter' 'CONT'", Xscan

2850 IF (Xscan>4) RND (Meas\$z"In") OR (Xscan>1016) RHD (MEast="Mm") THEN GOTO Bi

9

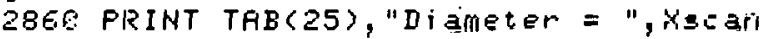

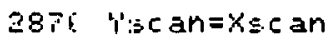

2880 IF Xscario THEN GOTO Step 


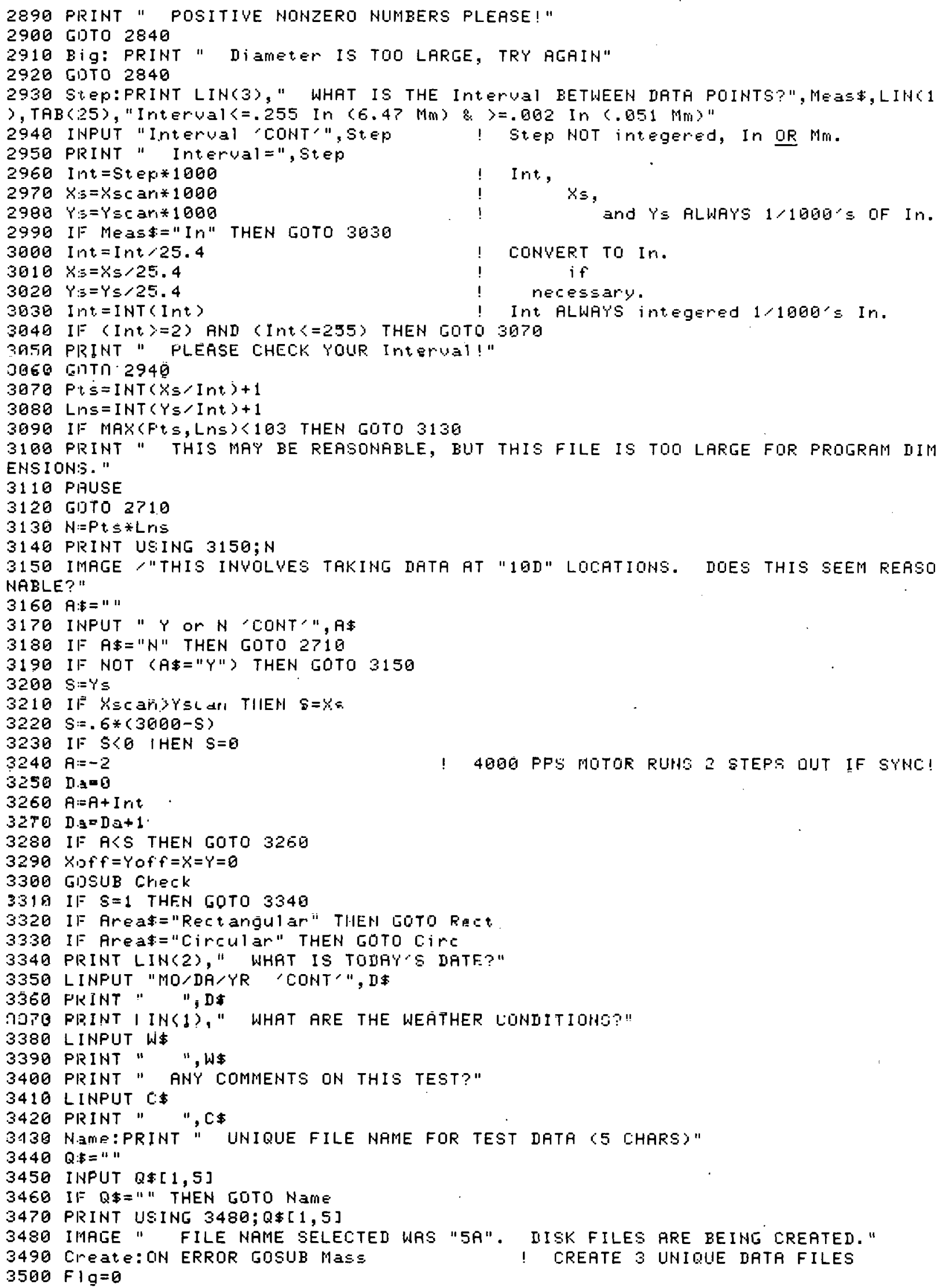


3510 CREATE O\$:"1",2

3520 IF Flg=2. THEN GOTO Name

3530 IF $F I g=1$ THEN GOTO 3500

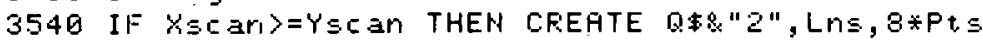

3550 IF $Y \leq r a r_{1}>X \leq c$ an THEN CREATE 0\%\&" $2 ", P t s, 8 * L n S$.

3560 IF $F 1 g=1$ THEN GOTO 3500

3570 IF $X S C$ ar $>=Y S C$ an THEN CREATE Q\$\&"3", LnS, 4*Pt

3580 IF $Y$ Scan>Xscan THEN CREATE Q\$3" $3 ", P t \equiv, 4 *$ LnS

3590 IF Flg=1 THEN GOTO 3500

3600 FRINT LIN $(1)$, "WHAT IS THE LOCAL TIME?"

3610 LINPUT "HR:MN "CONT" ", T\$

3620 PRINT" ", T\$

3630 PRINT LIN(2)," The next step is aligning the mount to the sun."

3640 PRINT LIN(3)," DO YDU NEED INSTRUCTIONS FOR ALIGNIHG THE MOUNT?"

3650 A:E=" "

3650 INFUT "Y" or $N$ "CONT" ", H*

3670 IF $A \$=" N "$ THEN GOTO 3810

3680 IF NOT $\{$ $\$=" Y ")$ THEN GOTO 3650

3690 PRINT PFGE," Align the tester cart so that it is in a North-South orientat. ion",LIN(1)," and lower the 4 support feet."

3700 PRUSE

3710 PRINT LIN(2)," Loosen locks on both axes and roughly al ign the reference t ube to the sun."

3720 PHUSE

3730 PIRINT LIN(2)," Turn on the tracking motor and do fine alignment using the reference tute", LIN(1)," mounted sight and the fine alignment motors."

3740 PIAUSE

3750 PRINT LIN(2)," Check to be sure that the alignment pinhole in the upper le ne carriage member", LIN(1)," casts its image or the table reference mark."

3760 PAUSE

3770 PRINT LIN(2)," If the two sun sight pinholes do not align simblataneously the reference tube" LIN(1)," must be realigned to the tatie."

3780 PIAUSE

3790 PRINT LIN(2)," If the alignment i E proper the mount should now track the $\equiv$ un.

3300 PRUSE

3810 PRINT PFGE," We will now measure the dark current and gain ratio of the tw o diodes."

3820 PRINT LIH(2)," Install the opague cover or the reference tute and in the 1 ower filter holder slot." LINC1?," PRESS cOONT" TO PROCEED."

3830 PIAUSE

3840 R:z=Tz=Rat io=0.

3850 OFF INT \#2 ! OFF IHT TO ALLOW WFHS

$386 \theta$ REDIM $A(200)$

3870 FIJR $J=1$ TO 2

3880 WRITE IO 2,$5 ; 35$

3890 WAIT 500

3909

3919

3925

3939

3940

3950

3960

3970

3980

3990

4009

4010

4020

4030

4040

4050

OUTPUT 2 WHS USING "\#,W"; 101

IF $\mathrm{J}=1$ THEN OITPUT 2 WHS USING "\#, W"; 12369 ! $\%$ ENABLE $(-)$, Int ENABLE IF J=2 THEN OUTPUT 2 WHS USING "\#,W";12353 ! X ENABLE $(+)$, Int ENABLE QUTPUT 2 WHS USING "\#,W"; 8193 OFF INT \#2

WR ITE IO 2,5;2

ENTER 2 WFHS 290 NOFORMAT;A(*) WAIT 20

ON INT \#2 GOSUB Ioerr

WRITE IO 2,$5 ; 33$

IF $J=2$ THEN GOTO 4990

! OPEN SHUTTER, ALLOW OUTPIT, RESET

FOR $I=1$ TO 100

$R z=F z+(16383-A(I * 2-1)) / 190$

$T z=T z+(16383-A(I * 2)) / 100$

NEXT 1

PRINT "TI = ", TI," RZ = ", RZ

4060 PRINT LIN(2)," REMOVE THE TWO OPAQUE COVERS FROM THE DIODES.", LIN(1)," IHSURE THE TABLE BAFFLE IS INSTRLLED, THEN PRESS 'CONT'." 


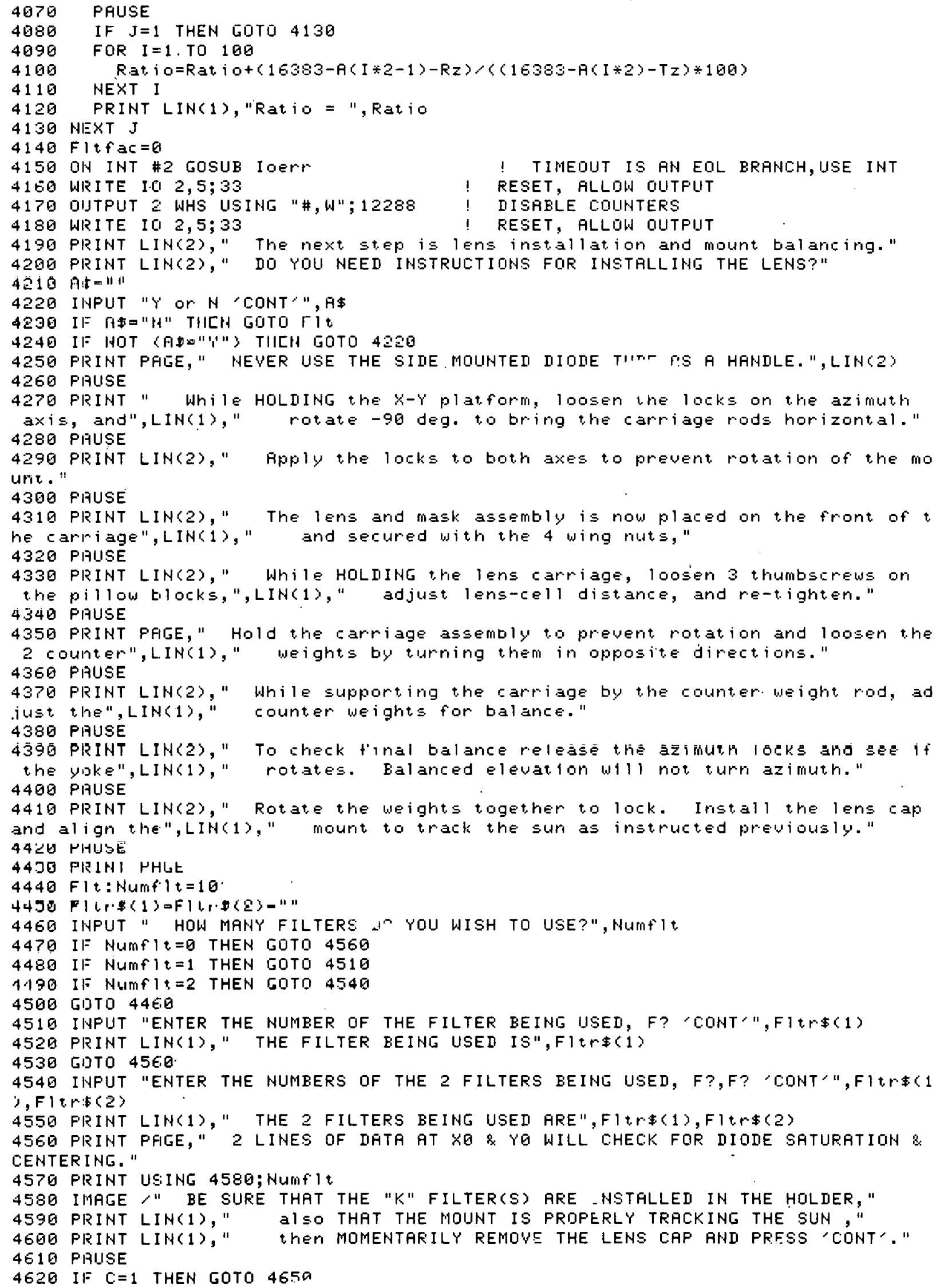




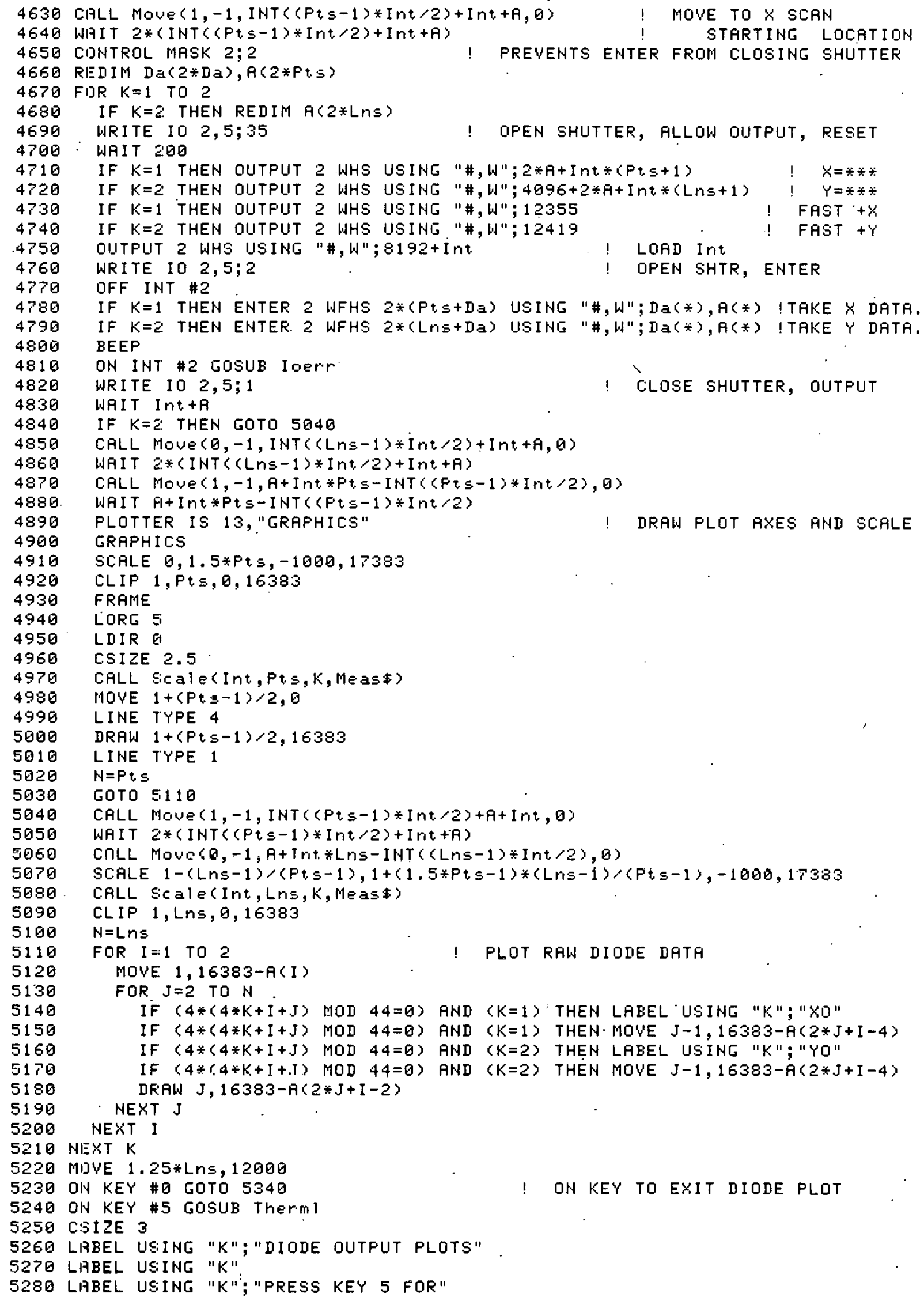

! PLOT RAW DIOIE DATA 


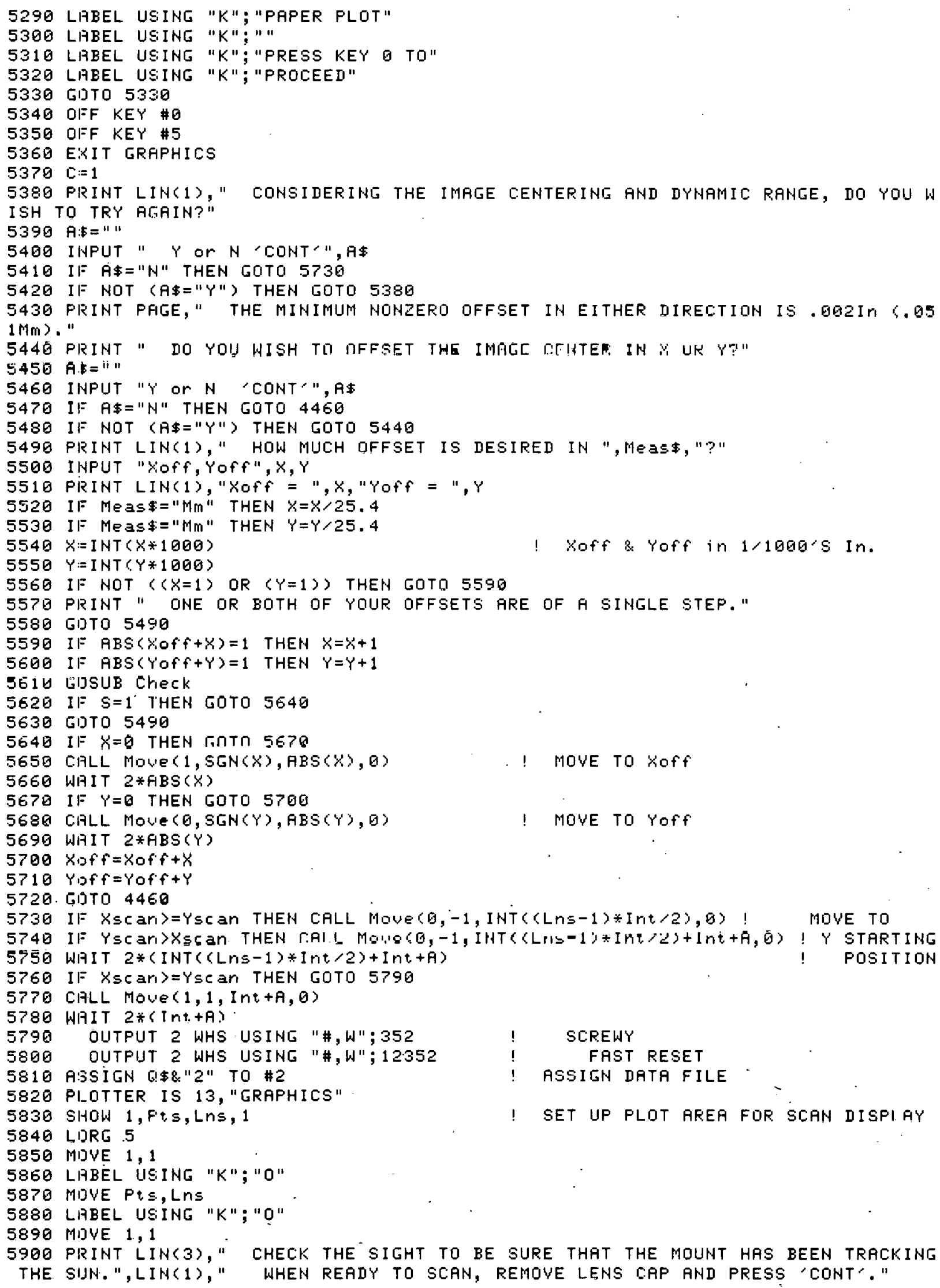




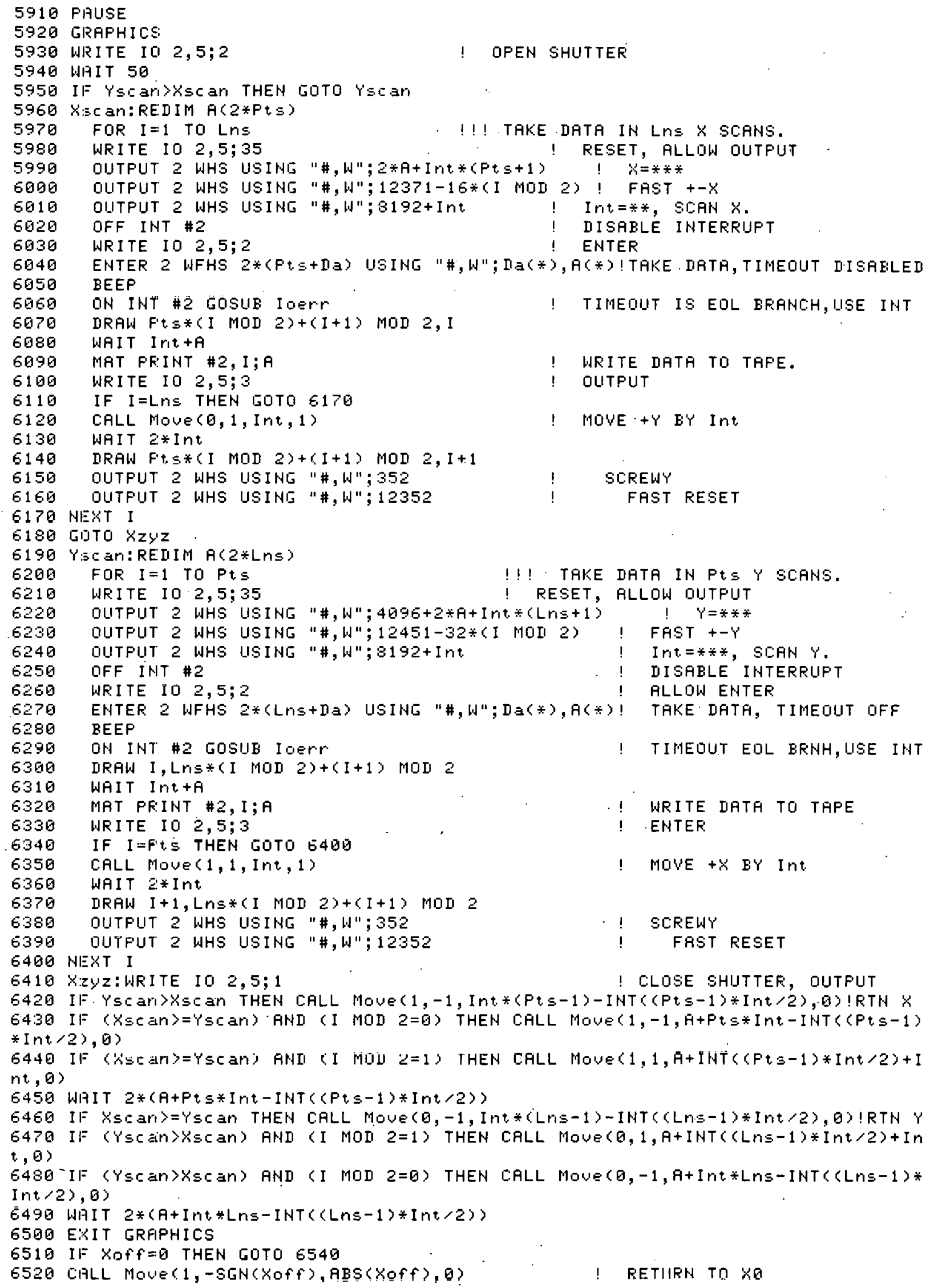


6530 WHIT $2 *$ HBS(XOff)

6540 IF Yoff $=0$ THEN GOTO File1

6550 CIFLL MOWE(g,-SGN(Yoff), ABS (Yoff), $\theta)$

6560 WHIT $2 *$ ABS (Yof $f$ )

657g File1:PFINT LIH(1)," PLEASE REPLACE THE LENS CAF, and CHECK THAT THE TAELE

IS AT XO, YB."

6580 PRINT LIN(1)," IF THE TABLE IS NOT AT XO, YE ERRORS IN THE SCAN MAKE THE IAH TA INVALID.",LIN(1)," A NEW SCAN WILL BE MADE IF YOU ANSWER 'H'."

E59G INPUT" DATA WALID? $Y$ or $N$ 'COAT"

6600 IF $\mathrm{Val}$ id\$="N" THEN GOTO Zero

6610 IF NOT ( $V a l i d \$=" Y "$ ) THEN GOTO 6590

6620 A:SSIGN * TO \#2

6630 A:3SIGN 0\$:" " TO \#1

6640 Alnal\$="HRS NOT"

6650 PRINT \#1; Xscan, Yscan, Step, Xeff, Yeff, Effscn, Ratio, Numflt, Fltrti*\}, Meas\$, Rrea

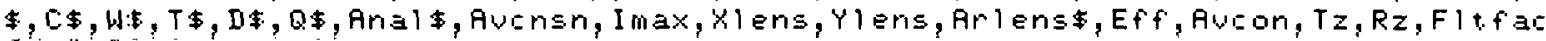

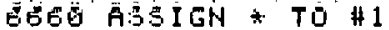

G6ig Lid What.

$6680 !$

$6690 !$

$6790 !$

$6710 !$

$6720 !$

ARAFARA

AR $A R$

ARAFIRRA

$6730 !$

AB $A R$

AR $R A$

\begin{tabular}{|c|c|c|c|}
\hline $\mathrm{NH}$ & HWH & \multicolumn{2}{|c|}{ AARAARA } \\
\hline NHN & NN & $\mathrm{AH}$ & $\mathrm{AF}$ \\
\hline $\mathrm{NH}$ & PANNA & \multicolumn{2}{|c|}{ ARAARAA } \\
\hline NN & NNN & AH & \\
\hline NN & & AR & \\
\hline
\end{tabular}

LL
LL
LL
LL
LLLLLLL

YY YY
YY YY
$Y Y$
$Y Y$
$Y Y$

S\$S55SS

6740

AR $A F$

ss

6769

6770

6796

6790 AMI:PRINT PAGE, "WHAT IS THE NAME OF THE FILE 'YOU WISH TO ANFLYZE?",LIN<1)

6800 ON ERRDR: GOSUB Mass

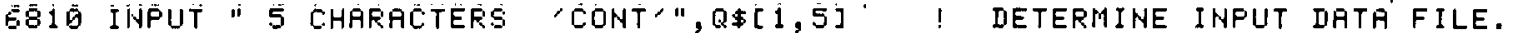

$0030 \Gamma \lg =0$

6839 A:SSIGN \#1 TO Q\$2 " $1 "$

6840 II Flg=1 THEN GOTO 6820

6880 IF Flgm THEH GOTO GT90

$6860 \mathrm{~F} / \mathrm{g}=0$

6870 A:SSIGN \#2 TO Q\$\&"2"

6880 IF Flg=1 THEN GOTO 6820

6890 ASSIGN \#3 TO Q\$\&"3"

6900 IF FIg=1 THEN GOTO 6820

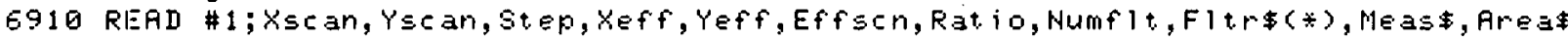

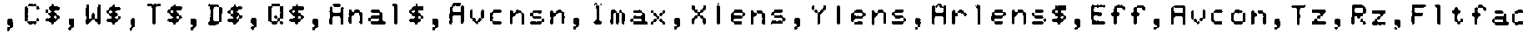

6920 II Areat:="Circular" THEN Yscan=Xscan

5930 Int $=5 x \in k+1000$

$6940 \quad x: 3=x \operatorname{scar} * 1000$

$6950 \quad Y s=Y s c a r * 1900$

6960 IF MEas:="In" THEN GOTO POQ0

6979 $x^{\prime}=x 5 / 25.4$

$6980 Y: Y s / 25.4$

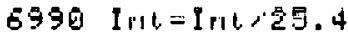

7000 Int $=I N T$ (Int)

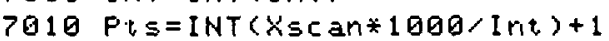

7020 LnS=INT (Yscan*1000/Int) +1

7030 PRINT UEING $7040 ; Q \$, D \$, T \$$, Numflt, Anal $\$, X s c a n$, Meas

7040 IMAGE [File ", $K$, " recorded on ", $K$, " at "K" using ", $K, " f i l t e r(s)$ "K" bee $n ", "$ Jata reduced. "The area which was scanned was ", $K, X, K$

7050 IF Area\$="Circular" THEN PRINT USING 7060;Area\$, C\$, W\$,PtS, LnS,FItr\$(*)

7060 IMAGE $2 X, K "$ " "ノ, "Comment $=", K /$ "Weather = ",K/"Pts = ",K," LnS = ", K/K, $2 X, K$

7970 IF Areat="Rectangular" THEN PRINT USING 7080;Yscan, Meas\$, Area\$,C\$, W\$,PtS,Ln $\Xi, F 1+r: * *)$

7080 IMAGE " by ",K, $X, K, X, K "$ " "/ "Comment = ", K/"Weather = ",K/"Pts = ",K," LnS $=", K, K, 2 x, k$,

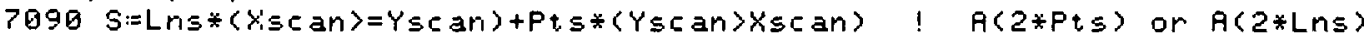




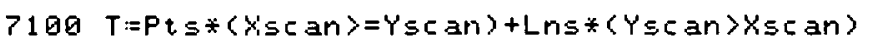

7110 RIEIM $A(2 * T), Z$ (Lns, Pts)

7129 II Anal $\$=$ "HAS NOT" THEN GOTO. 7240

depending upon $s c$ an direction

7130 PRINT USING $7140 ;$ Arlens\$, Rrea\$, Effscn, Ruensn

7140 IMAGE "This ",K," lens which forms a "K" image area had a SCRNHED ARER", 1DX, "Efficiericy = "DDD.DD"\% and"/1EX, "Ave concentration = "DDDD. ID/

7150 IF Areat="Circular" THEN PRINT USING $7160 ;$ Xeff, Meast,Eff, fucon

7160 IMAGE "The smaller Circular image area of diameter ",K, $X, K, "$ had an IMAGE AREA", $/ 11 X, " E f f i c i e n c y=$ ", DDD. DD, "\% and"/11X, "Ave Concentration = ", IDDD. DD

7170 IF Areat="Rectangular" THEN PRINT USING 718 ; Xeff, Yeff, Meast, Eff, Fucon

7180 IMAGE " The smaller Rectangular image of dimensions "K" by ", $K, X, K " h a d$ an

IMAGE AREA", $11 \mathrm{X}$, "Efficiency = ",DDD.DD, "\% "/11X, "Ave Concentration = "DDDD.DD

P190 PRINT LIN(1)," FILTER FACTOR = ", Fitfac

3200 B:F" "

7210 INPUT " DO YOU WISH TO RECOMPUTE EFFICIENCY? Y Or $N$ 'CONT'", $\$$

7220 IF $A \$=" N "$ THEN GOTO 8010

7230 IF NOT (AD="Y") THEH GOTO 7210

7240 PIRINT $L I N(1)$," What area < the scanned area do you wish to use for calcul at. ions?", LIN(1), TAB(20), "In units of ", Meas

7250 IF Areat="Circular" THEN INPUT "IIiameter = ? CONT" Xeff

7260 .IF Areat="Circular" THEN PRINT TAB(15), "Diameter = ",Xeff

7270 IF Areat="Rectangular" THEN INPUT " $X, Y=$ ? "CONT" "Xeff, Yeff

7280 IF Areat="Rectangular" THEN PRINT TRB(10), "Keff = ", Keff, "Yeff = ", Yeff

7290 IF Anal\$="HAS NOT" THEN GOTO 7350

7300 PRINT " DO YOU WANT TO RECALCULATE CONCENTRATION RATIOS RLSO?"

7310 A:D=" "

7320 IHPUT " $Y$ ' or $N$ 'CONT'", $A \$$

7330 IF $A=$ "N" THEN GOTO 7690

7340 IF NOT (A\$="Y") THEN GOTO 7300

$7350 \mathrm{Flt} f a c=\mathrm{F}$ at io

7360 IF Numflt=0 THEN GOTO 7400

7370 FDR I $=1$ TO Numf $1 \mathrm{t}$

7380 Fltfac $=F 1 t f a c * F(V A L(F 1 t r \$(I)[2,3]\rangle)$

3390 NEXT I

7400 PRINT USING 7410 ; Numflt,Fltr $\$(*)$, Ratio,Fltfac

7410 IMAGE $/ "$ The "K" filter(s) used: ", $3 A, X, 3 A / "$ together with the diode ga in ratio of "K/" result in a filter factor of "K

7420 PRINT LIN(1), " DO YOU WISH TO ALTER THIS FILTER FACTOR?"

7430 A: $=" 1 "$

7440 INPUT "Y Or $N$ 'CONT'",A\$

7450 IF $A \$=" N "$ THEN GOTO 7500

7460 IF NOT (A\$="Y") THEN GOTO 7420

7470 PRINT LIN(1)," WHAT FILTER FACTOR WOULD YOU PREFER? (FItfac=Ratia:F(N). )"

7480 INPUT "Filter Factor $=$ ? "CONT" "FItfac

7490 PRINT" FILTER FACTOR = ",FItifac

7500 PRINT LIN(1)," CONCLHTRATIUN RATIOS are now being calculated."

7516 FDR $J=1$ TO $S$

7520 READ \#2,J;A(*)

7530 FOR I=1 TO T

7540 IF Yscan $>$ Xscan THEN GOTO 7600

7550 IF J MOD $2=0$ THEN GOTO 7580

$7560 \quad Z(J, I)=(16383-A(2 * I)-T z) * F 1 t$ fac $\langle(16383-A(2 * I-1)-R z)$

7570

7580

7590

7690

7610

7620

7630

7640

7650 NEXT 1

NEXT J

7660 READ \#3, 1

7670 MAT PRINT \#3;Z

7680 GITO 7710

7690 REAT \#3,1 


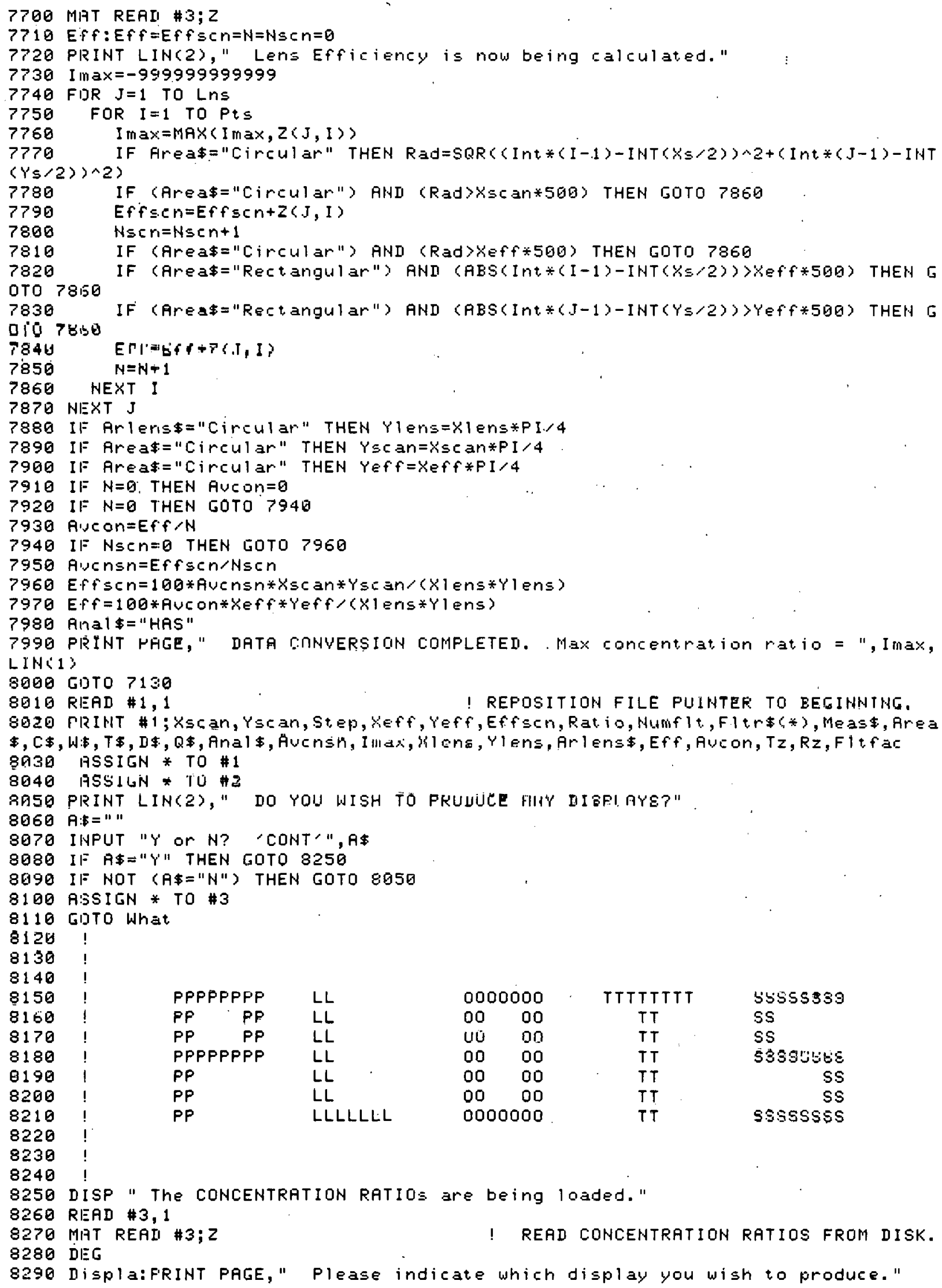




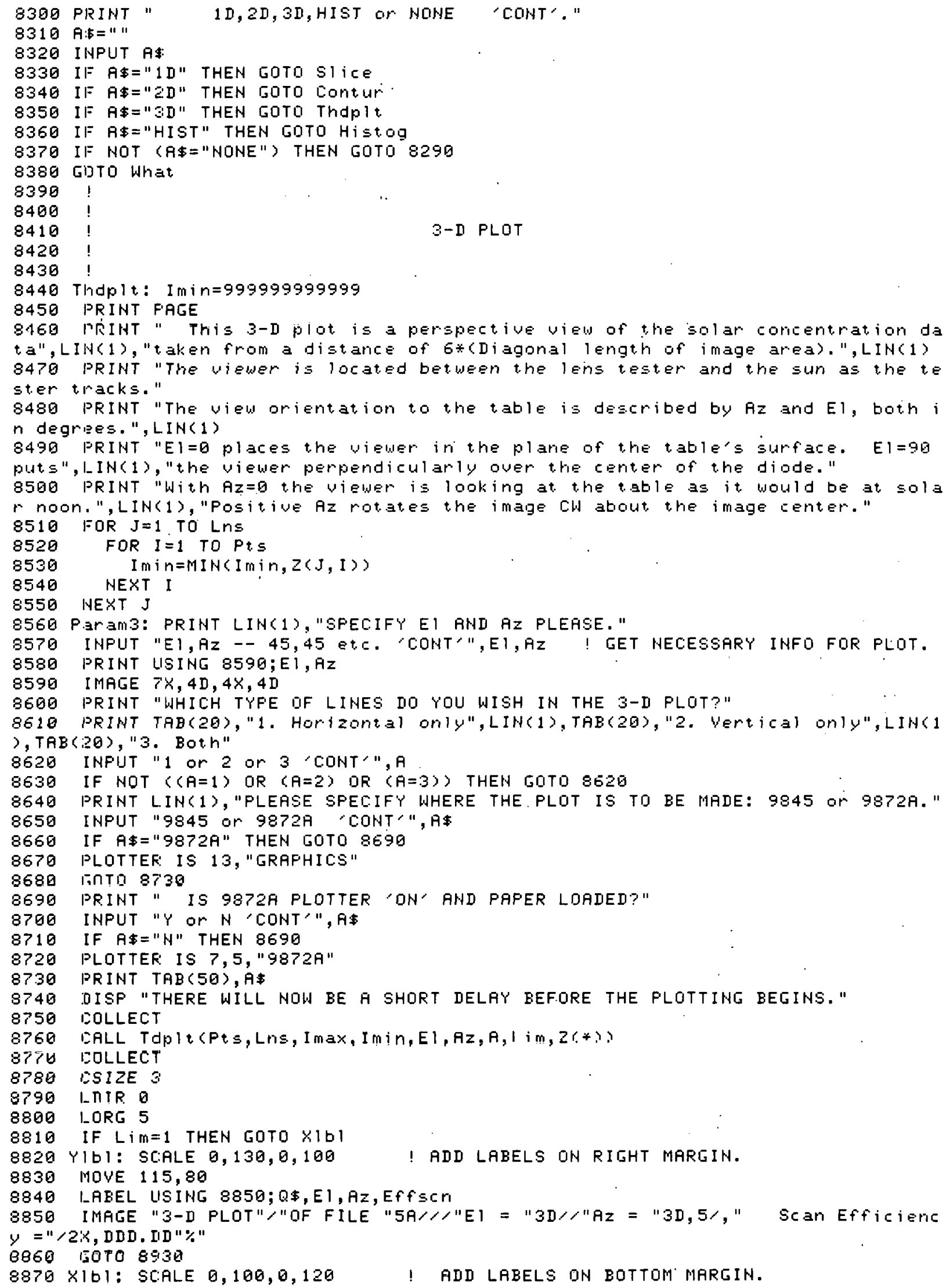




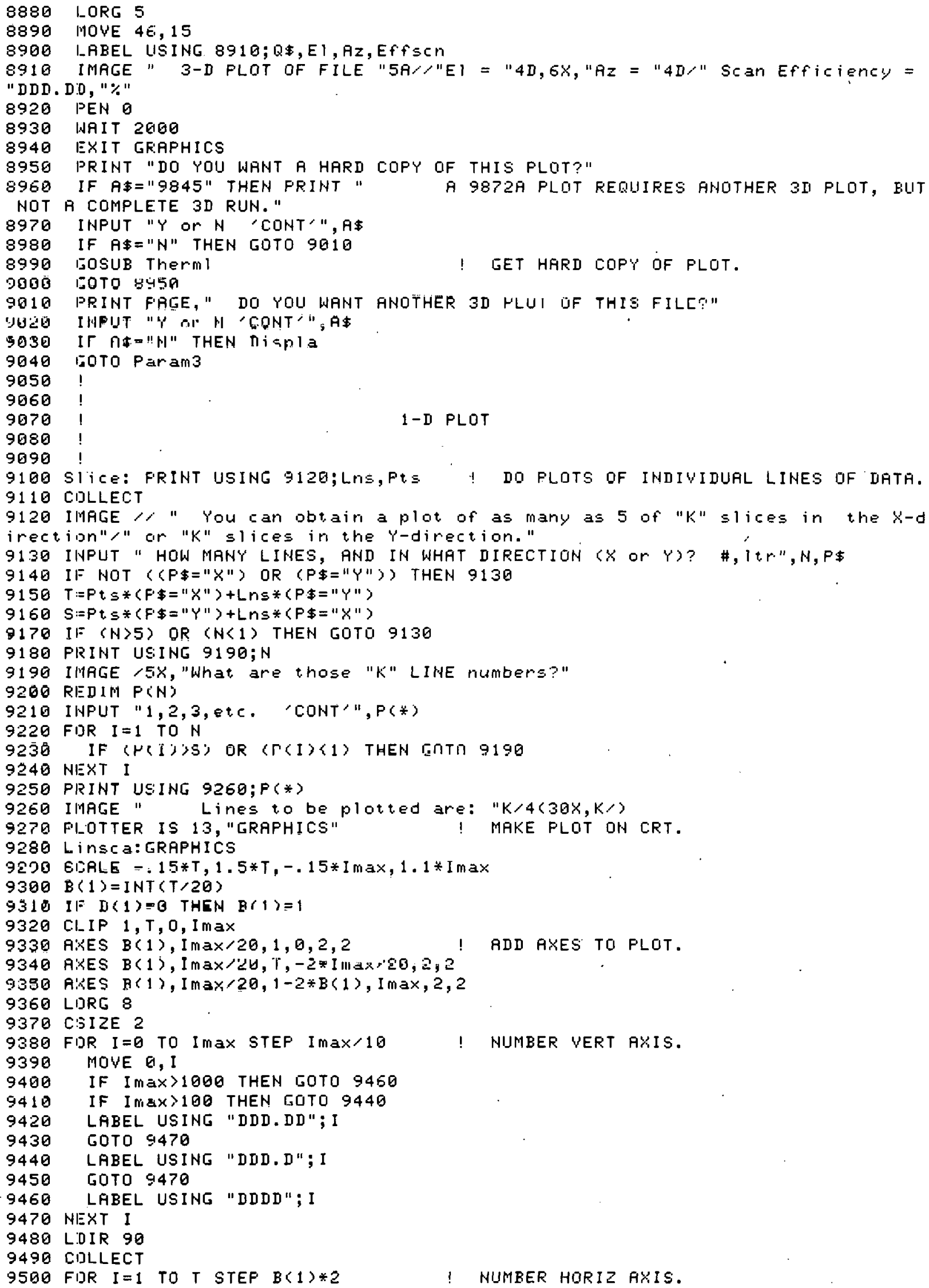




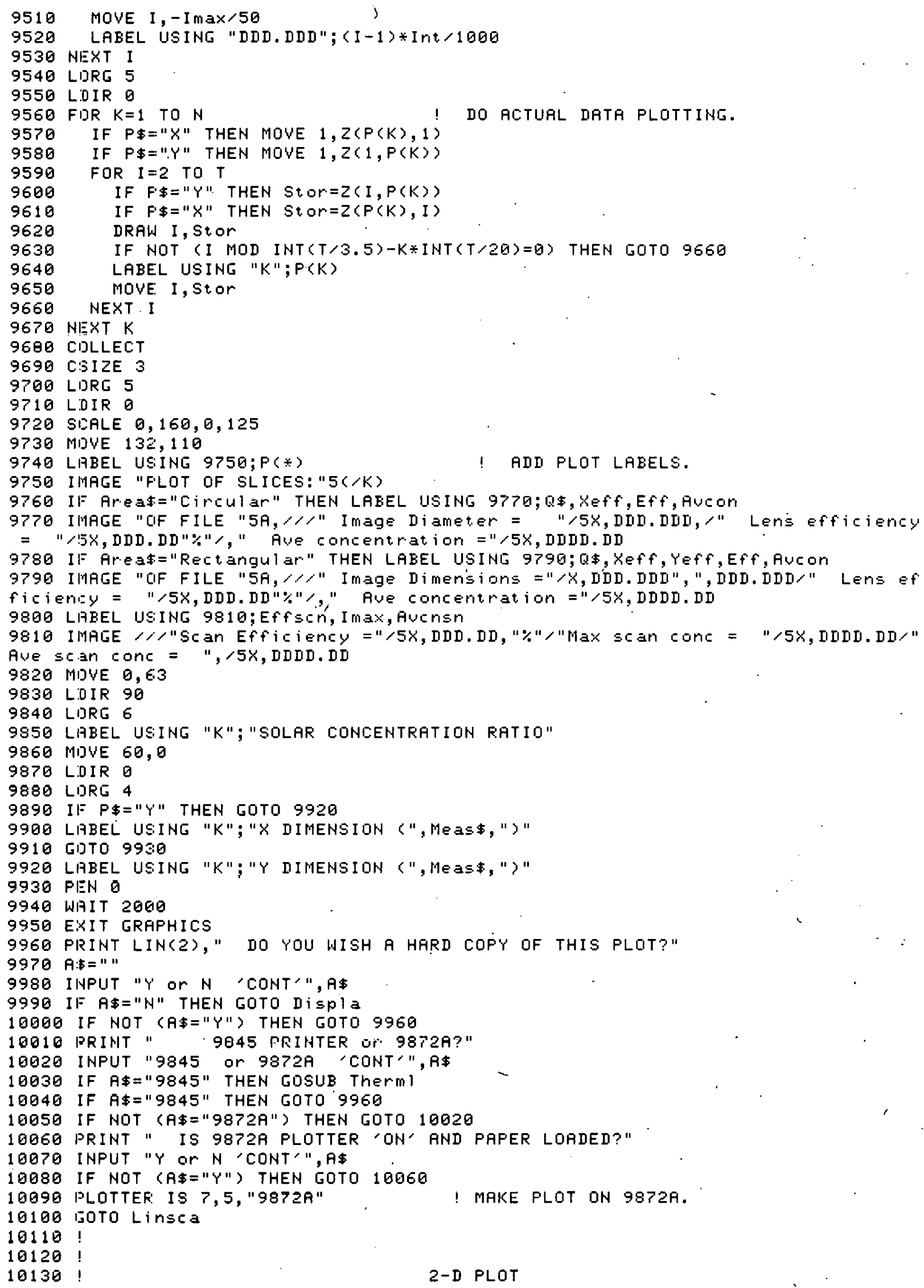




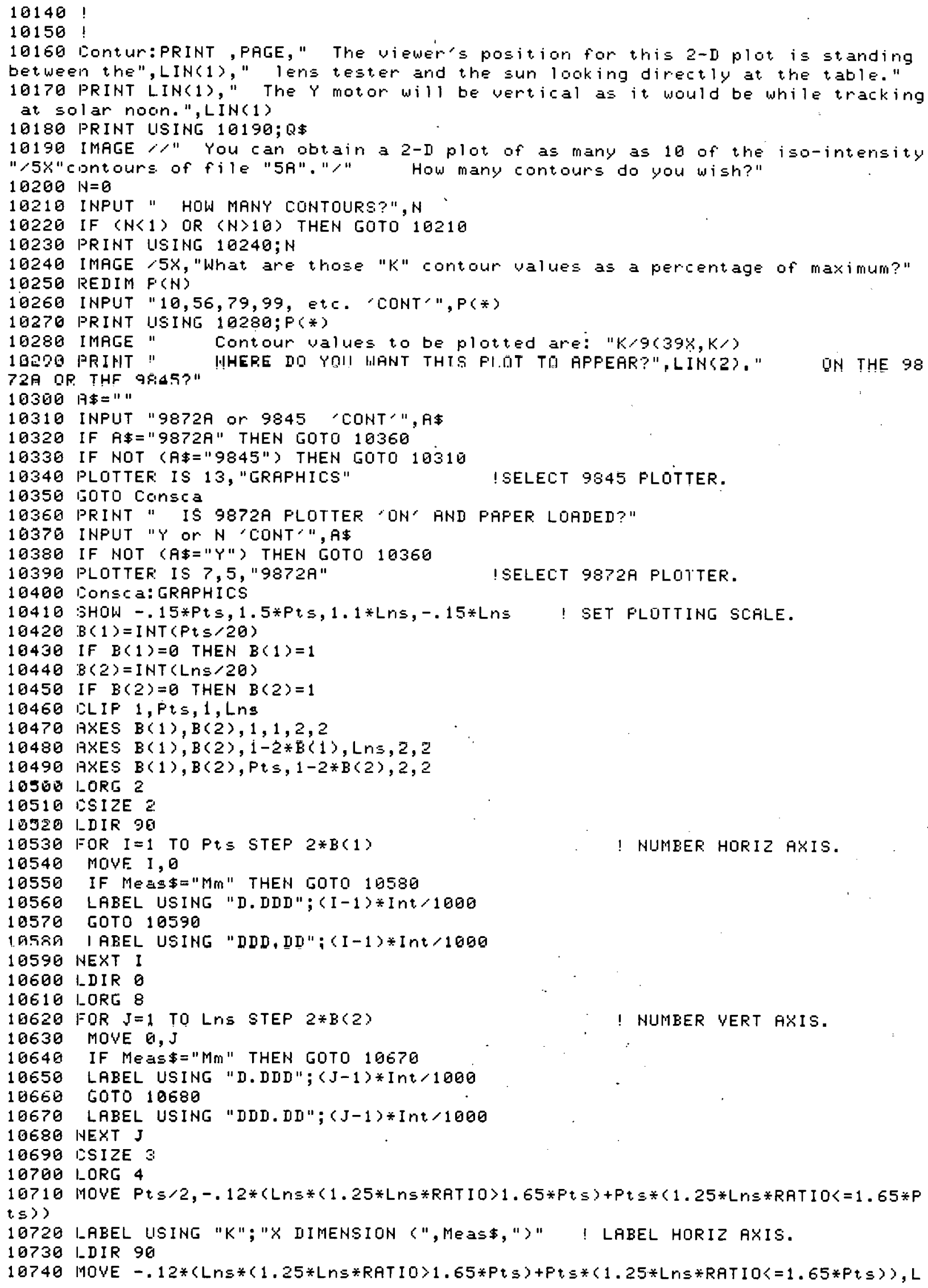




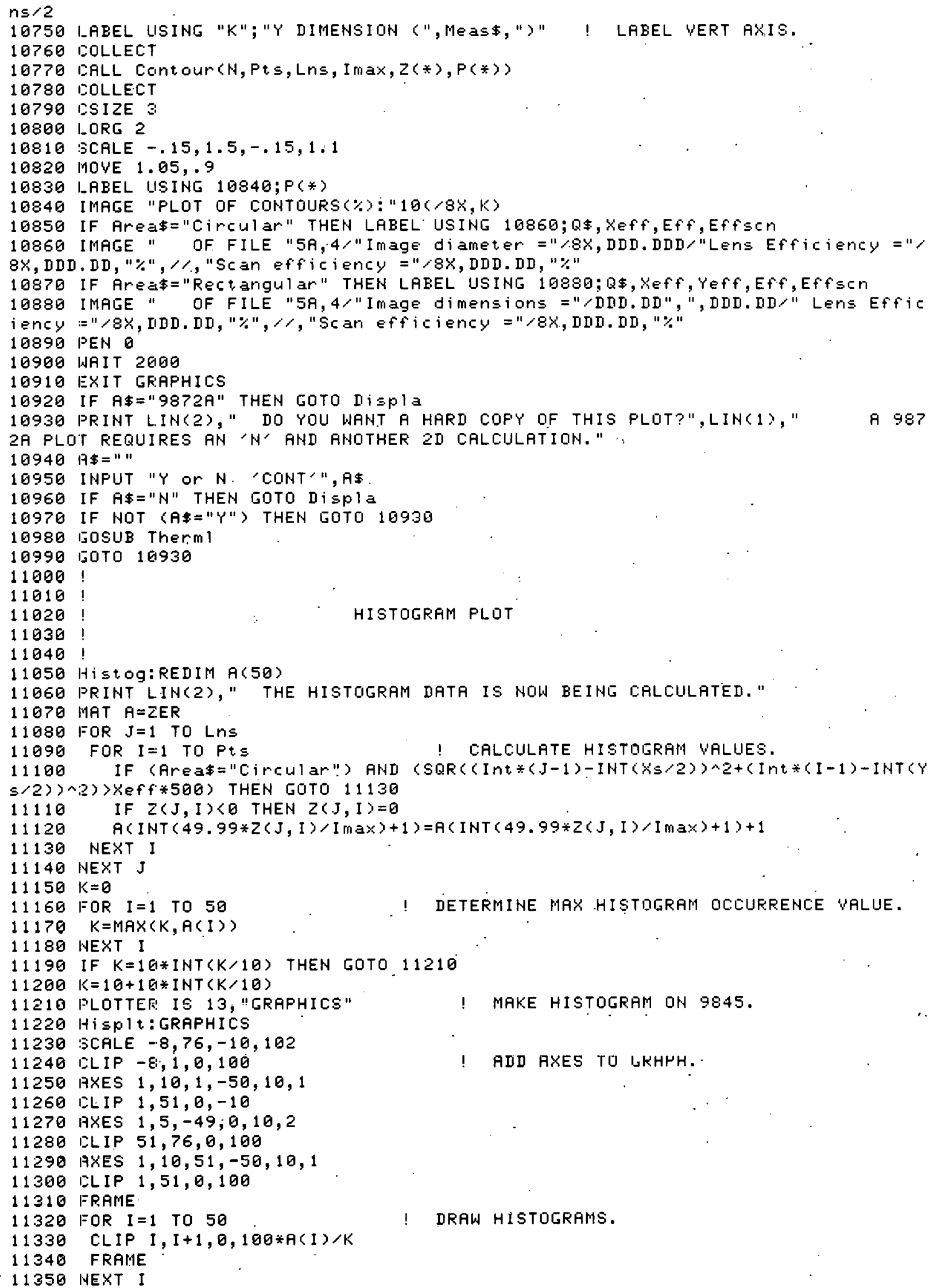




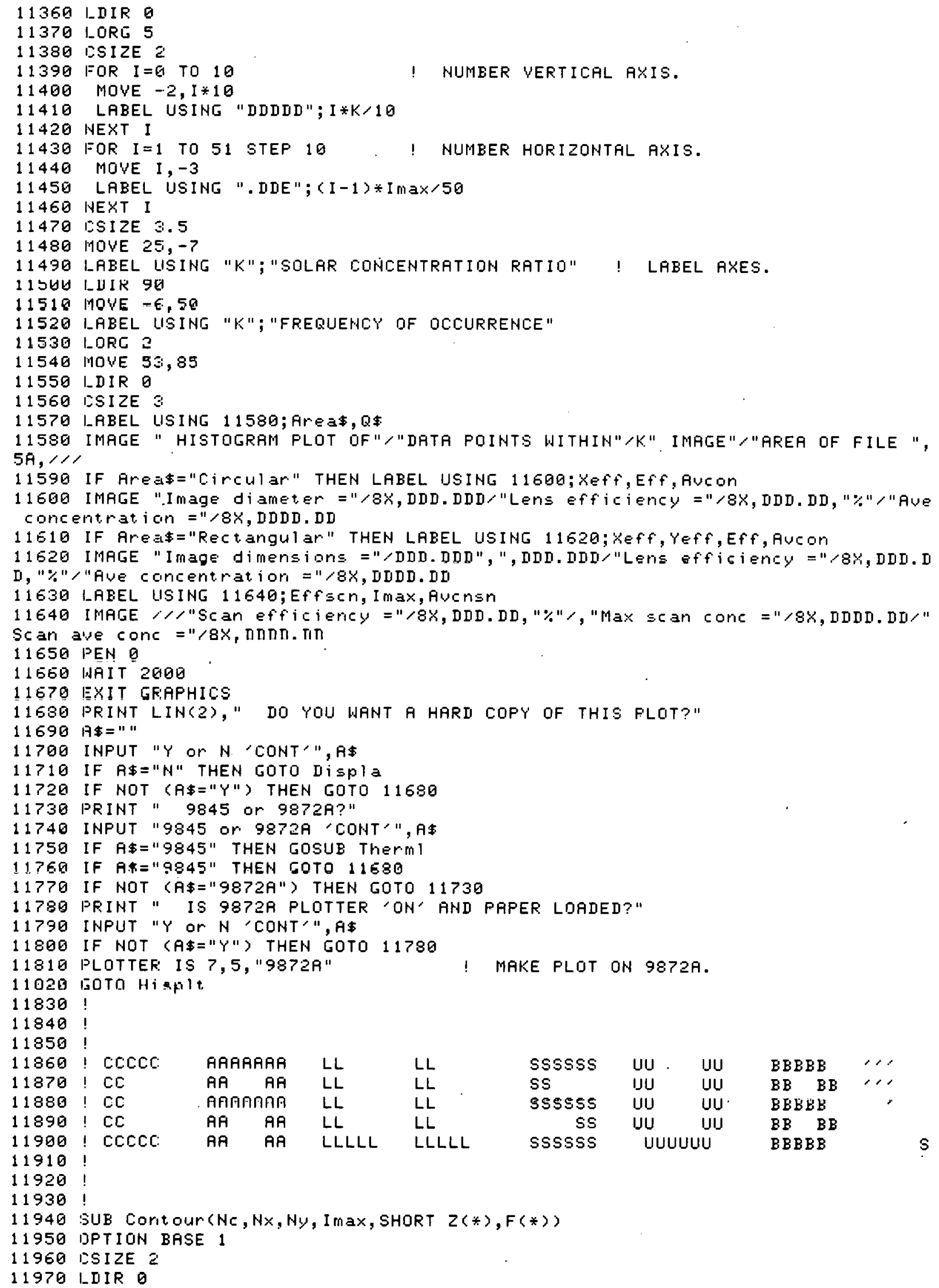

$\begin{array}{llllr}\text { CCCCE } & \text { AA } & \text { AR } & \text { LLLLL } & \text { LLLLL } \\ & & & \end{array}$

$L L \quad L L$

LL LL

LL $\quad$ LL 


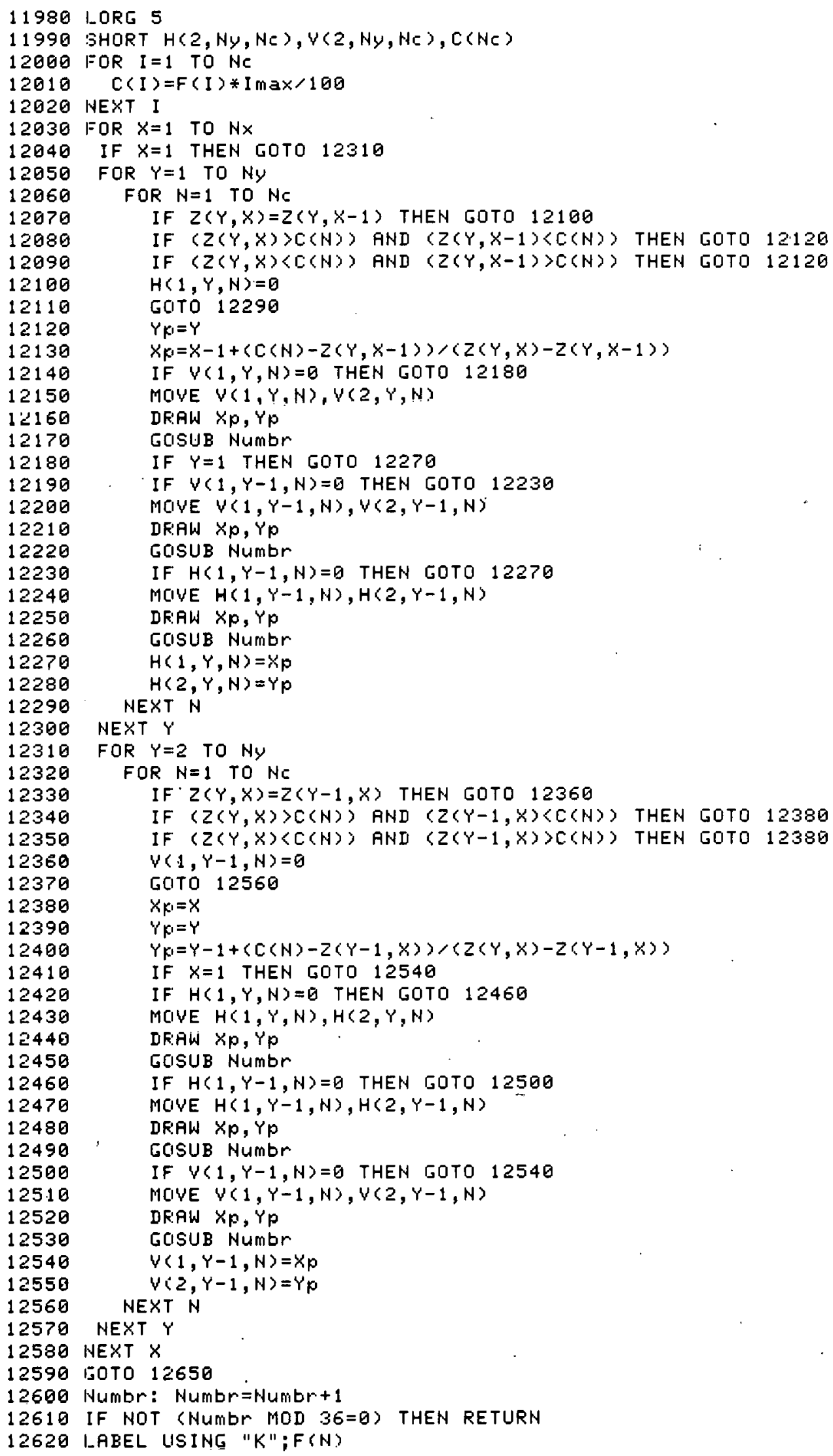




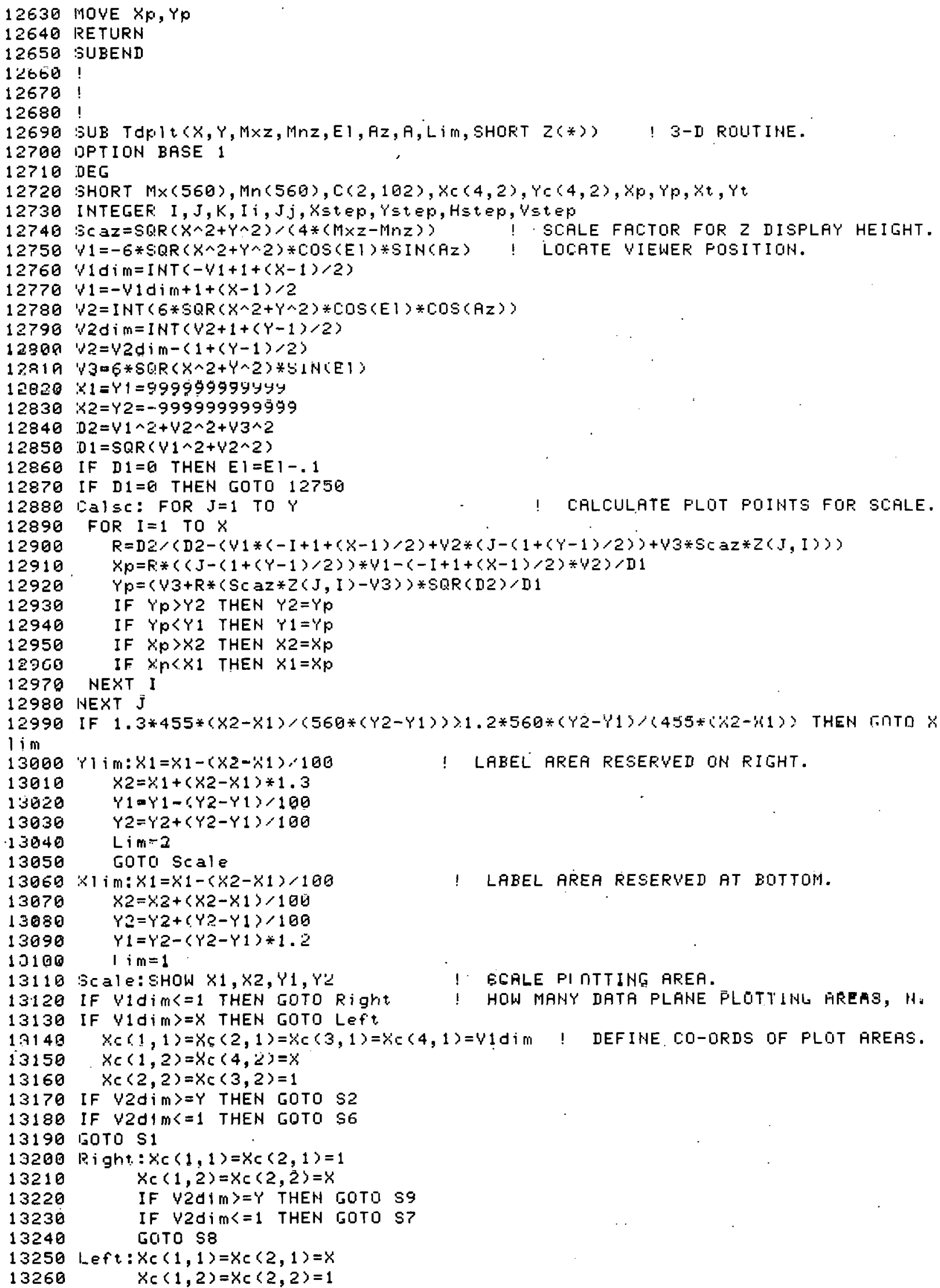




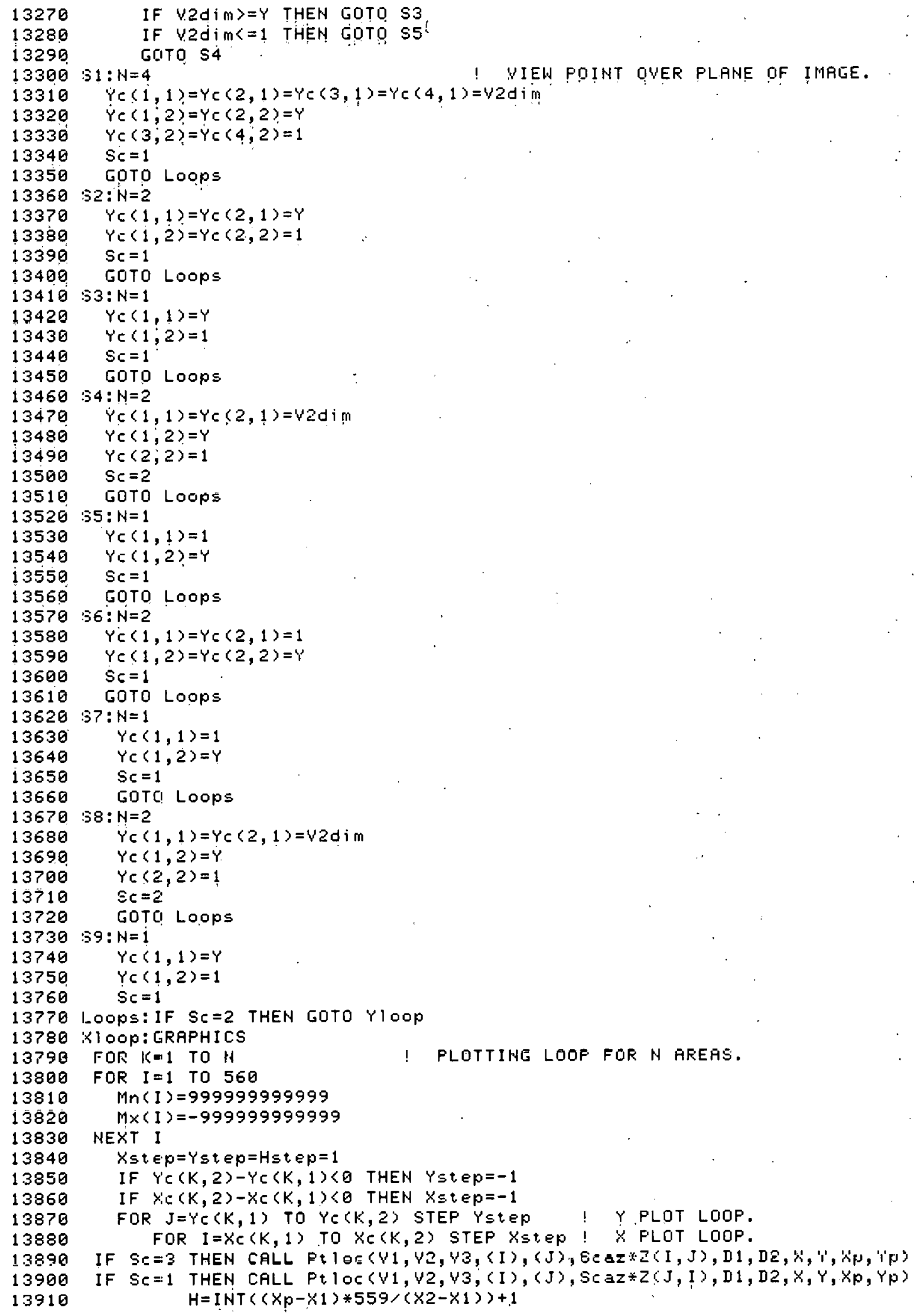




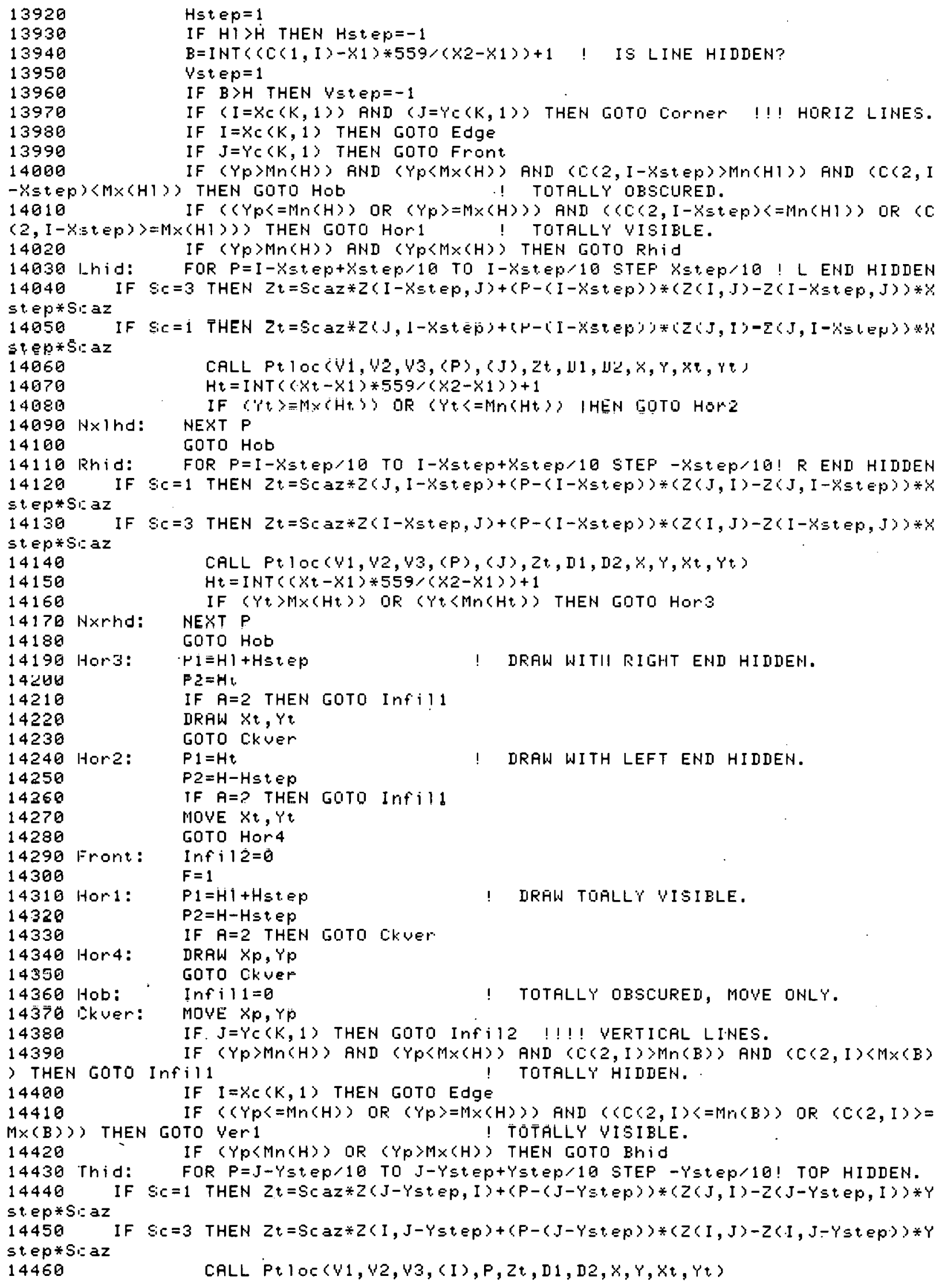




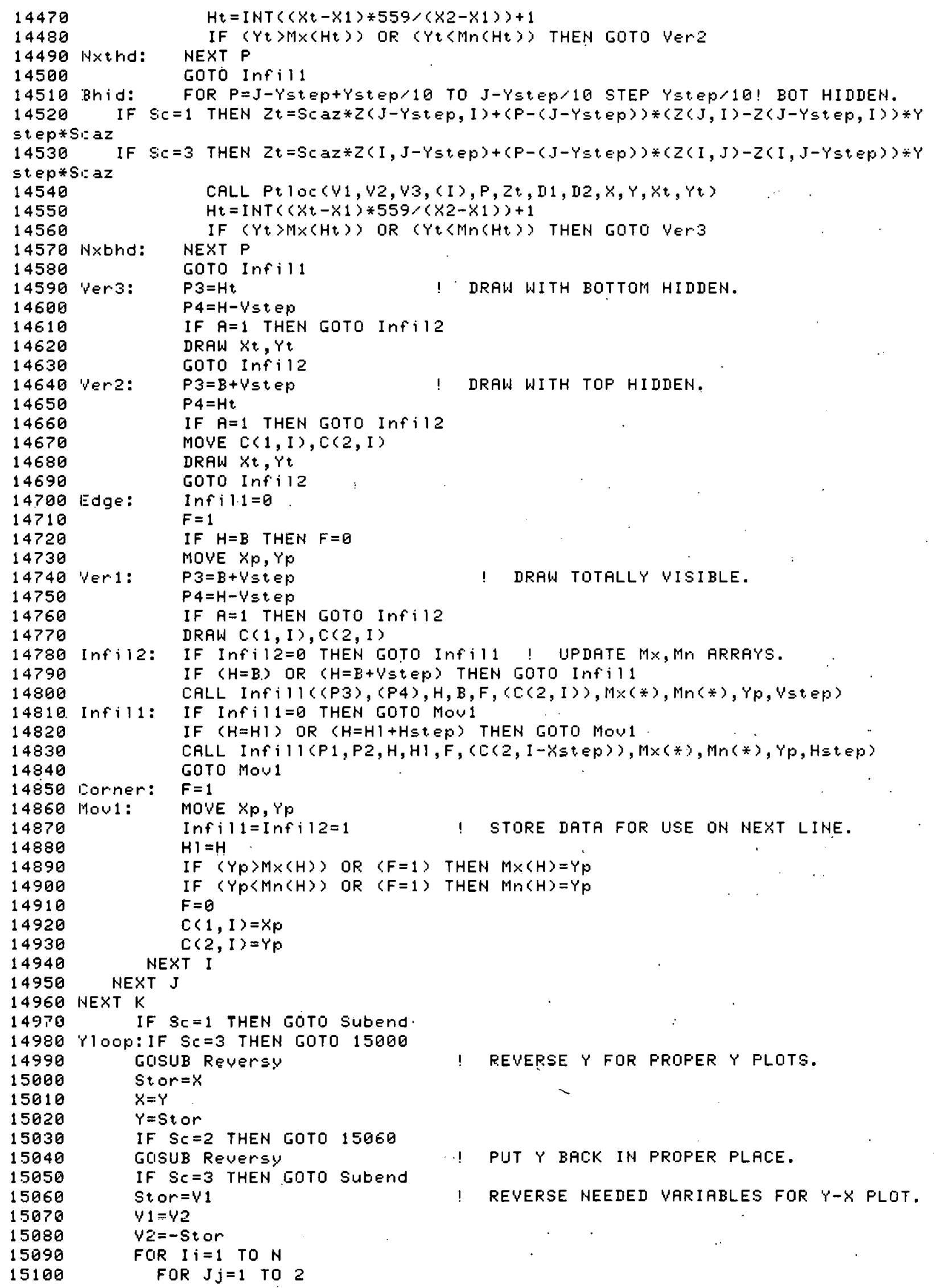

! REVERSE Y FOR PROFER Y PLOTS.

! PUT $Y$ BACK IN PROPER PLACE.

! REVERSE NEEDED VARIABLES FOR $Y-X$ PLOT. 


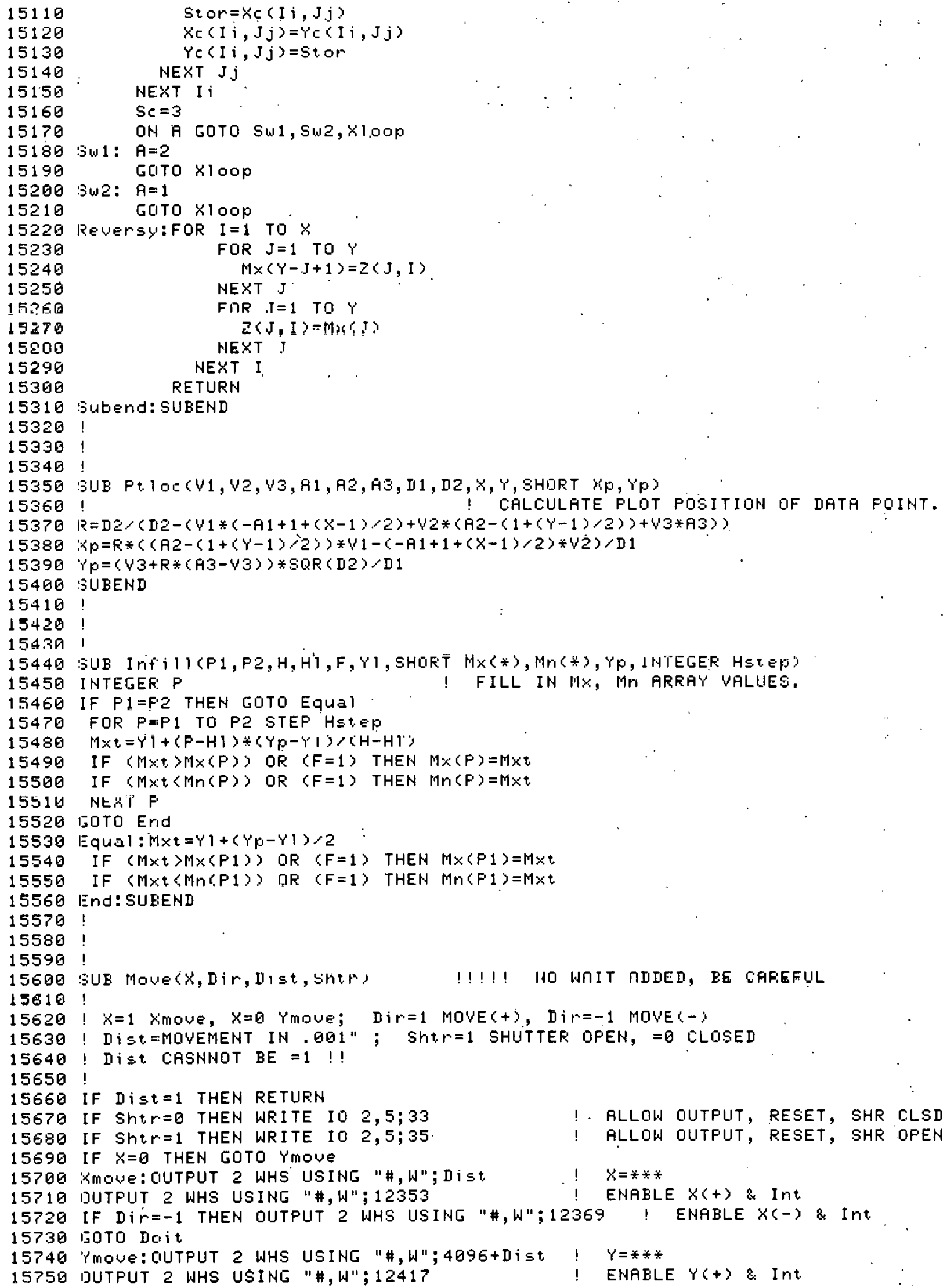




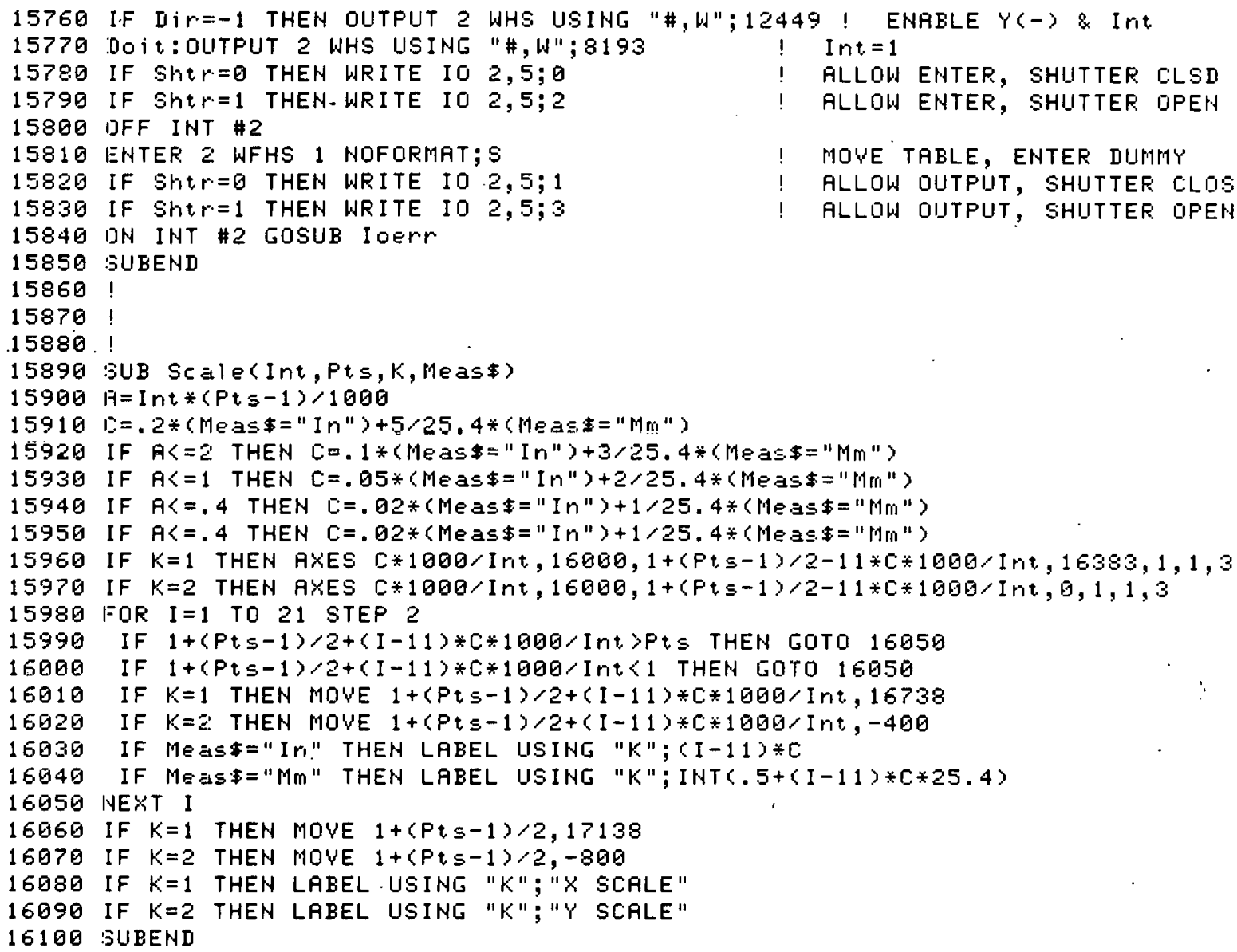




\section{Table of Variables for Lens Tester Program}

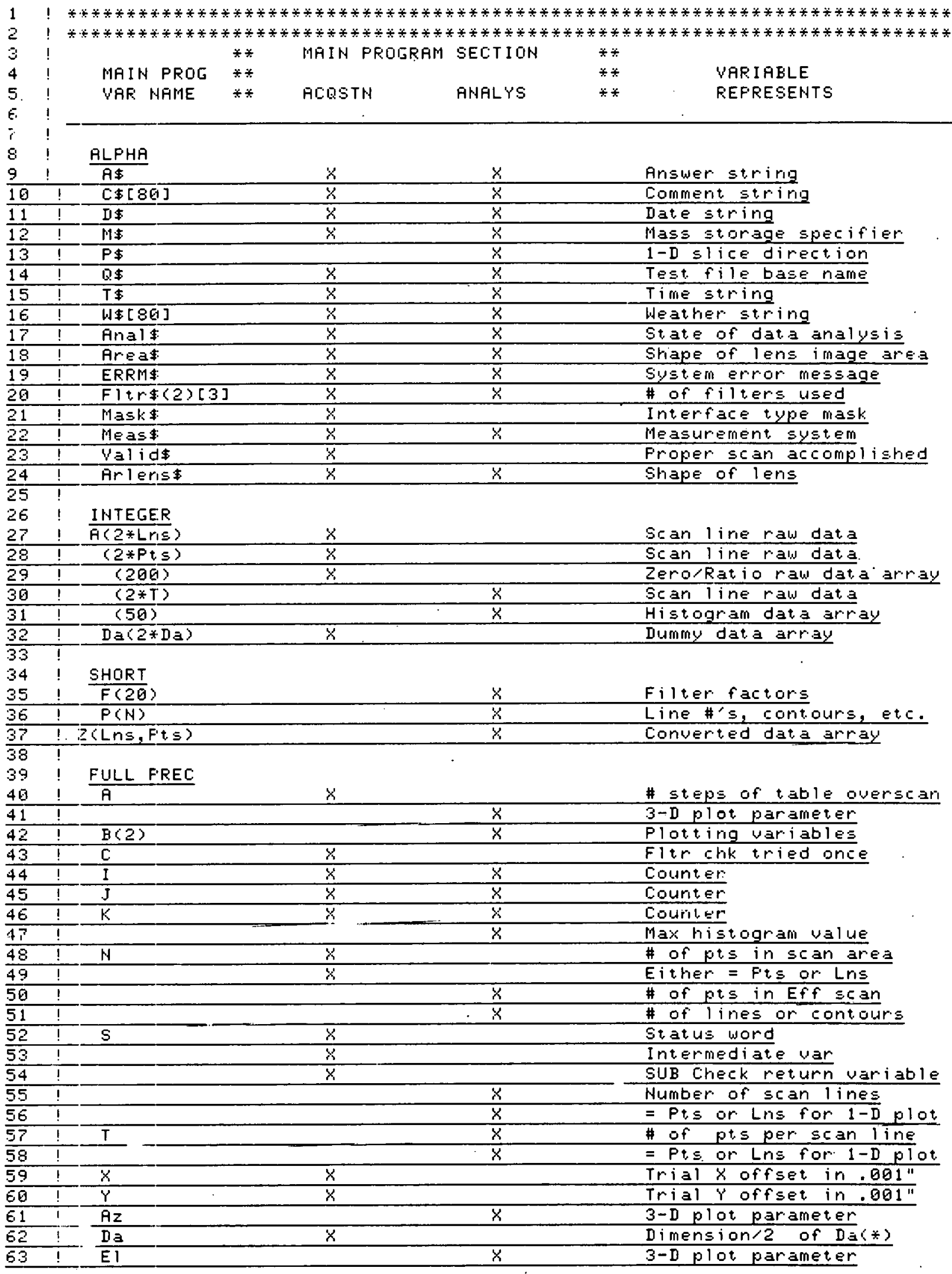




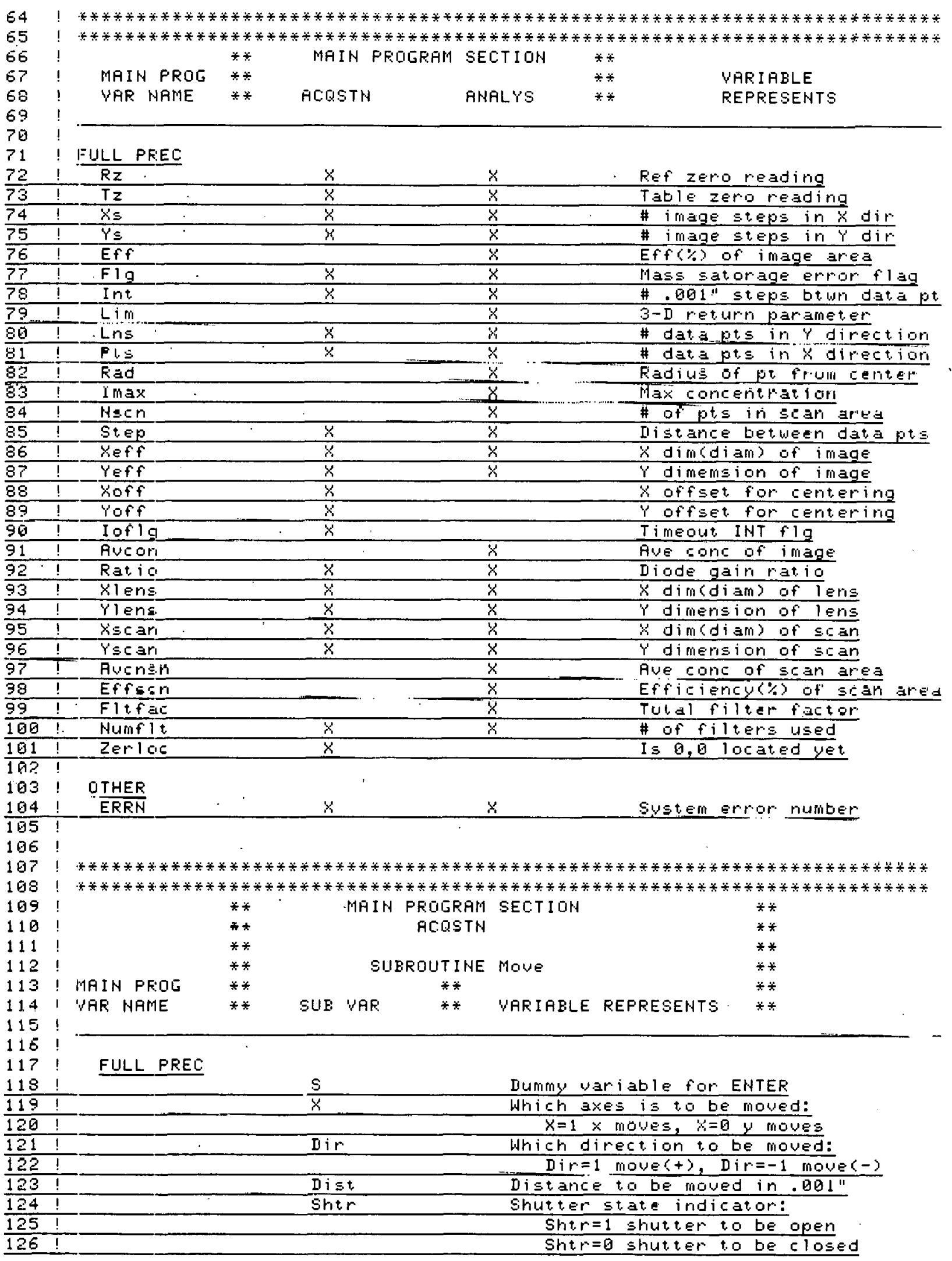




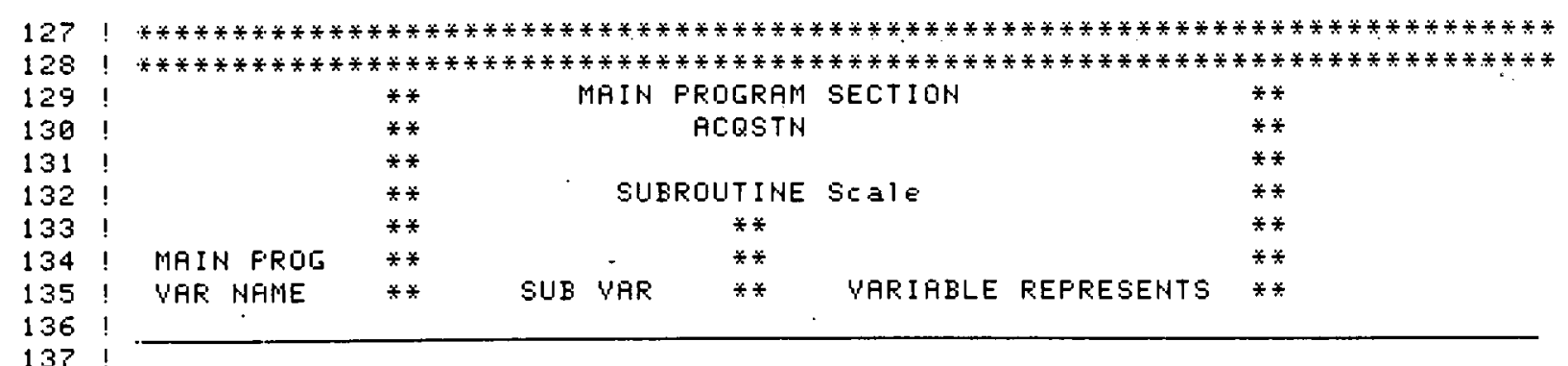

$137 !$ I

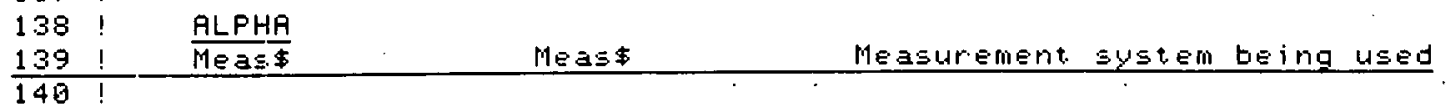

141 FULL PREC . . :

\begin{tabular}{llll}
$142 !$ & $A$ & Length of datascan line \\
\hline $143 !$ & $C$ & Interual for axis tick marks \\
\hline $144 !$ & $\mathrm{K}$ & $\mathrm{K}$ & Counter \\
\hline $145 !$ & $\mathrm{K}$ & Indicator of $X$ or $Y$ trial scan \\
\hline $146 !$ & Int & Int & Interual betwen datapoints \\
\hline $147 !$ & Pts & Pts & Number of egints in scan line
\end{tabular}

1501 ）

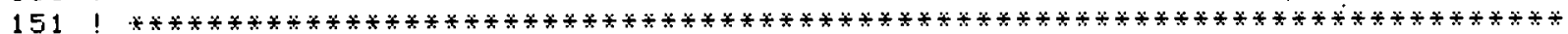

156 ! MAIN PROE

157 ! WAR NAME

** MAIN FROGRAM SECTION

$\because *$ RNALYS

$* *$

$\ddot{*} *$

$\div *$

sut

SUBROUTINE Contaur

SUB VRR . $* *$

VARI I AELE "REPRESENTS

ㅜㅜ

$* *$

$* *$

$\stackrel{\circ}{*}$

16日! SHORT

161 ! C C C NC) Concentration contour values

$162 ! \mathrm{P}(\mathrm{N}) \quad \mathrm{F}(*) \quad$ \# contours to be plotted

$163 !-H(2, N y, H C) \quad$ Horizontal contour segment locations

$164 !-V(2, H y, H c)$ Vertigal contour segment locat, ions

165 ! Z(Lns,Pts) Z(*) Data array with values to be plot.ted

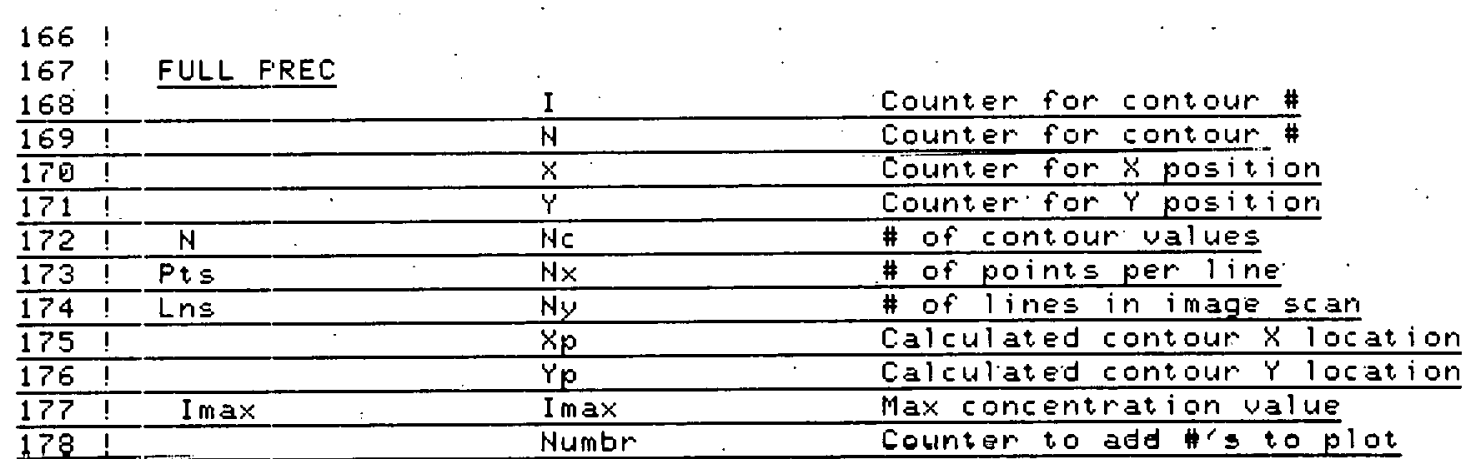




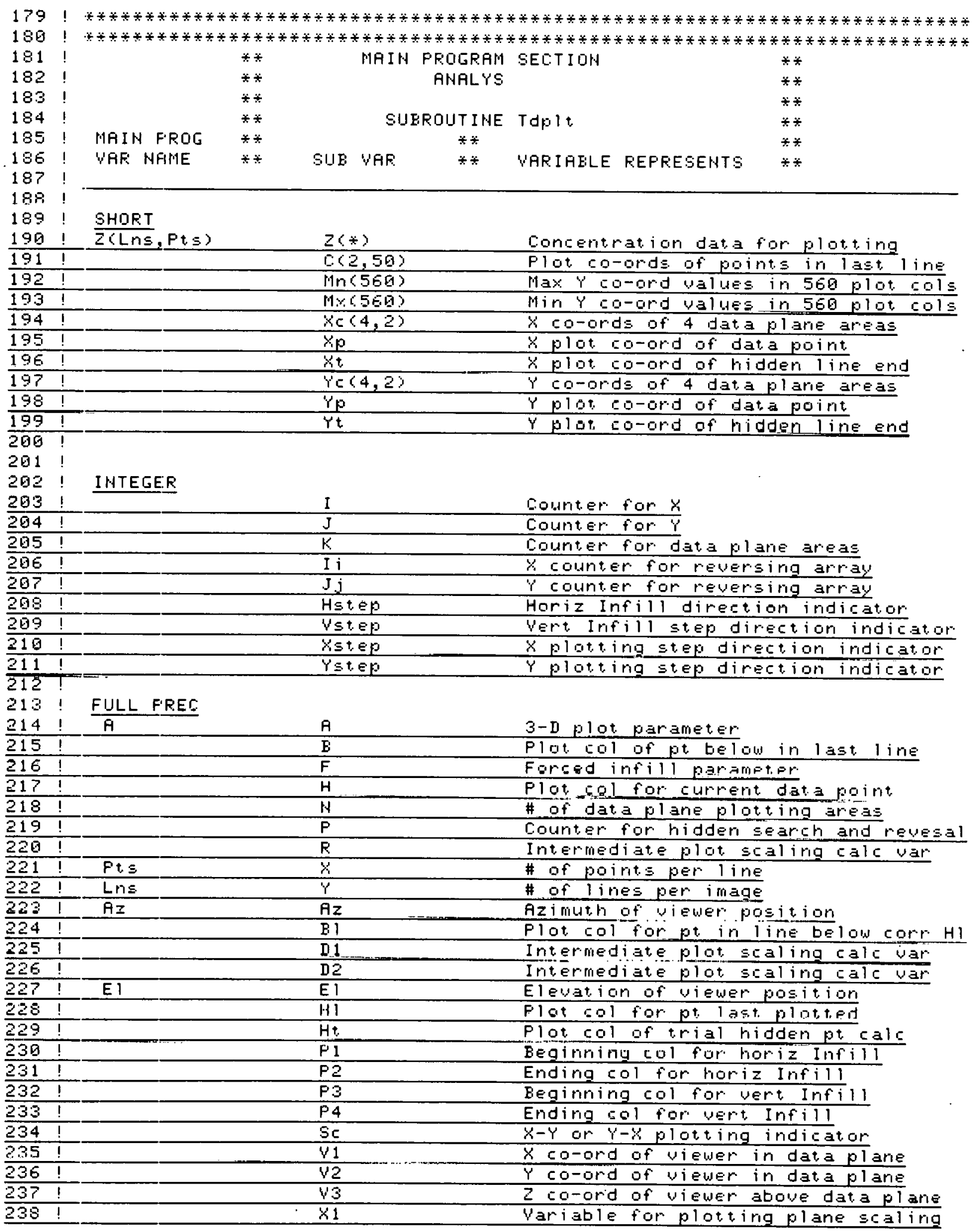




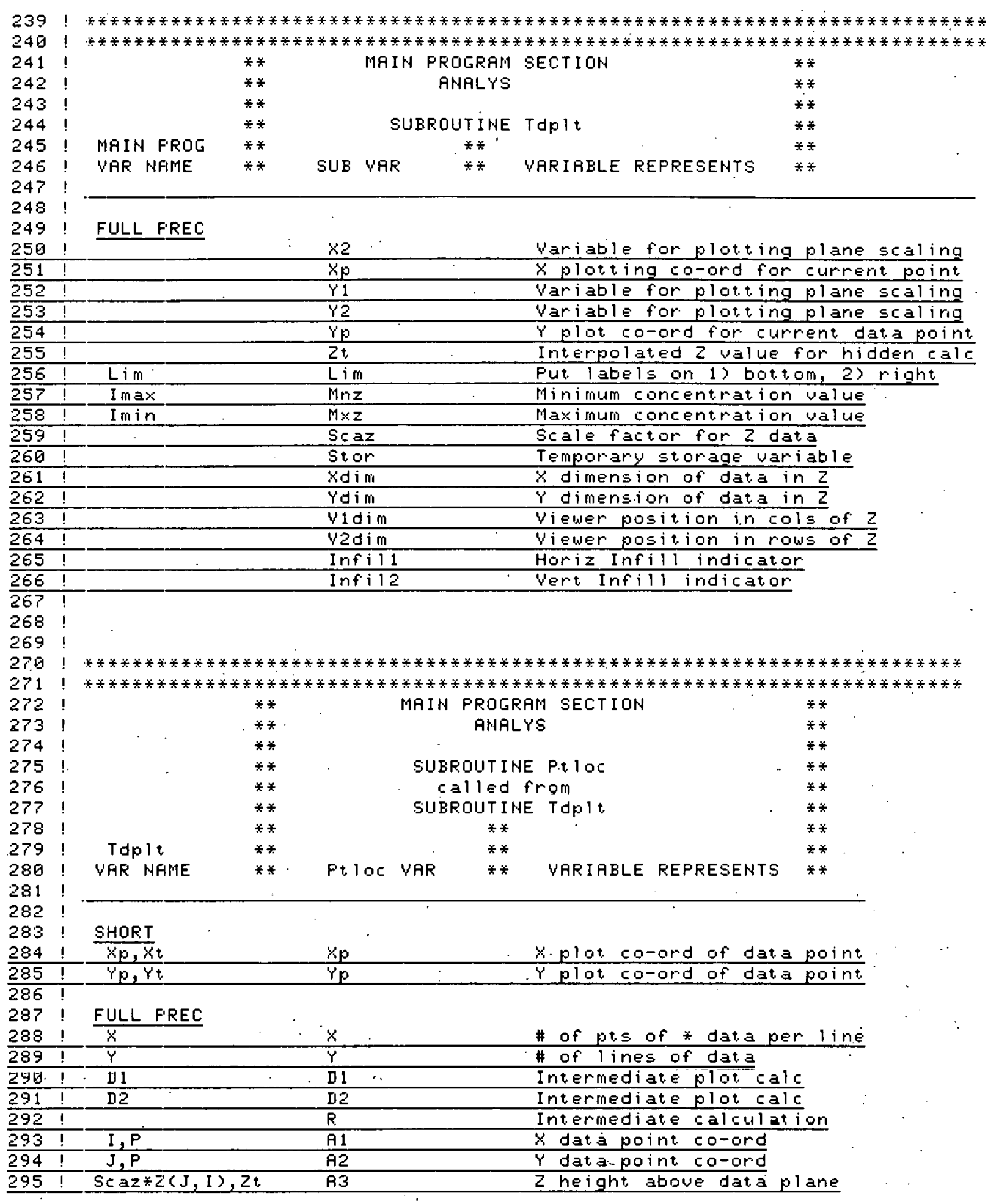




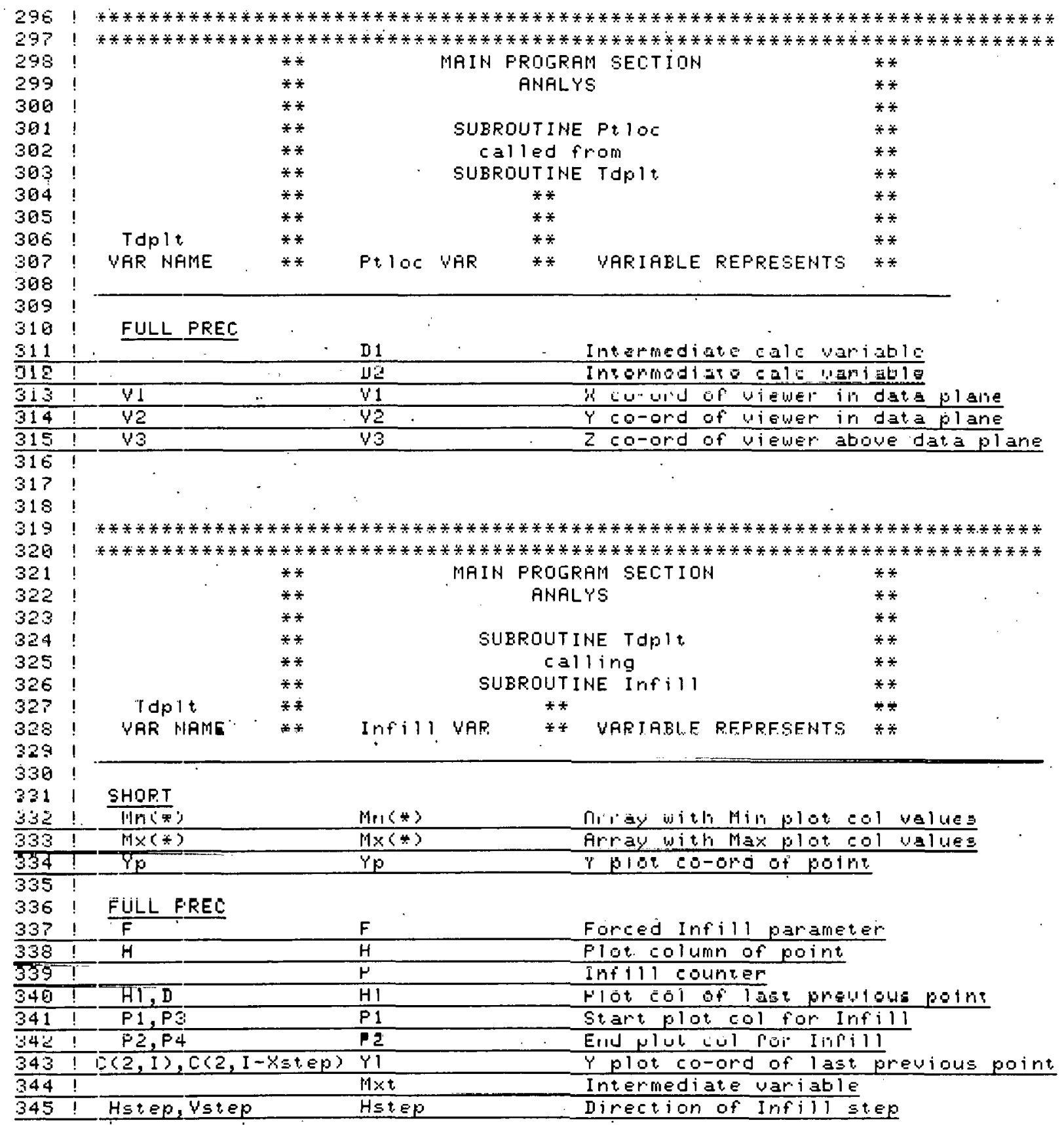




\section{DCMSPC}

SAHIIA'S FRESHEL LENS TESTER SYSTEM

The Fresnel Lens Tester System (Lens Tester) is an aut amated system designed and built by Sandia Hational Latoratories, flbuguerque, HEw Mexico, to map the cell plane irradiance pattern cimage) produced by a fresnel concentrator lens. A point detector diode of active dianeter . 129" $i$ E mounted on a 2 axis $(X-Y)$ motorized positioning table. This allows a raster sian of points in a plane fiarallel to the lens. Maximum diode movement in each axis is 4 inches. The fresnel lenses are mounted on an aluminum arriage with a square, clear aperture af 19 la inches. ! Lenses are ligunted on the carriage by use of $1 / 8$ inch thick aluminum lens ! board: which are specially constructed for each lens shape. The earriage ! i E mounted on three, 344 inch dianeter case hardened steel rods which ! mowe in linesr ball bushing pillow blocks for lens to diode distance adjustments. The range of lens to diode distances $i=4$ ta 30 inches.

The $x-\gamma$ table and lens carriage assembly is suspended in a le lestron14 telescope fork and mount drive which has been modified by the addition ! of two $1 / 2$ inch spacers to widen the yoke by 1 inch, allowing the table ! it $\equiv f u l l 4$ inch travel. Two fixed and tho 15 pound moveatle counter! weight: balance the system allowing the tatile and lens to accurately ! track the sun during test operations using the lesestron closk drive. As ! the lens carriage is moved forward the two steel counterweights are moved t.o the rear to preserve balance. The celestron mount is bolted to a whesled base for portability. The base has at ached locking feet that securely hold the system in position during operation.

The signal from the table mounted diode is compared to that of ari identical reference diode mounted in a 1 1.4 inch aluminum tube mounted to the declination axis of the celestron mount. The reference tube has been painted flat black on the inside to reduse reflections. $A$ peep sight molunted on the reference tube $i=$ used for proper tracking alignment. of the system. A set of calibrated inconel neutral density filters is ! weEd over the table mounted diode to keep its maximum signal bomparable ! to the reference diode one sun signal. The maximum me asureable image ! concentration ratio is 2aga. The acceptence angle of the diode detector. ! has been inereased by remouing the front of the diode can. The accep! tanee angle of the system $i s$ then $1 \mathrm{mited}$ by the filter holder $3 s s e m b l y$. ! With one filter in the lower position the accepted cone $i s+-45$ degrees: with two filters the angle is nearer +-35 degees.

The systeri is controlled by a Hewlett Fackard 9845 a alculator through an $H-F$ 98032A 16-bit parallel duplex interface. Custom digital control ! Electronics mounted on the tester baseplate accept the calculator output ! commands, and perforii the table movements, shutter control, data acq! uisition, et. c., required for system operations. The two diode signals ! piss through identical preamps mounted directly under each diade. Two ! identical 14-bit analog to digital converters (AIC's) are mounted in ! a box on the bottom side of the table platform. The convert lines of ! both fIL: s are tied together allowing sinultaneows sampling of both ! the table and reference diode signals. The two digital data words are ! then multiplexed.to the 9845 calculator for storage on either mag tape ! or floppy disk. Each image data sample has an accompanying reference sample to compensate for minor insolation flutuations.

nata is taken from a rectilinear grid of data points whose size and ! sampling interual are determined by operator keyboard input. The $x$ and ! ' data sampling intervals are identical. Calibration necessary for later. ! data reduction is performed by taking dark (insolation=a) readings and ! light. (one sun) readings for each diode. Data reduction calculates a ! concentration ratio value for each pair of data walues for each point on 
! the data grid. The individual concentration ratio values are summed over

! the entire image area, as well as a smaller specified area, to calculate

! lens efficiencies for different size soler cells. If a circular image

! area is desired the data values in the corners of the scan, outside the

! desired ciroular areas, are ignored. Eoth efficiericy areas must be the

680

690

same shape: circular or rectangular.

After lata conversion, various plots of the concetration ratios can be produced an either the 9845 LRT or an at ached $X-Y$ plotter. Plots ini- 


\section{DCMOPB}

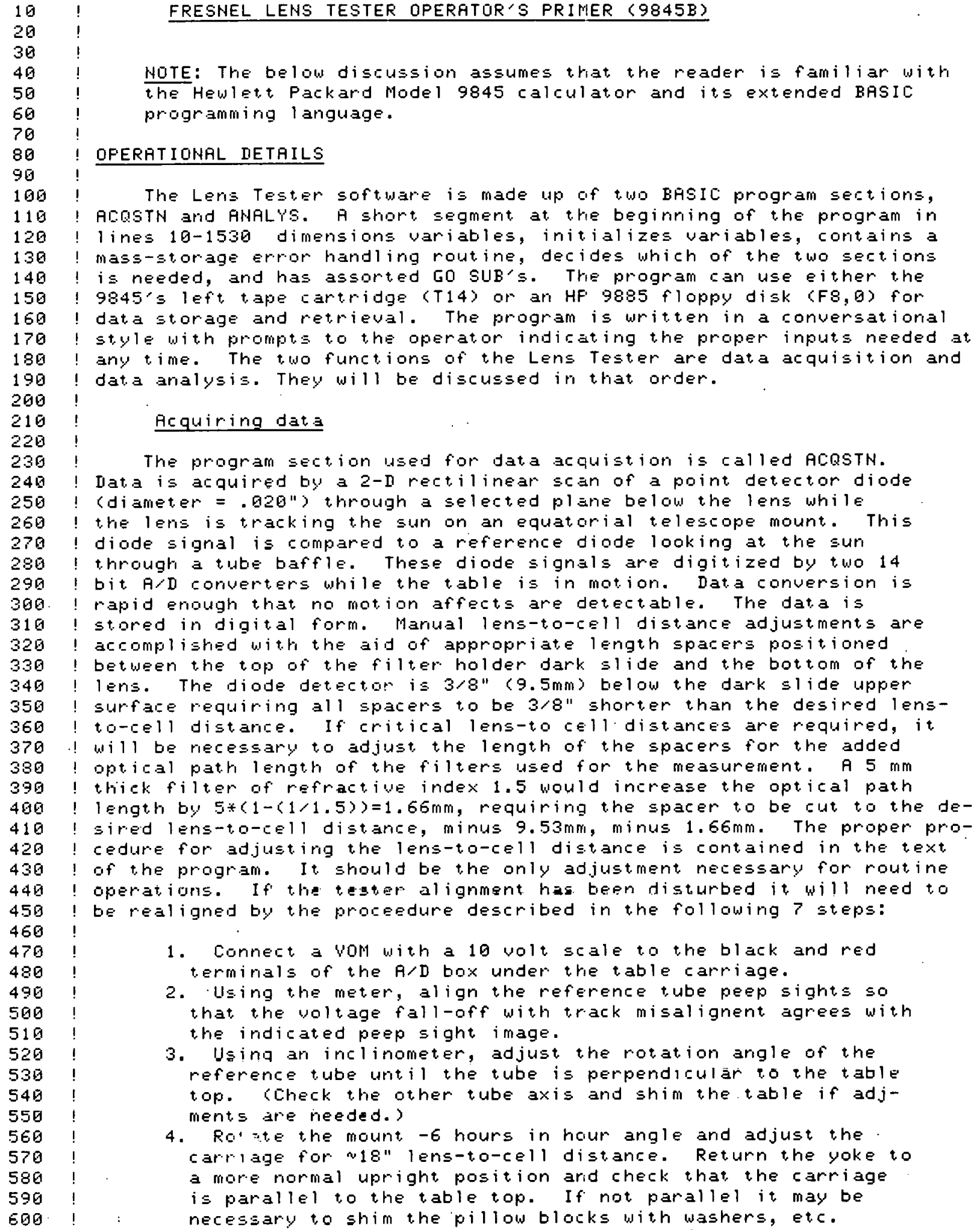


5. Align the reference tube peep Eights to again track the sur. With no lens board on the lens carriage make sure that the sun's image, projected by the 1/16" hole in the upper edge of the lens carriage, is centered or the cross, etched into the table platform near the $Y$ motor. If the sun's disk does not fall on this cross, re-do steps 1 to 4 above.

6. With the mourt tracking the sur adjust the table calibration baffles(s) using the vol on the tilue and black terminals of the $\mathrm{A} / \mathrm{D}$ box in the manner described in ateps 1 and 2 aboue.

7. Don't EVER bump, hold, or disturb the reference tube.

Dnce the lens-to-cell distance has been adjusted and the mount is tracking the sun, the sean dimensional parameters must be determined from operator keytoard inputs. Two measurement systems can be used: inches (In) or millimeters (Mm). Once a measurement, systehs has beeri selected all dimensions for that test (scan) must be in the units selected. Hhy and all parameters can be selected tifferent.ly far other tests. Ho matter what system is selected or what scan varameters arp sntered the $X-Y$ table can only make movements in stepa of . 901 ". All scan lengths and data taking interwals are converted to an integer

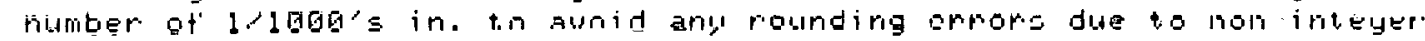
step sizes, eti. For this reason the nuniber of data points per line may vary from your intended value because of integer arithrotic.

To awoid damage to the filters from the concentrated sunlight the filters must never be exposed to the high flux area unless they are making a high speed scan (4",sec). One pulse to a translator results in ! a table movement of .001". Because of mechanical limitation the table cannot be stopped or started above 509 pps (1/2" per sec). It must be started below 1 /2" per sec and gradually 'ramped up' to 4"/sec. ! To accomplish this ramping-up the table is always backed away from the ! designated image area by an amount proportional to the expected concent tration ratio of the image. The table must also be ramped-down tefore stopping. To ramp-down outside the image area, the table is al lowed to proceed past the image area a distance equal to the original backup. It is reasoned that the larger the image area, the lower

the possible concentration ratio that car result. The back-up distanres, $H$, is Galculated $a \equiv A\rangle=.6 \div(3900-S$ ) where $S$ is the largest image area dimension in .091". For sy3000 the backun is A. This resulta in a minimum scan line length of nearly 3 inches. When the filter stops at the end of each line it should be well nutside the imege area. The rampup and diwi is accomplished by charging and discharging a capacitor whose voltage control a $V-F$ converter. The capacitor charges toward 15 volts, but a 4.7 volt zener diode limits the voltage. Reraldse of coner $1 \mathrm{imiting}$, the ramp-up is nearly a linear 350 msec ramp, with full speed at ained in. 400 msec. The discharge to low speed is an exporiential decay with c150 msec t. ime constant. Selection of $Y-F$ converter componenta result in a ramed: down speed of w40 pps (.4"/sec) and a high speed of w4009 pps (4"/sec). The ramp-up and down times were selected experimeritally as the shortest times possible that consistently did not cause the table to lose position on either ramp-up or ramp-down.

The reason for the inequality in the expression for $A$ above is due to the manner in which the lens tester hardware is built. The tester has been built so that the $A / D$ converter receives a canvert pulse every Int number of steps during the entire table movement. In order for the system timing to be proper the only way to initiate a table mouement is to perform an EHTER... and begin taking data after Int steps. Since each of our Ecan lines begins well outside the desired image area we are required to take several data points that we really don't care to have. $A l \leq 0$ we must require that the backup interual is an integral number of Int's so that our first desired data point is where we really think it 
1230 ! showld be. The inequality for $A$ arises from the fact that we search for 1249 ! the smallest integer multiple of Int that is $>=.6 *(3000-5)$. Once a table 1250 ! movement has been initiated it can continue to its completion without any 1260 ! data taking, provided an appropriate length WhIT has been included in the 1270 ! program. The data collected before the scan reaches the desired area 1280 ! is placed in a dumy data array $\mathrm{D} a(*)$ and discarded. The data samples 1290 ! taken after the desired image area are ignored because the ENTER state1300 ! ment has already fulfilled its required amount of data before then.

1310 ! This sane data taking requirelient explains the EHTER statenent wsing the 1320 ! dummy data variable, S, in sub Move.

1330

The input area of the lens is calculated from the lens dimensions 1350 ! supplied by the operator. If the lens is neither circular nor rectang-

1360 ! ular, or some special gadget or feature restricts the light transmission, 1370 ! the operator must calculate the equivalerit round or rectangular unot-

1380 ! struted lens aperture that would be appropriate. Ilata will always be 1390 ! collected over a rectangular image area. The largest image dimension is

1400 ! used to select the direction in which the scans will be made. Scan lines 1419 ! are always taken in the longer direction, or in the $X$ direction if the 1420 ! image dimensions are equal. If a circular image is specified a square 1439 ! array of data points is taken with a restlting $X$ scan direction. For the 1440 ! Eireular case the entire square data array is taken, but the unneeded 1450 ! correr information is ignored in the efficiency calculations made later. 1460 ! The rectangular area need not be a square. Long, narrow areas in either 1479 ! the $X$ or $Y$ directions are permissable.

1480 !

1490

Qnice the scan parameters have been decided dark current and no-lens 1 ight current data are taken to eharacterize the two diode detectors.

1510 ! Heter installation of the lens and appropiriate filters, a scan line of 1520 ! data is taken throwgh the center of the image area in both the $x$ and the

1530 ! $Y$ directions. This serves the dual purpeses of checking for saturation 1549 ! of the diode detectors as well as checkirig to see how well centered the 1550 ! image is in the scan area. This centering routine can be repeated any 1569 ! number of times with warious table offsets and/or filters until the oper1579 ! ator $i s$ sat $i s f i e d$. Once the operator gives the oK the complete data scan $1589 ! i s t a k e n$. If one of the data scan 1 ines goes through the center of the 1599 ! image area it will be identical to one of the centering scan lines. If 1600 ! the number of stan lines $i$ ever, none of the scan 1 ines go through the 1610 ! certer of the image area. In this latter case the centering scan line 16ag ! may not look like any of the data sean lines. After the sian has been 1630 ! completed, additional data acquisitions or analyses car follow. There 1640 ! is no requirement, to immediately perform data reduction.

1650

1660

$1570 !$

1680

1690

1700

$1>10$

\section{Arialysis of stored data}

Ilata analysis is performed by the section RNALYS and depends upon the linearity of silicon PIM photodiode detector response to incident radiation. The Ratio and Tz,Rz readings taken before the lens was 1729! program are ali that is required to convert the pairs of reference and 1730 ! table diode readings to image area conceritration ratios. This concen1740 ! tration ratio conversion process is done for the entire rectangular 1750 ! array. The 1 ines of data are taken by table scans going in alternating 1760 ! directions. During the data conversion process every other line of data 1770 ! is reversed to make it appear that all data was taken from the same dir1780 ! ection. Once concentration ratios are calculated, lens efficiency is 1799 ! computed. An average concentration ratic for all the data points that 1809 ! fall within the desired image area is computed, as well as the trans1810 ! mitting area of the lers and and area of the desired image. Efficiency 1820 ! is calculated from these three values. Fll pertinent results and details 1839 ! are stored for later use. 
$1840 !$ At this point data analysis can be terminated or graphical displays 1850 ! of the concentration ratio data can be produced. In either case ad1860 ! ditional displays can be produced at a later date without the need to 1870 ! re-do the time consuming data reduction described above. Four graphical 1830 ! plots are available: A histogram of concentration ratio distributions, 1890 ! a 1-D plot of individual scan line data, $A$ 2-D contour plot of iso1900 ! irradiance values, and an unscaled 3-D representation of concentration 1910 ! ratio data displayed as height above the image plane. They can be per1920 ! formed, repeatedly, in any order.

1930

1940

1950

\section{ELECTRICAL DETAILS}

1970

Electrigal conflguration of the Lens Tester system is a hit inulved but. a brief description will be at tempted here. Complete electhical schematics, sketches of the system components, and additiurial necessary information are auailable. A Hewlet. Packard $98932 A$ 16-Ei? parallel interface card is used to talk to and from the Lens Tester. The HF 98032A 16-Eit Interface Installation and service Manual describes the operation and $U S E$ of the iriterace ard 1 te registse. The EASIC st. atements necessary to communicate with the interface are described in the HF Series $98 \mathrm{ag}$ Desktop Computer I/0 RoM Manual. The Staridard 98632A Interface card comes from HP with a select code of 2 . This can be easily changed, but with no reason for change, the Leris Tester Program uses a select code of 2 for $98032 \mathrm{~A}$ commurications. The operational deseriptions here are those used by the Lens Tester Program and are not. nesessarily the only way that some of these functions can be performed. Iat.a written to, or read from the interface is not to be confused uith control functions and status characters which can also be written to, and read from the interface registers. In addition the actual interface is only the small tox that plugs into the rear of the 9845. The Lens Tester itself is a peripheral that commuricates with the calculator

2180 ! and there are registers in the Lens Tester itself. The two should not 2190 i the confused.

Iats, two 8 bit bytes of informatior, car be written to tho $98032 \mathrm{~A}$ interface wsing an OUTFUT gtatement. Dnce uritteritin the interface card this data is presented to the peripheral hens Tester as le parallel TTL latched data lines. Data is read from the peripheral by using an ENTER 2250 ! statement. This reads the 16 interface data input 1 ines that are con2260 ! trolled by the Lens Tester. Register 5 af the 98032A card is used as 227日 ! both the control 'out' register from the 9845, and the status 'in' reg2280 ! ister to the 9845. Information can be written to this register using 2290 ! WRITE ID 2,$5 ; x$, where $x$ represents the information to be written.

2300 ! Information i $r e a d$ from the interface by using sTatus 2,$5 ; s$, where $s$ 2310 ! contains the returned information. Register 5 of the $98932 A$ is a. 15 2329 ! bit register but only the lower 8 bits are meaningful. When writing to 2330 ! register 5, the upper s bits are ignored. Wher ireading regietor 5 , the 3340! upper 8 bite are always a's. The Lens Tester uses only 3 of the control 2350 ! bits of register 5: RESET=32, CTL1=2, and CTL $\theta=1$. It a combinat 1 on uf 2360 ! these functions is desired their arithmetic sum is written to the

2370 ! register, i.e. a WRITE I0 2,5;33 performs both a RESET and sets the CTLO 2380 ! control bit to a 1. A WRITE I0 2,5;35 would do that in addition to set2390 ! ting CTL1 to a 1 . When reading from register 5 the 1 and 2 bits are 2400 ! the Extended Status Input Lines, STI0 and STI1, respectively. These bits 2410 ! are used to pass information from the peripheral to the 9845 indirectly, 2420 ! and independently of the data lines. All data inputs and outputs of the 2430 ! 93032R are normally negative true logic unless appropriate Configuration 2440 ! Jumpers have been installed to perform data inversion of those values. 2450 ! In most cases these jumpers have been installed in an attempt to use pos2460 ! itive true logic. 
A 53 conductor cable, either with or without the 50 extension cable, may be used with the system. The 16 parallel calculator data output.

2490 ! lines are wsed to commuicate with the different counters and registers 2500 ! withir the Digital Control Chassis. The lower 12 bits are used as data 2510 ! to be transmitted, while the upper 4 bits are used as addresses to multiplex the data to its proper destination. When reading data from the

2530 ! tester all 16 of the calculator data iriput lines are used as data, al2540 ! though only the lower 14 bits contain information. The upper two bits 2550 ! are allowed to float high. WFHS is used for all Lens Tester data entry 2569 ! operations. The 16 calculator data input lines are read in negative 2579 ! true logic because the 9345 does not allow data inversion for WFHs's. 2580 ! The two high order bits being high restlts in them always being read as 2599 ! zeroes. The A $/ D$ butputs are in positive true logic. A g from the A D 2600 ! is read as a 16383 by the 9845 , and a 16383 is read as a 0 . Proper 2610 ! H/D values are obtained by subtracting the read value from 16383.

There are two 12 bit and one 8 bit binary count down counters in the Digital Control Chassis. The two 12 bit counters are to kesp track of $X$ and $Y$ table movements, while the 8 tit counter controls the dat a 2660 ! taking interual. 12 bit resolution allows 4095, .091" steps in either $2670 ! x$ ar $Y$, while 8 bit reslution allows the data taking interval to be as 2680 ! large as 255, .001" steps. The data taking interval is strictly a pos$i$ ion count and is insensitive to ramp-uk or ramp-doun conditions. Iata can be taken at ary time the table is mowing. There are additional reggisters to enable the $X$, $Y$, or Int counters, program fast or slow movement. and control the direction of movement in each axis. There are three special MUK control words which cause actions regardless of the 12 data lines. These three comands cause the table to move slowly in $-x$ and $-Y$ simultareowsly, or to take $a$ single step in the $X$ or $Y$ directions.

The peripheral control 1 ines CTLO and CTL1 are used to control the readrurite and shutter functions of the tester. The interface control line logit levels canot tie inverted by Configuration Jumper selection. Setting a CTL to zero actually sets the hardware line in the Digital

2810 ! Control Chassis to a one. Pragram-wise, CTL1=0 will close the shut ter, 2820 ! while CTL1=1 will apen the shutter. CTLG=g enables an ENTER operation, 2830 ! while a CTLB=1 enables an OUTPUT while disabling an ENTER. The proper 2840 ! control line must be set before attempting a data transfer or an $I / 0$ 2850 ! TIMEOUT error will hang up the calculator. (CTLO is used to multiplex, 2860 ! MUX, the Handshake Eircuitry between. in and out Handshakes.? A simple

2870 ! RESET (WRITE I0 2,5;32) of the interface card sets both control ines to 2880 ! zero, closing the shutter and allowing ENTER operations. Hardwired 2890 ! circuits handle the actual Handshake for the data transfers. Timing 2900 ! diagrams for both OUTPUT and ENTER Handshakes are included for trouble2910 ! shooting purposes.

2920

Ari alternate method to write a contral word, $x$, to register 5 of interface card $\# 2$ is to execute:

\section{CONTROL MASK $2 ; x$ 20 CARD ENRBLE 2}

There is a control mask for each interface, and at POWER-ON they are all set to zero. A control mask statement is needed if a mask other lhari 0 $i=$ desired. Thiz CARD ENABLE statement loads the current control mask irto register. 5 of a $98032 A$ interface $\# 2$. In our case the same function is performed by simply executing:

\section{WRITE IO 2,$5 ; x$}

Definition of the HRITE IO control word, $x$, is the same as the for the CONTROL MFSK described prewiously. The mask does not change unless a 
3090 ! new conTfOL MASK is executed. If the same control word, $x$, were always 3100 ! wagd, there would be little difference which method were wsed. If $X$

3110 ! changes often, as it does in our case, the WRITE IO approach uses fewer 3120 ! program lines. Ffter an EHTER WFHS is performed, the current control 3130 ! mask $i=$ loaded to the cand from which the data was ENTER'ed. If no 3140 ! COHTROL MRSk has been executed, this mask will be a 9 , permitting ENTER 3150 ! handshakes from the Lens Tester, but causing the shut ter to close. To 3160 ! prevent the shut er from closing after each line of data, a CONTROL MASK 3170 ! 2:2 is executed before starting the data scan. Even though no CARD

3180 ! EHAELE's are ever used, this mask=2 kepep the shut ter open unit explic3190 ! thy told to close with a WRITE I0 2,5;日 after the scar is completed.

3260

3210

3220

3230

2240

3250

3260

3270

3280

3290

3365

3310

3320

3330

3340

3350

3360

3370

3389

3390

3400

$3410 !$

3420

34313

3440

3450

$346 \mathrm{H}$

$347 \mathrm{G}$

3480

3496

3500

3510

3529

3530

3544 Information going to the Lens Tester is transferred using the command DUPUT 2 WHS USING "\#, W"; XXXXX, where the $X^{\prime}$ 's can be numerical digits. The USIHL "\#, W" portion outputs a 16 bit binary word without the barriage return and line feed normally used by the 9845 . If the number output is in the rarige of $0-4095$ the data is Mux'ed to the $x$ counter. In order to write to the $Y$ counter, 4096 must be added to the desired humber. 64998 losds a 2 in the ' $Y$ counter.) The Interual counter is ddidessed by adting 8192 to the proper ibterval. The gontrol dat. a registers are addressed by adding lezsy to the suli of the walues of all the control tits that are to be set high. (Data inversion is. performed for a WHS allowing all values ollTPUT with WHS to be in positive true logic.) The weights for the various control registers are listed below:

$\frac{\text { COHTROL REGISTER }}{\frac{\text { EIT WEIGHTS }}{1 \text { I3BG }}}$

Control Function
Enable Interual Eunter
High Sped Movement
Move in the $-X$ direction
Moue in the - $y$ direction
Enable $x$ counter
Enable $Y$ counter.

The absence of setting a tit perterns lie eomplemant of that bantroi furctisn. El, mot Serthly the -Y dimertion, the +Y direction is selected. af soumse rhe +Y direction could be selected, but if the y coumler is not enabled, or if a non-zero number has not been loaded in the $y$ caldriter, no $\checkmark$ movement can take place. If a control register has been written ia, it retains that value until writesen to again with a different value. A 12286 command not only addresses the control registers but also stops the counter elock. For this reason it is a good idea to always perform a 12 gye befure writing th the tester.

3560

In addition to thr atowe multiplex godes there are three codes used

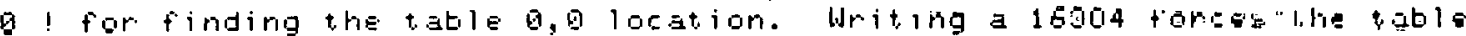

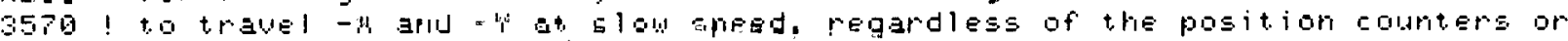
3580 ! enating simeuitry. This command is called 'GU li Hari gTore" ant ia 3590 ! ugaful bhen truing to lotate the o, o position. There are six sigrals

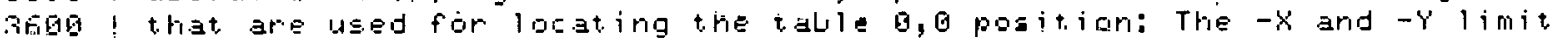

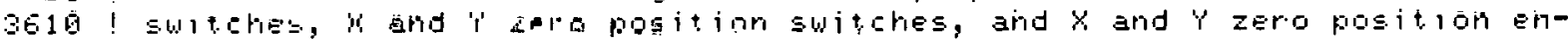

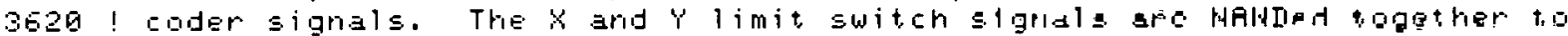
3630 ! form NoT(xh*Yh). The zero positon swithes and encoder signals are 3640 ! multiplexed by the 256 bit of the calculator data output lines, as well $3650 ! 3 \equiv$ the $x$ and $Y$ enable signals. If the 256 bit is high, zero encoder. 2606 ! Eignals are selected:' if the 256 bit is low, zero switch signals, are sel3670 ! ected. The two signalj thus selected by the 256 bit are NoRed with their. 3680 ! respective $X$ and $Y$ enable signals to produce one slgnal that is either an 3690 ! Encoder or switch signal from the one axig that is enabled. This signal 37 G ! is normally STI1. However, any time the 'Go To HARD STOPS' command has 3710 ! teen ordered the woT(xh*Yh) signal is instesd multiplexed to STI1. 
3720 ! H test of STI during a 16384 command will indicate when the limit 3730 ! switches have been reached. Once the corner has teen reached a movement 3749 ! in $+X$ is programmed with the 256 bit of Int remaining low. This selects 3750 ! the $X$ zero switin for STI1. A continuous test of STIl then indicates 3760 ! when the zemo syith has been reached. 8 motion is stopped at this time 3770 ! by outfutting a 12288 (disable counter). A command of 29490 causes the 3780 ! table to take one step in the $x$ direction. By now enabling $-x$, OUTPUT3799 ! ting 20480, and subsequently setting the 256 bit high, a test of STII 3809 ! will indicate if the zero encoder indicates a true zero position. This 3810 ! single step process auoids any problems of possibiy missing an encoder 3820 ! signal between two table steps because of delays in I/0 to the 9845 . $A$

3830 ! similar process is repeated for $Y$ using the 24576 command which is a 3840 ! single step in the $Y$ axis.

3850

To make the table move. 509" in the $-x$ direction in the fast mode, 3870 a 500 is loaded into the $x$ counter. The $x$ enable, $-x$, fast spesd, and Int enatile are selected by OUTPUTting a $(12288+64+16+2+1)=12371$. Ho mowement will ociur until an ENTER WFHS... statement is executed. The ENTER $1 \mathrm{i} \equiv$ t heed only contain one variable name to start the table in motion. The 9845 cannot perform any other function unt $i$ the ENTER... statement data $1 \mathrm{i}$ st $i \leq$ sat $i \leq f i e d$. The data $1 \mathrm{i}$ st must be sat $i \leq f i \in d$ before the table movement is completed. The movenent. must proceed at least one Gount beyond the last data taking location. Since the minimim Int value $i=$. Bu1", the minimum movement is one beyond, or. 002". If the last. dat.a location coincides with the end of mowement the last handshake will not toe completed and the caliulator will hang tp. If the table movement. goes far beyond the last data location, it may be necessary to add an appropiate WAIT to the program to awoid at tempts to OLTFUT new data 40 ag ! while the table is still moving. (Any RESET DR 1228 command sent to the 4019 ! $93032 R$ disables the clock circwit causing all table movements to cease. ? The $x$ counter will count down one digit each time the table steps. When the counter reaches zero, the gate that passes step pulses to the $x$ counter and translator is disabled, stopoing the table at -. sog" in $x$, with the $x$ counter at. zero. The $x$ and $Y$ counters work independently allowing movements in toth axes simulatareously. Since there is only 4070 ! one lock circuit both axes must move in the same speed mode. To allow 4080 ! the table sufficient ramp-down time there are circuits to indicate 4090 ! when 352 counts remain. The first enabled position counter to reach 4100 ! a count of 352 sends a ramp-down signal to the V-F converter. If a tast mowement in toth axes was less than. $352 "$ no ramp-down signal would 4120 ! occur, causing an atrupt table stop with resultant loss of position. 4130 ! For this reason fast table movements showld be used only if the travel 4140 ! will be ouer. 352". If the other positicn counter has more than 4150 ! 352 count 5 left when the ramp-down 3 tarts, it may have to finish its 4160 ! count at the 400 pis rist of the ramped-ioun fast clock.

$4179 !$

Eecause of the way the fast/slow speed selection is made, the ramp-
process is initiated an the first stepping pulse after every ENTER up process is initiated on the first stepping pulse after every ENTER
statement, whether the movement is fast or slow. If the move is shorter than .352", no ramp-down signal is generated. In this case the V-F converter is left in the 4 g日g pos mode, even if the move was slow. If a fast san is selected with no intervening action, the table will attempt. l to start at 4000 pps. The result will be a stalled motor with no movement, Even though the calculator thinks the movement has occured. To reset the $V-F$ back to it s. slow mode after short mowements, it is necnecessary to perform a SEREWY FRST RESET. This consists of enabling one of the position counters and loading 352 into that counter. This gives a $\equiv$ ignal to the $\psi-F$ converter to ramp-down. The only other requirement is that the capacitor be given approximately 300 msec to discharge. This returns the pulse rate to 400 pps allowing a proper ramp-up for a tast scan. 


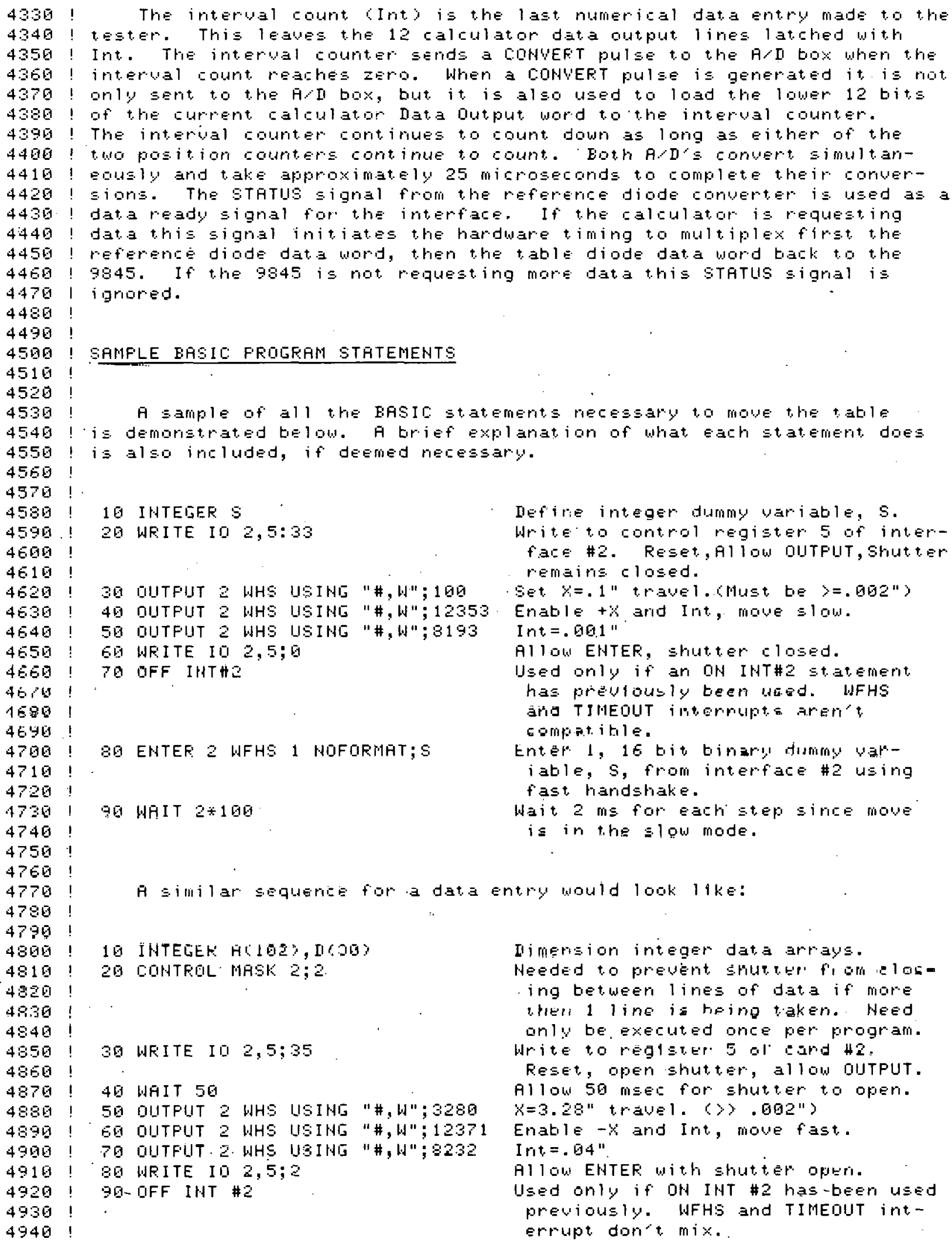

$4920 !$ 9日- DFF IHT \#2

Defire integer dummy variatle, $S$. Write to control register 5 of interfare \#2. Reset, Allow DUTFUT, Shutter remains closed.

Set $x=.1 "$ travel. (Must te $\rangle=.002 ")$

Enable +8 and Int, move $\equiv 1$ ou.

Int $=$. gas $1 "$

Allow ENTER, Shut ter closed.

Jsed only if an ON INT\#2 statement

has previously teen wä. WFHS

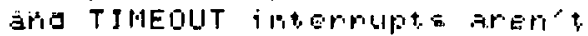
eompotitile.

Q0 ENTEF 2 WFHS 1 HOFORMAT; $S$

Enter 1, 16 tit tinarol dummy variable, s, from interface \#2 using fast handshake.

96 HFIT 2*10日 Wait 2 ms for ear step since move is in the slow mode.

$A$ Ellijlar sequenie for a data entry would look like:

10 IHTEGER HC102?, [1,OS?

20 COHTFEL MASK $2 ; 2$

30 WRITE IU 2,$5 ; 35$

Iimersion integer data arrays. Weeded to prevent shut te' fi oli elosing between lines of data if mare l. peri 1 line ia heing taken. Need anly be. executed once per program. Write to reglster 5 al and 42 Reset, open shutter, allow DUTPUT. Allow 50 mset for shutter to open. $x=3.28 "$ travel. (〉. .002")

Enable $-x$ and Int, move fast. Int $=.04 "$ ".

A1 1 ow ENTEF with shut ter optri. Used only if OH INT \#2 has-been used previously. WFHS and TIMEOUT interrupt don't mix. 


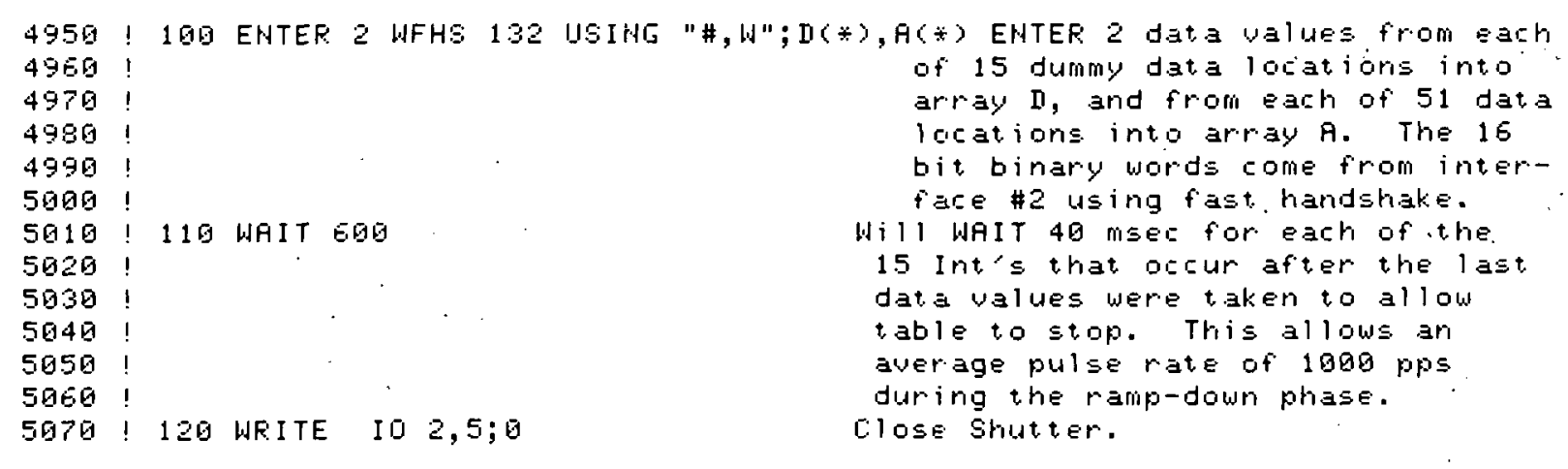




\section{DISTRIBUTTION:}

TIC-4500-R69, UC-63c (278)

The Aerospace Corporation

P.O. Box 92957

Los Angeles, CA 90009

Attn: S. Leonard

Acurex Corpuration

Aerotherm Group

485 Clyde Avenue

Mountain View, CA 94042

Allii. H. Sund

US Department of Ënergy (4)

Albuquerque Operations Office

Attn: D. T. Schueler

E. A. Walker (3)

Albuquerque, NM 87185

Applied Solar Energy Co.

15251 E. Don Julian Rd.

City of Industry, CA 91746

Attn: R. J. Barchet

Arizona Public Service Co.

411 North Central Avenue

Phownix. AZ 85036

Attn: I. McGuirk

Arizona Stale University

rollege of Engineering

'lempe, AZ 85281

Attn: C. E. Backus

The BDM Corporation

Technology Applicátions Center

2600 Yale Boulevard, SE

Albuquerque, NM 87106

Altn: W. R. Kauffman

US Department of Energy (3)

Division of Photovoltaic Energy Systems G00 E Street, NW

Washington, DC 20585

Attn: A. D. Krantz

L. M. Magid

M. B. Prince

E-Systems, Inc.

Energy Technology Center

P.O. Box 6118

Dallas, TX 75222

Attn: M. O'Neill
General Electrtic Company (4)

Advanced Energy Programs Dept.

P.O. Box 8661

Philadelphia, PA 19101

Attn: E. M. Mehalick

N. F. Shepard, Jr.

R. Hodge

A. S. Kirpich

Hallmark Cards

25th \& McGee Street

Kansas City, MO 64141

Altn. J. C. Rhoads

Jer Prupulainn Lahoratory (4)

-4800 Oak Grove Drive

Pasadena, CA 91103

Attn: W. Callaghan

R. Forney

R. Ferber

R. Ross

Martin Marietta Corporation (2)

Denver Division

Box 179

Denver, CO 80201

Attn: S. Broadbent

U. Hughtes, MS C1000

Microwave Associates, Inc.

108 Turquoise Avenue

Kalboa Islaind, $\mathrm{C} \wedge$ 9262?

Attn: S. Deem

Motorula (2)

8201 E. McDorarell Rd.

Scottsdale, AZ 85203

Attñ: C. M. Zittle

B. Sanders

New Mexico State University

New Mexico Solar Energy Instituto

Box 3SOL

Las Cruces, NM 88003

Attn. I. S. Zwibel

Oak Ridge National Laboratory

P.O. Box X

Oak Ridge, TN 37830

$\Lambda$ ttn: S. Kaplan 


\section{Distribution (cont)}

Optical Science Group

24 Tiburon Street

San Rafael, CA 94901

Attn: K. Williams

Research Triangle Institute

P.O. Box 12194

Research Triangle Park, NC 27709

Attn: R. M. Burger

Rockwell International

P.O. Box 1085

Thousand Oaks, CA 91360

Attn: J. A. Cape

Solar Energy Research Institute (3)

1617 Cole Blvd.

Golden, CO 80401

Attn: C. Bishop

Library (2)

Solar Kinetics, Inc.

Box 47045

Dallas, TX 75247

Attn: G. Hutchinson

Solarex Corporation

1335 Piccard Drive

Rockville, MD 20850

Attn: R. C. Hamilton

Spectrolab

12500 Gladstone

Sylmer, CA 31342

Attn: K. R. Ronney

Sun Trac Corporation

Subsidiary of OPTO Technology, Inc.

540 Zenith Drive

Glenview, IL 60025

Swedlow, Inc.

12122 Western Ave.

Garden Grove, CA 92645

Attn: D. Holdridge

Thermo Electron

101 First Ave.

Waltham, MA 02154

Attn: R. Sharlack
Varian Associates, Inc.

611 Hansen Way

Palo Alto, CA 94303

Attn: H. J. R. Maget

Alliance Tool Corporation

Fresnel Optics Division

1300 Mt. Reed Rd.

Rochester, NY 14606

Attn: H. Walter

1415 J. T. Hillman

1500 W. A. Gardner

1550 F. W. Neilson

1556 S. A. Ingham

1556 R. L. Hughes

1556 E. A. Igel

1556 C. E. Robertson

1556 G. S. Phipps (10)

1556 A. A. Sehmer

2146 H. T. Weaver

4700 J. H. Scott

4710 G. E. Brandvold

4713 B. W. Marshall

4714 R. P. Stromberg

4720 D. G. Schueler

4721 J. V. Otts

4721 H. J. Gerwin (2)

4723 W. P. Schimmel

4724 E. C. Boes

4724 B. D. Schafer

4724 C. B. Stillwell (30)

4724 A. B. Maich

4724 L. C. Beavis

4726 E. L. Burgess

5133 R. J. Chaffin

5811 R. A. Assink

5811 L. A. Harrah

5824 J. N. Sweet

5824 R. B. Pettit

8214 M. A. Pound

3141 L. J. Erickson (5)

3151 W. L. Garner (3)

For: DOE/TIC (Unlimited Release) 


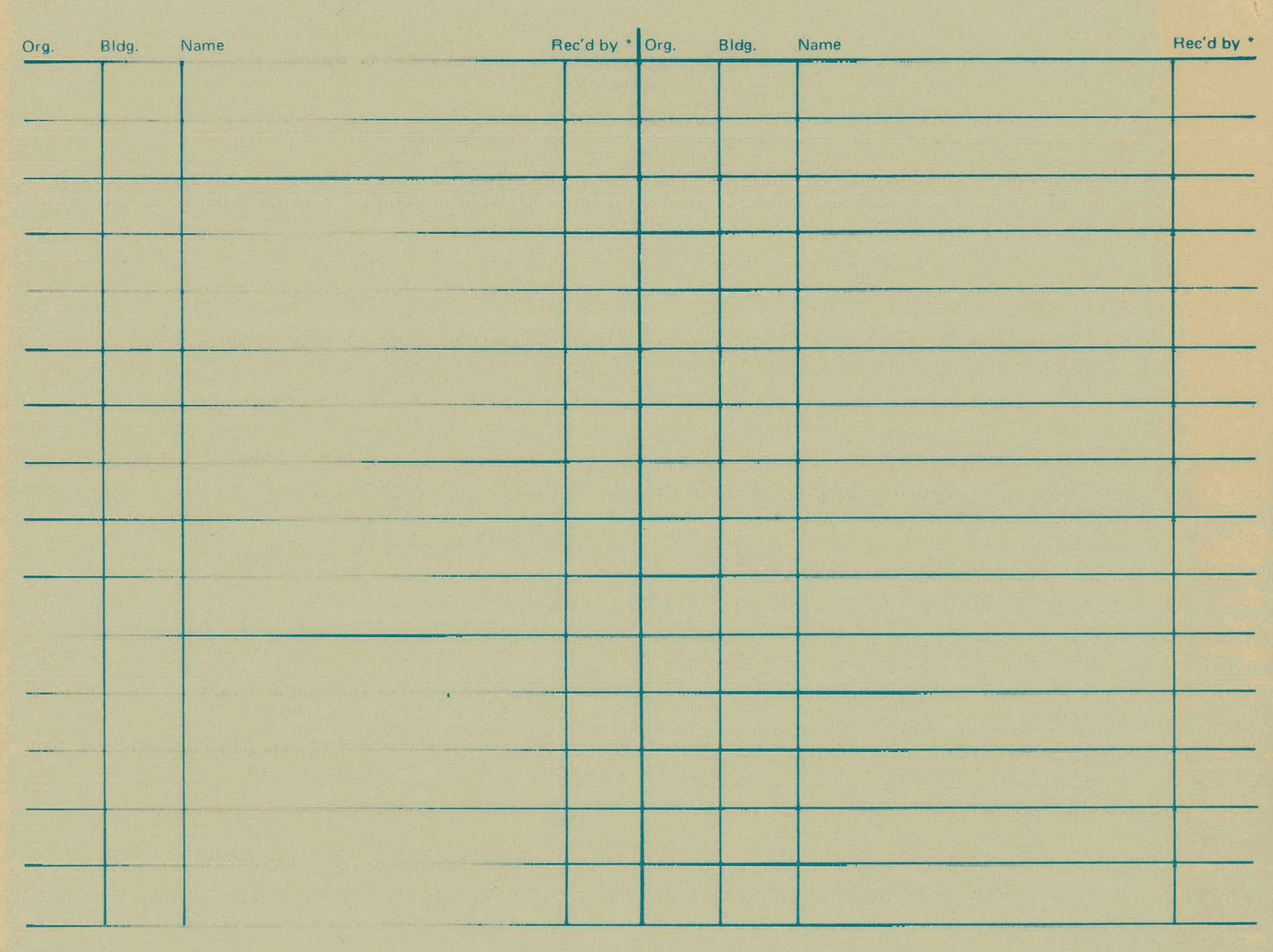

